\title{
DESENVOLVIMENTO DE UM SISTEMA ÓPTICO PARA RETINOGRAFIA E ANGIOGRAFIA DIGITAL.
}

\author{
Érica Gabriela de Carvalho
}

Dissertação apresentada ao Instituto de Física de São Carlos, da Universidade de São Paulo, para obtenção do título de Mestre em Ciências: Física Aplicada.

Orientador: Prof. Dr. Jarbas C. de Castro Neto

São Carlos 2006 


\section{FOLHA DE APROVAÇÃO}

Membros da Comissão Julgadora da Dissertação de Mestrado de apresentada ao Instituto de Física de São Carlos, da Universidade de São Paulo, em I___.

Comissão Julgadora:

(Assinatura)

(Nome/Instituição)

(Assinatura)

(Nome /Instituição)

(Assinatura)

(Nome/Instituição) 


\section{AGRADECIMENTOS}

- Ao meu orientador, pela confiança e oportunidade;

- À Fátima, pela orientação, amizade, paciência e disposição durante o desenvolvimento e a finalização deste trabalho;

- Aos companheiros do P\&D, presentes diariamente com ajuda, ânimo, respeito, compreensão, amizade e muito apoio, abrandando sempre os momentos mais difíceis e tornado-os agradáveis e divertidos;

- Ao Mário pela confiança, orientação, paciência e, principalmente, pela generosidade em transmitir e compartilhar seu conhecimento;

- Ao Renato pela imensa paciência e valiosa companhia;

- Aos meus pais pelo incentivo incansável;

- Aos meus amigos, próximos e distantes, pela torcida e apoio;

- Ao pessoal da OPTO Eletrônica pelo carinho, respeito e amizade com que fui recebida; 


\section{Sumário}

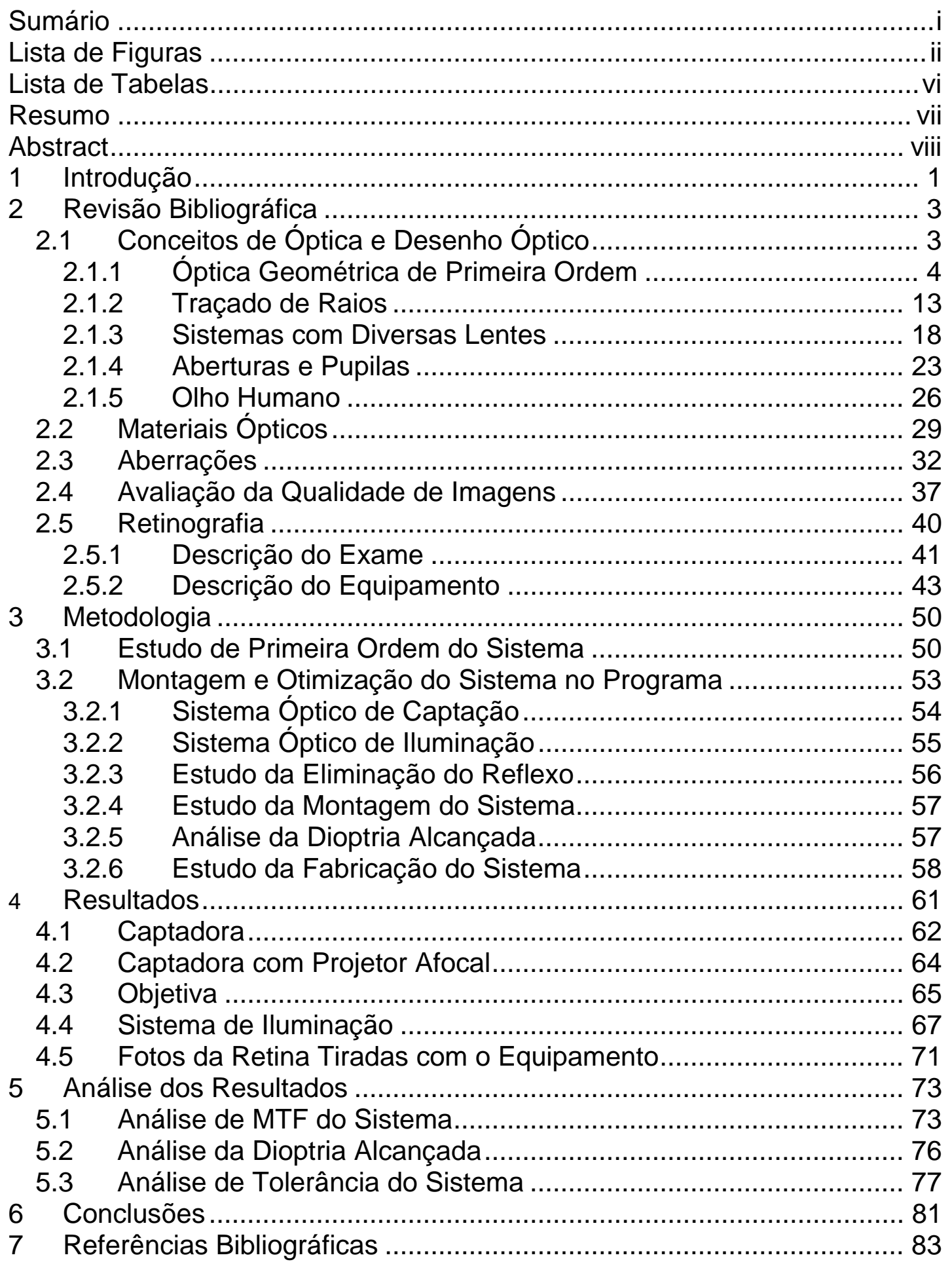




\section{Lista de Figuras}

Figura 1: Diagrama representativo da passagem de uma frente de onda plana pela interface entre dois meios.

Figura 2: llustração de um raio representando o caminho percorrido por um ponto da frente de onda ao passar pela interface entre dois meios.

Figura 3: Desenho ilustrativo da posição dos pontos principais e secundários de um sistema óptico fictício.

Figura 4: Desenho ilustrativo da posição dos pontos nodais. O prolongamento do raio incidente intercepta o eixo óptico no ponto nodal primário $\mathrm{N}_{1}$. O prolongamento do raio que emerge do sistema intercepta o eixo no ponto nodal $\mathrm{N}_{2}$ secundário

Figura 5: Desenho do traçado de raios formando uma imagem.

Figura 6: Diagrama ilustrativo para definição das equações que determinam a posição e o tamanho da imagem.

Figura 7: Refração de um raio por uma superfície esférica. 15

Figura 8: llustração dos parâmetros utilizados na aproximação paraxial do traçado de raios.

Figura 9: llustração dos parâmetros envolvidos para a descrição das equações de transferência do traçado de raios paraxial.

Figura 10: llustração dos parâmetros envolvidos para a determinação das equações de transferência do traçado de raios meridional.

Figura 11: Representação esquemática do campo de visão de um sistema óptico. 25

Figura 12: Esquema simplificado da formação de uma imagem pelo olho ${ }^{[5]}$.

Figura 13: Estrutura anatômica do olho ${ }^{[6]}$

Figura 14: Diagrama de Abbe apresentado no catálogo de vidros do fabricante Schott com destaque para a classificação Crown ou Flint. 
Figura 15: Ilustração do traçado de raios através de uma lente com aberração esférica.

Figura 16: Ilustração do traçado de raios através de uma lente com astigmatismo

Figura 17: Ilustração do traçado de raios através de uma lente com coma. 35

Figura 18: Ilustração de uma imagem com curvatura de campo formada por sistema óptico. 35

Figura 19: Ilustração de uma imagem formada por sistema que provoca distorção.

Figura 20:Ilustração do traçado de raios através de uma lente com aberração cromática axial longitudinal.

Figura 21: Padrão de linhas iluminadas e escuras que é projetado pelo sistema óptico pode fornecer informações sobre a resolução e o contraste do sistema. 39

Figura 22: Ilustração da radiância do objeto e da irradiância da imagem após a passagem pelo sistema óptico.

Figura 23: Retinografia colorida realizada com o equipamento "ADS

1.3 color" da Opto Eletrônica S/A.

Figura 24: Retinografia anerítra realizada com o equipamento "ADS

1.3 color" da Opto eletrônica.

Figura 25: Esquema do sistema de iluminação utilizado em grande parte dos retinógrafos.

Figura 26: Ilustração do traçado de raios dos sistemas de iluminação e captação através da pupila do olho.

Figura 27: Desenho esquemático do sistema de captação de um retinógrafo convencional. 46

Figura 28: Arquitetura geral dos retinógrafos convencionais patenteados há mais de 30 anos. 48

Figura 29: Esquema de um telescópio e um telescópio invertido. 51

Figura 30: Desenho esquemático da proposta para o retinógrafo 52

Figura 31: Curva de sensibilidade da câmera utilizada. 52 
Figura 32: Padrão de distribuição geométrica de sensibilidade cromática (padrão Bayer) ........................................................ 53

Figura 33: Foto do equipamento montado.

Figura 34: Desenho Óptico da captadora formando a imagem proveniente do fundo do olho.

Figura 35: Ilustração da captadora desempenhando o papel da Parte 2 do sistema de iluminação. 63

Figura 36: Desenho Óptico do projetor afocal acoplado à captadora. 64

Figura 37: sistema de captação utilizando uma objetiva Ideal. 65

Figura 38: Desenho Óptico da objetiva do sistema. 66

Figura 39: sistema de captação completo incluindo a objetiva desenvolvida no projeto.

Figura 40: Desenho Óptico da Primeira parte do sistema de iluminação

Figura 41: Desenho Óptico do sistema de iluminação completo.

Figura 42: Figura do sistema óptico de iluminação completo na posição para a montagem.

Figura 43: Indicação da posição da formação da imagem do fundo do olho dentro do sistema de iluminação. 69

Figura 44: Fotos de Retinografia Colorida em olho normal. 71

Figura 45: Fotos de Retinografia Anerítra em olho normal. 71

Figura 46: Fotos de Angiografia Fluoresceínica em olho normal. 71

Figura 47: Fotos de Angiografia Fluoresceínica em olho com patologia.

Figura 48: Fotos de Angiografia Indocianínica em olho com patologia. 72

Figura 49: Gráfico de MTF da objetiva do sistema.

Figura 50: MTF do sistema de captação considerando uma objetiva ideal. 74

Figura 51: Gráfico de MTF do sistema de captação completo...... 75

Figura 52: Gráfico de MTF do sistema de iluminação completo. 75

Figura 53: Gráfico da probabilidade da Modulação ser alcançada em $10 \mathrm{lp} / \mathrm{mm}$. 
Figura 54: Gráfico da probabilidade da Modulação ser alcançada em $20 \mathrm{lp} / \mathrm{mm}$.

Figura 55: Gráfico da probabilidade da Modulação ser alcançada em $30 \mathrm{lp} / \mathrm{mm}$. 78

Figura 56: Gráfico da probabilidade da Modulação ser alcançada em $40 \mathrm{lp} / \mathrm{mm}$. 79

Figura 57: Gráfico da probabilidade da Modulação ser alcançada em $50 \mathrm{lp} / \mathrm{mm}$. 79

Figura 58: Gráfico do MTF 80\% provável após a fabricação do sistema. 80 


\section{Lista de Tabelas}

Tabela 1: Valores aproximados dos raios de curvatura, espessuras e índices de refração do olho humano ${ }^{[2]}$, lembrando que estes valores variam para cada indivíduo e até mesmo para os dois olhos de um mesmo indivíduo

Tabela 2: Especificação da precisão dos equipamentos de fabricação e aferição utilizados no projeto............................................ 59

Tabela 3: Principais parâmetros ópticos do conjunto captadora................ 63

Tabela 4: Parâmetros ópticos do projetor afocal.................................. 64

Tabela 5: Parâmetros ópticos do conjunto objetiva. ................................ 65

Tabela 6: Parâmetros ópticos da primeira parte do sistema de iluminação

Tabela 7: Tabela indicando o resultado da alteração no foco do sistema para uma lente simulando as dioptrias do olho. 


\section{Resumo}

Neste trabalho foi desenvolvido um sistema óptico para observação e captação de imagens do fundo do olho. Este exame, conhecido como Retinografia, é realizado por especialistas da área de Oftalmologia que permite ao profissional a observação e o registro da imagem da retina. Outro exame realizado com o mesmo equipamento é a angiografia que consiste na observação da fluorescência nas veias da retina após a injeção intravenosa de uma substância. O sistema óptico do retinógrafo é composto por dois sistemas coaxiais, um de iluminação e outro de captação. Por permitir a observação em tempo real, o sistema possui uma abertura angular bem maior que a dos equipamentos com câmera fotográfica, gerando diversas aberrações que são minimizadas ao longo do desenvolvimento do projeto óptico. Por serem sistemas coaxiais, um reflexo central é gerado na imagem e o projeto visa também minimizá-lo. O sistema óptico desenvolvido neste trabalho foi fabricado, testado e está sendo utilizado no primeiro retinógrafo digital desenvolvido no país. 


\begin{abstract}
In this work an optical system for eye fundus observation and image capture was developed. This examination, known as retinography, is realized by specialists of the Ophthalmology area in order to make possible to observe and capture eye fundus images. Beside the color and red free retinography, another examination can be realized with the same equipment is the angiography. It consists in the observation of the fluorescence of the dye injected to the patient. It occurs on the retino's blood vessels after the dye is injected intravenously. The fundus camera optical system consists of two coaxial systems, one for illumination and other for captation. As real-time eye fundus observation is one of its features, the system angle aperture is quite larger if compared to equipments that use regular analog cameras, cause aberrations that are minimized during the optical system development. By being a coaxial systems, a central reflex is generated on the image, which the project proposes to solve. The optical system project was development, manufactured, tested and currently being used in the first digital fundus camera developed in our county.
\end{abstract}




\section{Introdução}

A Óptica é uma das áreas que mais permite à Física ter seus conceitos aplicados à fabricação de equipamentos que atendem à demanda de diversas áreas científicas e comerciais. A Óptica Geométrica vem se destacando devido ao conhecimento e aperfeiçoamento das técnicas de Desenho Óptico. Existem hoje no mercado diversas opções de programas específicos para Desenho Óptico que permitem não só o desenvolvimento de projetos, mas também a análise completa do desempenho do sistema incluindo cálculos de tolerâncias de fabricação e montagem, avaliação da qualidade da imagem, operação em regimes de temperatura variável, espalhamento da luz, aplicação de filmes finos e outras. Dentre os programas mais utilizados destacam-se o CodeV do fabricante Optical Research Associates (ORA), o OSLO da Lambda Research e o Zemax da Zemax Development Corporation.

Esses programas utilizam como base a Óptica Geométrica, a Óptica Física e técnicas matemáticas e computacionais para a realização de iterações consecutivas das funções de otimização para que o sistema atinja seu maior desempenho. Para a utilização desses programas é necessário que o usuário tenha conhecimento suficiente para realizar um estudo de primeira ordem adequado ao sistema e saber interpretar os resultados obtidos reconhecendo se as análises realizadas pelo programa são condizentes com o resultado teórico esperado.

Os equipamentos que possuem sistemas ópticos são amplamente utilizados em diversas áreas de aplicação que vão desde as máquinas fotográficas e os 
projetores simples até sofisticados equipamentos médicos, militares e industriais. Os equipamentos médicos que realizam diagnóstico por imagem já estão no mercado há décadas e vêm ganhando um espaço cada vez maior.

A Retinografia, um exame que consiste na observação e captura de imagens da retina, é feita com freqüência por pacientes que possuem doenças como diabetes, toxoplasmose, glaucoma, degeneração macular e outras, para possibilitar diagnósticos efetivos ou complementares e ainda para o acompanhamento de tais patologias. Os retinógrafos tradicionais utilizados para a realização deste exame vêm sendo aperfeiçoados ao longo das últimas décadas para possibilitar maior comodidade ao médico e ao paciente. A Retinografia digital vem substituindo a Retinografia convencional pois possibilita o diagnóstico em tempo real e elimina a etapa de revelação de filmes fotográficos.

O objetivo desse trabalho é desenvolver um sistema óptico completo para um retinógrafo digital que consiste em dois sistemas trabalhando em conjunto, um sistema de iluminação e um sistema de captação. Após o projeto do sistema será feita sua análise completa incluindo a avaliação da qualidade da imagem, a análise de tolerâncias para a fabricação e finalmente sua montagem e alinhamento.

O sistema óptico desenvolvido nesse trabalho foi projetado e otimizado com o auxílio do programa CodeV. Esse sistema foi introduzido no equipamento completo com o auxílio de engenheiros mecânicos e eletrônicos e está sendo comercializado pela empresa OPTO Eletrônica S/A de São Carlos. 


\section{Revisão Bibliográfica}

Este capítulo, além de revisar conceitos básicos de Óptica Física e Geométrica necessários para a realização do trabalho, apresenta uma visão geral da teoria de Desenho Óptico e suas características fundamentais como o estudo de aberturas e pupilas e aberrações em sistemas ópticos. Será feita ainda uma abordagem das características dos materiais ópticos, destacando as propriedades apresentadas nos catálogos de vidros comerciais relevantes para o trabalho.

O objetivo do sistema óptico desenvolvido neste trabalho é a fabricação de um equipamento oftalmológico que realiza exames clínicos, cujo princípio é a observação da retina, dessa forma será introduzida neste capítulo a descrição dos exames a serem realizados com o equipamento como um todo, a Retinografia e a angiografia.

Os programas para Desenho Óptico têm uma participação fundamental no projeto de qualquer sistema óptico. O programa utilizado foi o Code $\mathrm{V}$ da Optical Research Associates (ORA) que permite a realização de todas as análises pertinentes a este projeto.

\subsection{Conceitos de Óptica e Desenho Óptico}

O projeto e a análise de sistema de lentes usa cálculos baseados na Óptica Geométrica. O cálculo da formação da imagem requer a interpretação desses resultados geométricos com o uso da Óptica Física. O modelo da Óptica 
Geométrica é suficiente para definir as propriedades da formação da imagem por uma lente bem como os parâmetros de fabricação dessa lente. ${ }^{[1]}$

Essa seção introduz a revisão dos conceitos básicos relevantes para 0 Desenho Óptico e para desenvolvimento do trabalho.

\subsection{1 Óptica Geométrica de Primeira Ordem}

O conceito de raio de luz (que nada mais é do que o caminho descrito por um único ponto da frente de onda) é muito mais conveniente para a grande maioria das aplicações devido à dificuldade de manipular matematicamente uma frente de onda. Num meio isotrópico, os raios de luz são linhas retas normais à frente de onda. Num sistema de lentes perfeito, os raios provenientes de uma fonte pontual convergem para um único ponto na imagem.

A óptica de primeira ordem ou óptica gaussiana, refere-se à óptica de sistemas perfeitos. As equações de primeira ordem podem ser obtidas reduzindo-se as equações trigonométricas exatas do traçado de raios para o caso limite onde a altura e os ângulos dos raios aproximam-se de zero. Essas aproximações são válidas na região próxima ao eixo óptico, conhecida como região paraxial. ${ }^{[2]}$

Nessa seção serão feitos uma breve discussão dos conceitos básicos de Óptica Geométrica e um rápido estudo da formação de imagens por sistemas ópticos "perfeitos". 


\subsubsection{Lei da Refração}

Vamos considerar uma frente de onda plana incidindo numa superfície plana que separa dois meios como é mostrado na Figura 1.

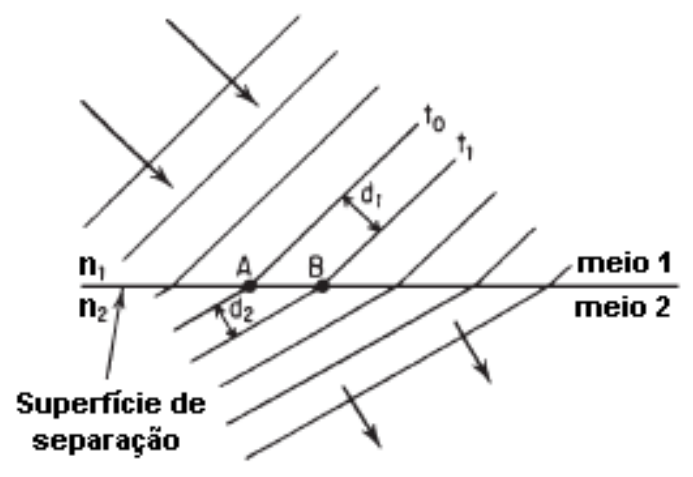

Figura 1: Diagrama representativo da passagem de uma frente de onda plana pela interface entre dois meios.

As linhas paralelas representam a posição da frente onda em intervalos regulares de tempo. O índice de refração do meio 1 é $\mathrm{n}_{1}$ e o do meio 2 é $\mathrm{n}_{2}$ $\left(\operatorname{com} n_{2}>n_{1}\right)$. A velocidade da luz no meio 1 é $v_{1}=c / n_{1}$ e no meio 2 é $v_{2}=c / n_{2}$ (onde c é a velocidade da luz no vácuo). Portanto, a velocidade da luz no meio 1 é $n_{2} / n_{1}$ vezes a velocidade no meio 2 e a distância que a frente de onda percorre no meio 1 num dado intervalo de tempo é $\mathrm{n}_{2} / \mathrm{n}_{1}$ vezes a velocidade que ela percorre no meio 2 .

Num tempo $t_{0}$, a frente de onda intercepta a superfície de separação entre os dois meios no ponto $A$; num instante $t_{1}=t_{0}+\Delta t$, ela intercepta a interface no ponto B. Durante esse tempo, a frente de onda se moveu uma distância no meio 1 igual a

$$
\mathrm{d}_{1}=\mathrm{v}_{1} \Delta \mathrm{t}=\frac{\mathrm{c}}{\mathrm{n}_{1}} \Delta \mathrm{t}
$$


e no meio 2 igual a

$$
\mathrm{d}_{2}=\mathrm{v}_{2} \Delta \mathrm{t}=\frac{\mathrm{c}}{\mathrm{n}_{2}} \Delta \mathrm{t}
$$

Vamos agora representar o caminho percorrido por um ponto da frente de onda por um raio que atinge a interface no ponto B (Figura 2).

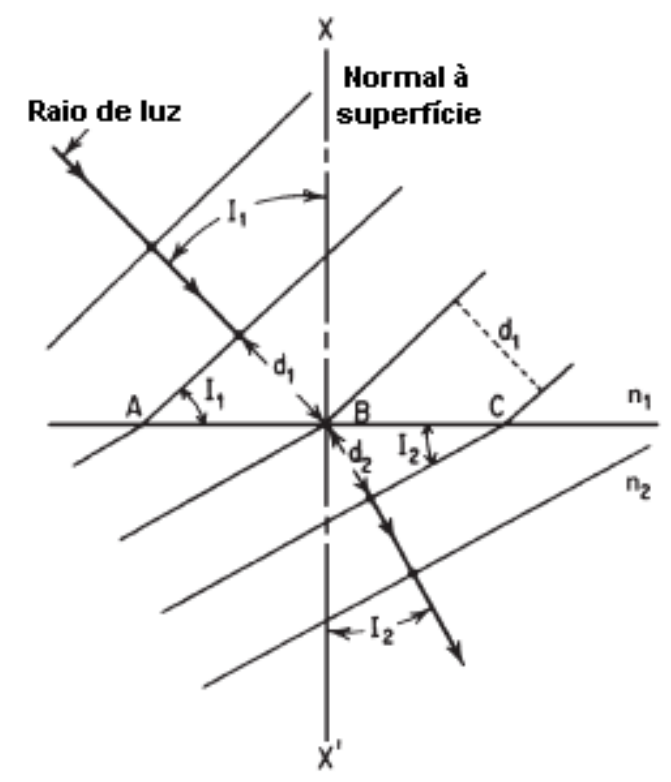

Figura 2: llustração de um raio representando o caminho percorrido por um ponto da frente de onda ao passar pela interface entre dois meios.

Como as linhas paralelas indicam a posição da frente de onda em intervalos iguais de tempo, então as distâncias $A B$ e $B C$ devem ser iguais. $O$ ângulo entre a frente de onda e a superfície $\left(I_{1}\right.$ ou $\left.I_{2}\right)$ é igual ao ângulo entre o raio (que é normal à frente de onda) e a normal à superfície XX’. Temos então

$$
A B=\frac{d_{1}}{\operatorname{sen} I_{1}}=B C=\frac{d_{2}}{\operatorname{sen} I_{2}}
$$

Substituindo nessa expressão os valores de $d_{1}$ e $d_{2}$ encontrados em (1) e (2), temos: 


$$
\frac{c \Delta t}{n_{1} \operatorname{sen} I_{1}}=\frac{c \Delta t}{n_{2} \operatorname{sen} I_{2}}
$$

Cancelando os termos iguais, temos como resultado a expressão:

$$
\mathrm{n}_{1} \operatorname{sen} \mathrm{I}_{1}=\mathrm{n}_{2} \operatorname{sen} \mathrm{I}_{2}
$$

Esta expressão foi apresentada primeiramente através da construção geométrica da direção dos raios incidente e refratado por W. Snell em 1621 e é conhecida como lei de Snell.

\subsubsection{Pontos Cardinais de um Sistema Óptico}

Um sistema funciona como uma "caixa preta" cujas características podem ser perfeitamente determinadas por seus pontos cardinais os quais podem ser resumidos em ponto principal primário e secundário, ponto focal primário e secundário e ponto nodal primário e secundário. Os pontos focais primário e secundário são os pontos para quais os raios que incidem paralelos ao eixo óptico convergem (ou focam) formando um ponto sobre o eixo. Se os raios que entram e emergem do sistema forem prolongados até se interceptarem, os pontos de intersecção irão definir uma superfície referenciada como plano principal. Em sistemas ópticos bem corrigidos, as superfícies principais são esferas centradas no objeto e na imagem. Na região paraxial, onde as distâncias até o eixo são infinitesimais, as superfícies podem ser tratadas como se fossem planas, daí o nome "planos principais". A intersecção dessas superfícies com o eixo são os pontos principais. O ponto focal secundário e o ponto principal secundário são definidos pelos raios à esquerda do sistema. $\mathrm{O}$ ponto focal primário e o ponto focal secundário são definidos pelos raios à direita do sistema. 
A distância focal efetiva (EFL) de um sistema é a distância do ponto principal ao ponto focal. A distância focal posterior (BFL), ou back focus, é a distância do vértice da última superfície do sistema até o ponto focal secundário. A distância focal anterior (FFL) é a distância do vértice da primeira superfície até o ponto focal primário. Essas grandezas estão ilustradas na Figura 3.

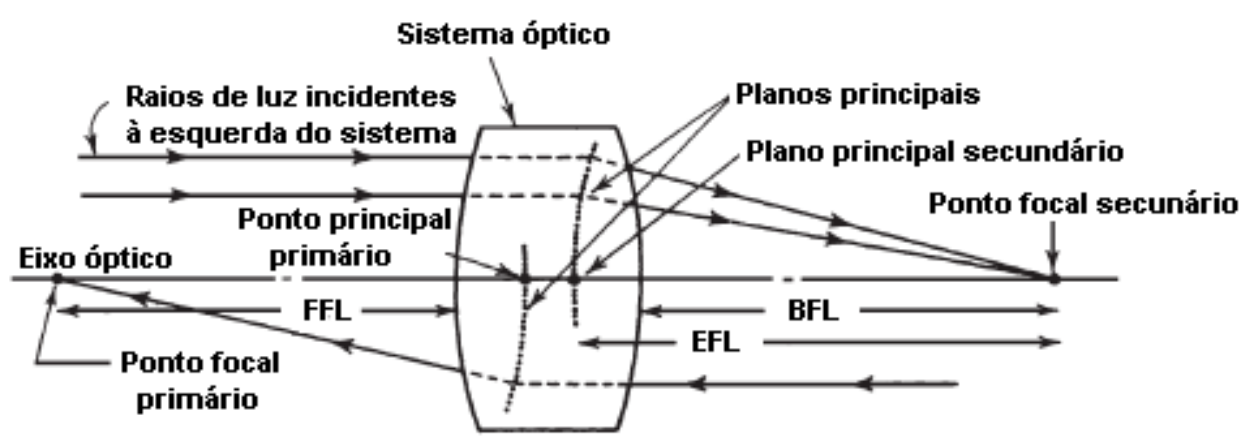

Figura 3: Desenho ilustrativo da posição dos pontos principais e secundários de um sistema óptico fictício.

Os pontos nodais são dois pontos axiais que interceptam o prolongamento dos raios incidentes e emergentes do sistema óptico. A posição desses pontos é facilmente ilustrada pela Figura 4. Quando o sistema óptico está circundado de ar por todos os lados, os pontos nodais coincidem com os pontos principais. Todo plano que contém um raio não axial e o eixo óptico é chamado de plano meridional e todo raio pertencente a estes planos são raios meridionais. Um plano perpendicular ao plano meridional que contém um raio meridional é chamado de plano sagital ${ }^{[3]}$. 


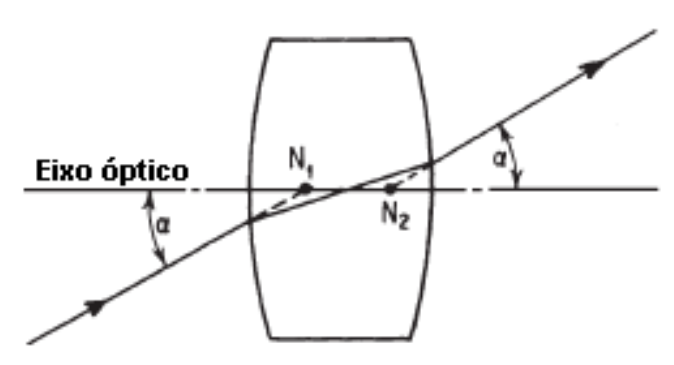

Figura 4: Desenho ilustrativo da posição dos pontos nodais. O prolongamento do raio incidente intercepta o eixo óptico no ponto nodal primário $\mathrm{N}_{1}$. O prolongamento do raio que emerge do sistema intercepta o eixo no ponto nodal $\mathrm{N}_{2}$ secundário.

\subsubsection{Formação de Imagens}

Quando os pontos cardinais de um sistema são conhecidos, a posição e o tamanho da imagem formada pelo sistema podem ser facilmente determinados. Na Figura 5, são mostrados os pontos focais $F_{1}$ e $F_{2}$ e os pontos principais $P_{1}$ e $P_{2}$ de um sistema óptico. $O$ objeto está representado pelo segmento AO. São necessários dois raios para representar a formação de uma imagem: um que incide paralelo ao eixo óptico e emerge passando por $F_{2}$ e outro que incide passando por $F_{1}$ e emerge paralelo ao eixo óptico. Um último raio que incide passando pelo ponto nodal primário e emerge, paralelo ao raio de entrada, passando através do ponto nodal secundário pode ser usado para completar o traçado ${ }^{[3]}$.

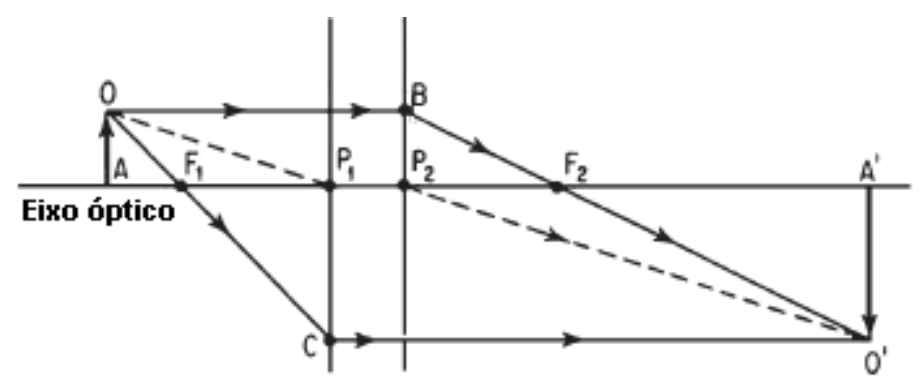

Figura 5: Desenho do traçado de raios formando uma imagem. 
O raio $\mathrm{OB}$, paralelo ao eixo do sistema, passa através do ponto focal secundário $F_{2}$ e a refração está representada a partir do plano principal secundário. $\mathrm{O}$ raio $\mathrm{OF}_{1} \mathrm{C}$, que passa através do ponto focal primário $\mathrm{F}_{1}$, emerge do sistema paralelo ao eixo. A intersecção desses dois raios no ponto O' indica a posição da imagem do ponto ${ }^{0}{ }^{[2]}$

Essa mesma construção pode ser aplicada para os outros pontos do plano objeto AO resultando nos demais pontos do plano imagem O'A'. Um terceiro raio pode ser traçado de $\mathrm{O}$ até o ponto nodal primário que irá emergir do ponto nodal secundário e será paralelo ao raio de entrada. Um raio de luz sempre se propaga paralelo ao eixo óptico entre os pontos nodais. Como foi indicado na seção anterior, se o objeto e a imagem estiverem no ar, os pontos nodais coincidem com os pontos principais, por isso, os raios $\mathrm{OP}_{1}$ e $\mathrm{P}_{2} \mathrm{O}$ estão tracejados na Figura 5.

Em termos de Óptica Geométrica, é sempre necessário adotar uma convenção de sinais para as grandezas envolvidas no cálculo de traçado de raios. Há várias convenções normalmente adotadas, a que foi escolhida neste trabalho é descrita da seguinte forma:

- Alturas acima do eixo óptico são positivas;

- Alturas abaixo do eixo óptico são negativas;

- Distâncias à esquerda do eixo óptico com relação ao plano de referência (plano principal ou focal) são negativas;

- Distâncias à direita do eixo óptico com relação ao plano de referência (plano principal ou focal) são positivas;

- Comprimentos focais de lentes convergentes são positivos; 
- Comprimentos focais de lentes divergentes são negativos.

Adotando esta convenção podemos agora determinar a posição e o tamanho de uma imagem formada por um sistema óptico.

Simplificando a Figura 5 para descrever as equações usuais, obtemos a Figura 6 apresentada em função das alturas do objeto e da imagem, h e h', dos comprimentos focais, f e f', das distâncias do objeto e da imagem aos planos principais, s e s' e das distâncias do objeto e da imagem ao ponto focal, $x$ e $x^{\prime} \cdot{ }^{[2]}$

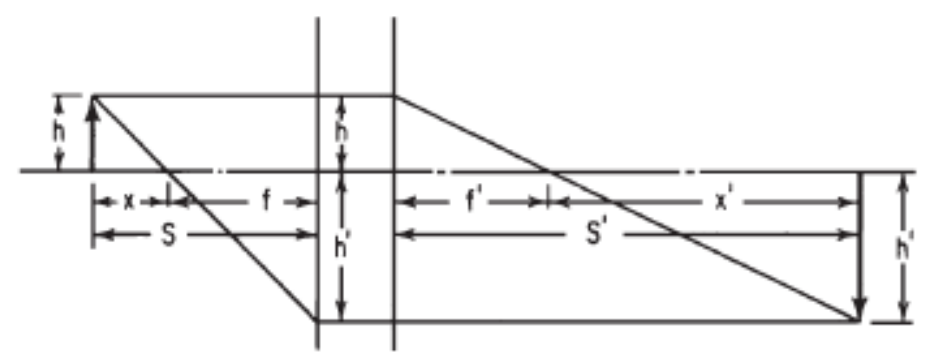

Figura 6: Diagrama ilustrativo para definição das equações que determinam a posição e o tamanho da imagem.

De acordo com a convenção de sinais adotada, h, f, f', x' e S' são positivas e x, S e h' são negativas.

Por semelhança de triângulo podemos escrever

$$
\frac{h}{\left(-h^{\prime}\right)}=\frac{(-x)}{f} \text { e } \frac{h}{\left(-h^{\prime}\right)}=\frac{\left(f^{\prime}\right)}{x^{\prime}}
$$

Se isolarmos $\mathrm{h}$ nas expressões apresentadas em (6), temos:

$$
\mathrm{ff}^{\prime}=-\mathrm{XX}
$$

Assumindo que o sistema inteiro está no ar (não abordaremos sistemas imersos em outros meios), 


$$
x^{\prime}=\frac{-f^{2}}{x}
$$

Esta é a forma newtoniana da equação de imagem e é muito usada para cálculos onde a localização dos pontos focais é conhecida.

Se substituirmos $x=S+f$ e $x^{\prime}=S^{\prime}-f$ na equação (8), podemos derivar a forma gaussiana da expressão para a localização da imagem.

$$
f^{2}=-x x^{\prime}=-(s+f)\left(s^{\prime}-f\right)=-s s^{\prime}+s f-s^{\prime} f+f^{2}
$$

Cancelando $f^{2}$ em (9) e dividindo por ss'f, temos:

$$
\frac{1}{s^{\prime}}=\frac{1}{f}+\frac{1}{s}
$$

ou, alternativamente,

$$
s^{\prime}=\frac{s f}{(s+f)} \quad \text { ou } \quad f=\frac{s s^{\prime}}{\left(s-s^{\prime}\right)}
$$

A magnificação lateral, ou transversa, de um sistema óptico é dada pela razão entre o tamanho da imagem e o tamanho do objeto, h'/h. Reagrupando a equação (6) podemos definir a magnificação m,

$$
m=\frac{h^{\prime}}{h}=\frac{f}{x}=\frac{-x^{\prime}}{f}
$$

Substituindo $x=s+f$ em (12) temos:

$$
m=\frac{h^{\prime}}{h}=\frac{f}{(s+f)}
$$

Notando que $f /(s+f)$ é igual a $s^{\prime} / s$, encontramos a expressão 


$$
\mathrm{m}=\frac{\mathrm{h}^{\prime}}{\mathrm{h}}=\frac{\mathrm{s}^{\prime}}{\mathrm{s}}
$$

\subsubsection{Traçado de Raios}

A Óptica Geométrica se baseia no conceito de raios de luz propagando em linha reta através de meios homogêneos. Esses raios podem ser refratados em superfícies curvas que separam meios homogêneos com diferentes índices de refração. Iniciaremos o estudo com a refração da luz em uma única superfície esférica e posteriormente descreveremos as equações que permitem determinar o traçado de raios através de várias superfícies distribuídas ao longo do eixo.

\subsubsection{Refração de um Raio em uma Superfície Esférica}

O caminho da luz através de um sistema óptico pode ser determinado pela Lei de Snell (5) utilizando apenas conceitos de Geometria e Trigonometria. Seguindo a notação adotada por $\operatorname{Smith}^{\dagger}$, vamos elaborar as equações que permitem descrever o caminho de um raio através de uma superfície esférica. A Figura 7 mostra uma superfície esférica, com raio $\mathrm{R}$ e centro de curvatura C, que separa dois meios com índices de refração n e n'; um raio (GQP), que incide a superfície num ponto $\mathrm{Q}$, cujo prolongamento atinge o ponto $\mathrm{P}$ onde intercepta o eixo óptico a uma distância $L$ da superfície. Porém, o raio é refratado pela superfície e atinge o eixo no ponto $P^{\prime}$ que se encontra a uma distância L' da superfície. O raio faz um ângulo U com relação ao eixo óptico

\footnotetext{
${ }^{\dagger}$ Devido à enorme diversidade de nomenclaturas e convenções de sinais, foi adotada por simplicidade a mesma notação descrita por $\mathrm{Smith}^{[2]}$ em toda a apresentação de traçado de raios e formação de imagens.
} 
antes da refração e U' depois da refração, e um ângulo I com relação a normal à superfície antes da refração e I' depois da refração ${ }^{[2]}$.

Novamente torna-se conveniente adotar uma convenção de sinais para as grandezas envolvidas:

- O raio de curvatura é positivo se o centro de curvatura está à direita da superfície;

- As distâncias à direita da superfície são positivas e à esquerda são negativas (como já havia sido definido anteriormente);

- Os ângulos de incidência e refração (l e l') são positivos se o raio percorre o sentido horário até a normal à superfície;

- Os ângulos entre os raios e o eixo (U e U') são positivos se os raio percorrem o sentido horário até atingir o eixo;

- A luz se propaga da esquerda para a direita. 


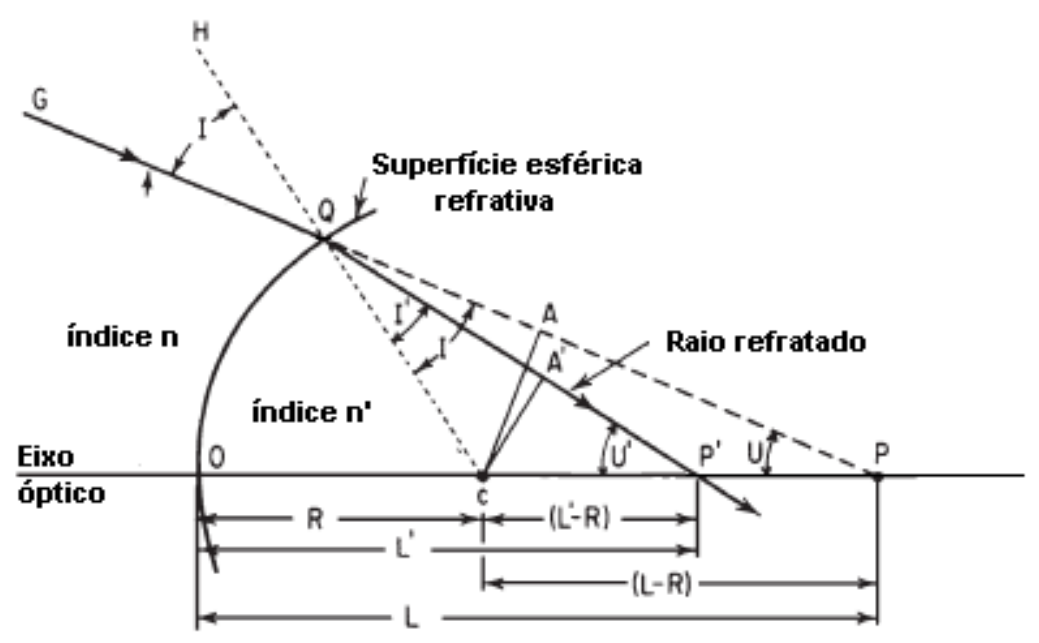

Figura 7: Refração de um raio por uma superfície esférica.

A partir dos triângulos PAC e QAC, temos:

$$
\begin{gathered}
C A=(R-L) \operatorname{sen} U \\
\text { sen } I=\frac{C A}{R}
\end{gathered}
$$

Aplicando a Lei de Snell (5),

$$
\operatorname{sen} I^{\prime}=\frac{n}{n^{\prime}} \operatorname{sen} I
$$

O ângulo externo QCO do triângulo PQC é $(-U+I)$ e o ângulo externo do triângulo P'QC é $\left(-U^{\prime}+I^{\prime}\right)$. Então $\left(-U+I=-U^{\prime}+I^{\prime}\right)$, portanto,

$$
U^{\prime}=U-I+I^{\prime}
$$

Do triângulo QA'C, temos:

$$
\operatorname{sen} l^{\prime}=\frac{C A^{\prime}}{R}
$$

Substituindo (16) e (19) em (17), chegamos à expressão: 


$$
\mathrm{CA}^{\prime}=\frac{\mathrm{n}}{\mathrm{n}^{\prime}} \mathrm{CA}
$$

Finalmente a posição de $\mathrm{P}^{\prime}$ é encontrada isolando $\mathrm{L}$ da expressão $C A^{\prime}=\left(R-L^{\prime}\right)$ sen $U^{\prime}$ vinda do triângulo $P^{\prime} A^{\prime} C$

$$
L^{\prime}=R-\frac{C A^{\prime}}{\operatorname{sen} U^{\prime}}
$$

Portanto, pode-se observar que, partindo de um raio que atinge o eixo óptico a uma distância $L$ da superfície esférica com um ângulo $U$, determina-se $U$ ' e L' após a refração. Esse processo é aplicado sucessivamente a cada superfície para traçar o caminho do raio ao longo do sistema óptico ${ }^{[2]}$.

\subsubsection{Aproximação Paraxial}

A aproximação paraxial é derivada do caso limite das equações trigonométricas para o traçado de raios. Esta aproximação pode ser aplicada quando as alturas em relação ao eixo óptico, bem como os ângulos que os raios fazem com o eixo, são muito pequenos. Dessa forma, observando a Figura 8, podemos fazer as seguintes considerações: $\frac{y}{R}<<1$ e $(\operatorname{sen} U=U)^{\ddagger}$.

$\ddagger$ Aproximação feita pela série de Maclaurin: $\quad \operatorname{sen} U=U-\frac{U^{3}}{3}+\frac{U^{5}}{5}-\frac{U^{7}}{7}+\ldots$ que para $U$ muito pequeno, resulta em $\operatorname{sen} U=U$. 


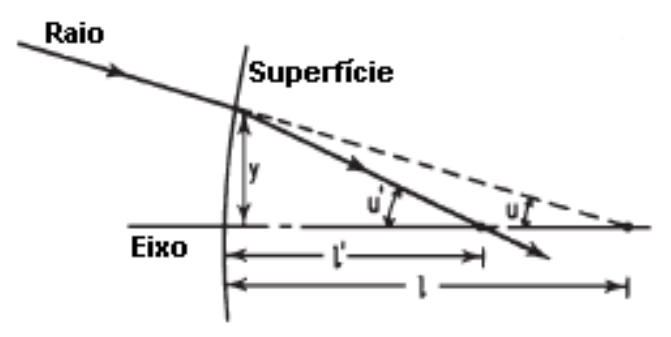

Figura 8: Ilustração dos parâmetros utilizados na aproximação paraxial do traçado de raios.

Dessa forma, as equações (15), (16), (17), (18), (20) e (21) podem ser representadas por:

$$
\begin{gathered}
\mathrm{ca}=-(\ell-\mathrm{R}) \mathrm{u} \\
\mathrm{i}=\frac{\mathrm{ca}}{\mathrm{R}} \\
\mathrm{i}^{\prime}=\frac{\mathrm{ni}}{\mathrm{n}^{\prime}} \\
\mathrm{u}^{\prime}=\mathrm{u}-\mathrm{i}+\mathrm{i}^{\prime} \\
\mathrm{ca}=\frac{\mathrm{nca}}{\mathrm{n}^{\prime}} \\
\ell^{\prime}=\mathrm{R}-\frac{\mathrm{ca}}{\mathrm{u}^{\prime}}
\end{gathered}
$$

Usamos letras minúsculas para as equações válidas na região paraxial apenas para distingui-las das equações trigonométricas exatas. Como as equações (22) à (27) são aplicadas apenas na região onde as alturas e os ângulos são infinitesimais, podemos simplificá-las, sem perder sua validade, eliminando os parâmetros i, u, ca, e seus respectivos conjugados, chegando às expressões (28) ou (29). 


$$
\begin{gathered}
\ell^{\prime}=\frac{\ell n^{\prime} \mathrm{R}}{\left(\mathrm{n}^{\prime}-\mathrm{n}\right) \ell+\mathrm{nR}} \\
\frac{\mathrm{n}^{\prime}}{\ell^{\prime}}=\frac{\mathrm{n}^{\prime}-\mathrm{n}}{\mathrm{R}}+\frac{\mathrm{n}}{\ell}
\end{gathered}
$$

\subsubsection{Sistemas com Diversas Lentes}

Para o estudo e projeto de sistemas ópticos é necessário traçar o caminho percorrido pelos raios ao longo de um sistema que pode ser composto por diversos componentes separados por uma dada distância e dispostos sobre o eixo óptico. Para estender o conceito de refração dos raios através dos diversos componentes do sistema óptico, serão definidas as equações de transferência que permitem, com o conhecimento dos ângulos e alturas dos raios em uma superfície, determinar os mesmos parâmetros na superfície seguinte. Nessa seção, será abordado o traçado de raios através de um sistema óptico axial imerso em um meio homogêneo seguindo as convenções e a forma de apresentação descrita na referência [2].

\subsubsection{Traçado Paraxial}

Observando a Figura 8 e considerando a aproximação paraxial ${ }^{\S}$, podemos escrever: $\mathrm{u}=-\mathrm{y} / \ell$ e $\mathrm{u}^{\prime}=-\mathrm{y} / \ell^{\prime} \mathrm{o}$ que corresponde também a $\ell=-\mathrm{y} / \mathrm{u}$ e $\ell^{\prime}=-\mathrm{y} / \mathrm{u}^{\prime}$. Substituindo estes valores em (29) e expressando a curvatura como o inverso do raio $(C=1 / R)$, temos:

$$
n^{\prime} u^{\prime}=n u-y\left(n^{\prime}-n\right) C
$$

\footnotetext{
${ }^{\S}$ Este estudo é válido na região paraxial. Embora sejam usados ângulos (e alturas) finitos (que na região paraxial são infinitesimais), isso não afeta a validade das expressões, pois na região paraxial, elas se aproximam das equações trigonométricas exatas. ${ }^{[2]}$
} 
A Figura 9 mostra o traçado de raios em duas superfícies esféricas separadas por uma distância $t_{1-2}$.

O ângulo $u_{1}^{\prime}$ é o ângulo do raio refratado pela superfície 1. As alturas dos raios ao atingirem as superfícies 1 e 2 são $y_{1}$ e $y_{2}$. A diferença entre $y_{1}$ e $y_{2}$, lembrando que o traçado é paraxial ${ }^{*}$, é dada por tu' ${ }_{1}$. Com isso, podemos afirmar a relação:

$$
y_{2}=y_{1}+t_{1} u_{1}^{\prime}
$$

Generalizando esta expressão para uma superfície j qualquer do sistema, temos a primeira equação de transferência:

$$
y_{j+1}=y_{j}+t_{j} u_{j}
$$

\footnotetext{
${ }^{* \star}$ Neste caso a aproximação feita foi: $\tan U=U$, válida também para ângulos muito pequenos.
} 

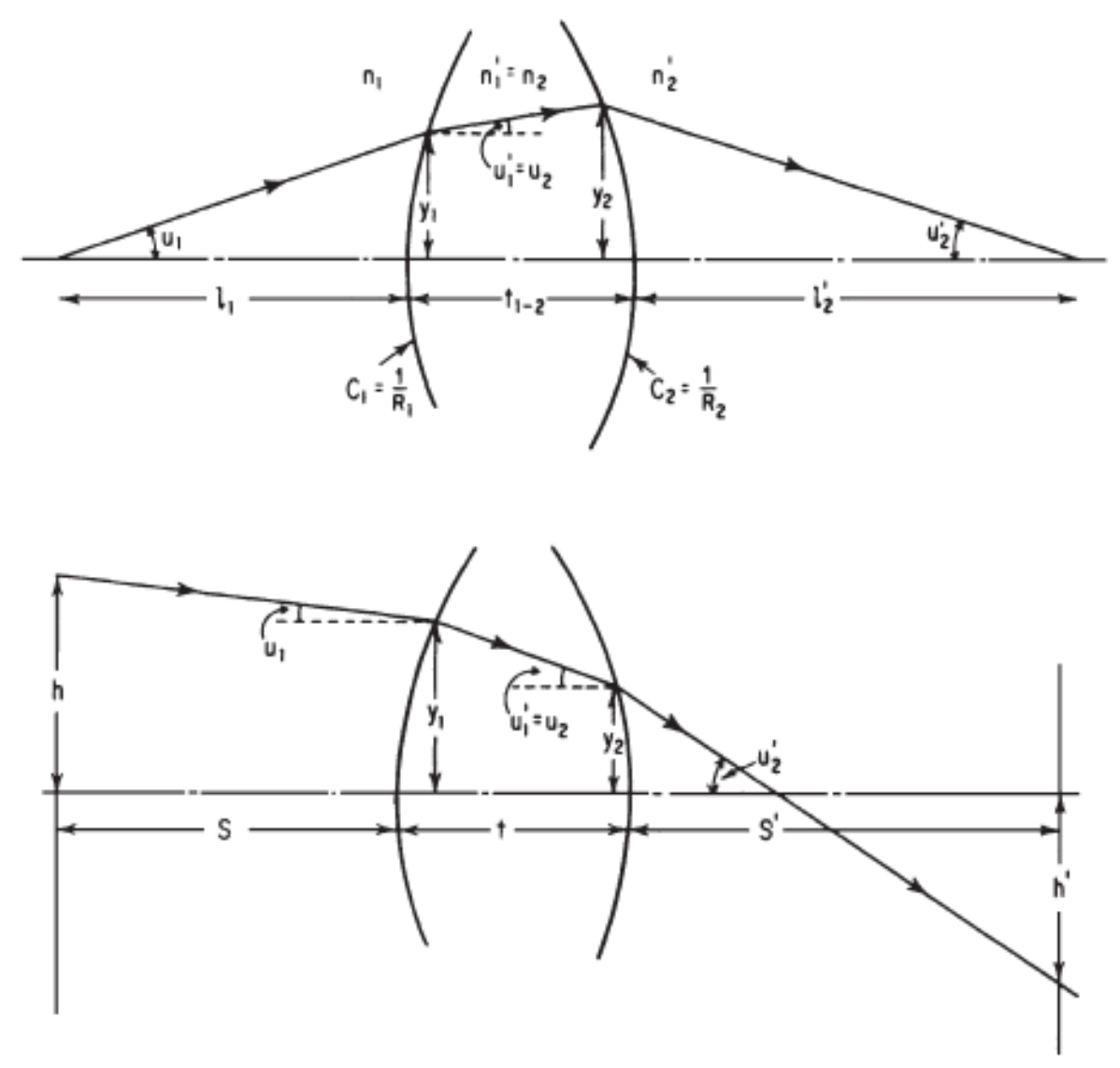

Figura 9: llustração dos parâmetros envolvidos para a descrição das equações de transferência do traçado de raios paraxial.

Três outras equações são derivadas diretamente do traçado geométrico do sistema. Um raio refratado por uma superfície será o raio incidente na superfície seguinte, assim como o índice de refração do meio de propagação do raio refratado por uma superfície, será o índice do meio incidente para outra superfície. Um exemplo disso é que $u_{1}^{\prime}=u_{2}, y_{1}^{\prime}=y_{2}, n_{1}^{\prime}=n_{2}$. Generalizando estas expressões, chegamos a mais três equações de transferência:

$$
\begin{aligned}
& u_{j+1}=u^{\prime}{ }_{j} \\
& y_{j+1}=y^{\prime}{ }_{j}
\end{aligned}
$$




$$
\mathrm{n}_{\mathrm{j}+1}=\mathrm{n}_{\mathrm{j}}
$$

Para a última superfície do sistema, representada por k, temos:

$$
\begin{gathered}
\ell_{\mathrm{k}}^{\prime}=\frac{-\mathrm{y}_{\mathrm{k}}}{\mathrm{u}_{\mathrm{k}}^{\prime}} \\
\mathrm{h}^{\prime}=\mathrm{y}_{\mathrm{k}}+\mathrm{s}_{\mathrm{k}}^{\prime} \mathrm{u}_{\mathrm{k}}^{\prime}
\end{gathered}
$$

Podemos assim determinar os parâmetros para o traçado de raios através de todo o sistema.

\subsubsection{Traçado Meridional}

O traçado paraxial de raios é, em geral, uma aproximação muito coerente que reproduz de maneira satisfatória a descrição do sistema. As diferenças entre os valores exatos e os determinados com cálculos paraxiais estão basicamente na medida da performance do sistema. Essas diferenças aparecem na prática como aberrações no sistema óptico que devem ser corrigidas para garantir o bom funcionamento do sistema.

O traçado mais exato de raios é o traçado meridional. O traçado meridional é um caso especial do traçado geral de raios oblíquos onde os raios são restritos ao plano que compõe o eixo óptico ${ }^{[4]}$.

Para descrevermos as equações para o traçado meridional, vamos considerar a Figura 10. O segmento $Q$ é normal ao raio incidente e representa a distância do vértice da superfície até o raio. Q', normal ao raio refratado, é a distância do vértice da superfície ao raio refratado. Os ângulos que os raios incidente e refratado fazem com normal à superfície são indicados por I e I' 
respectivamente ${ }^{\dagger \dagger} \cdot D_{1-2}$ é a distância que o raio percorre entre as duas superfícies separadas por uma distância t. A distância, sobre o eixo óptico, do ponto de intersecção do raio na superfície ao vértice é representada por z que será positiva quando estiver à direita da superfície. Essas e as demais grandezas envolvidas nos cálculos seguintes podem ser observadas na Figura 10.

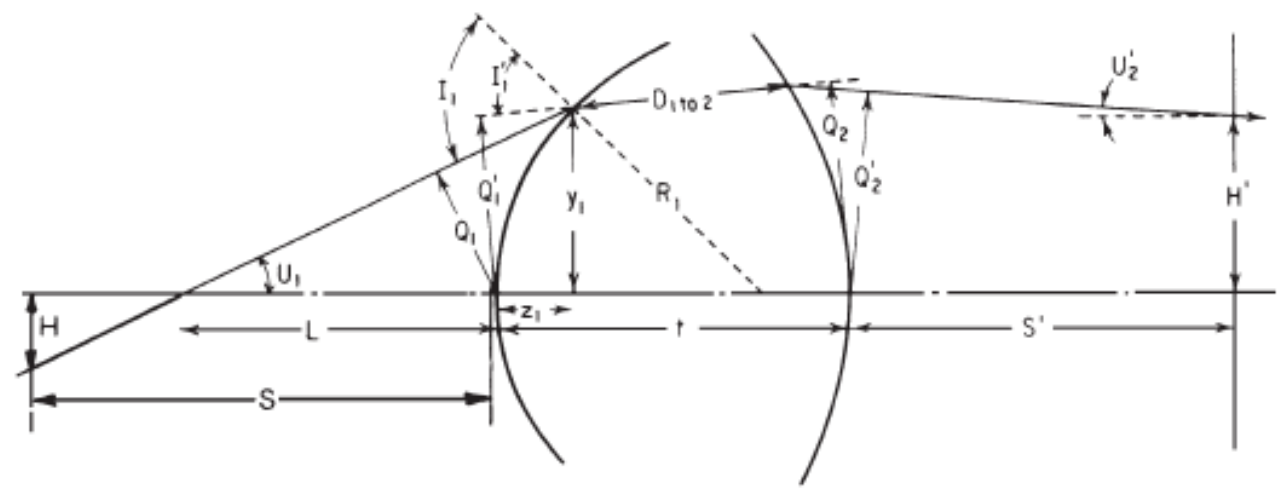

Figura 10: Ilustração dos parâmetros envolvidos para a determinação das equações de transferência do traçado de raios meridional.

Através das relações trigonométricas, obtemos as expressões:

$$
\begin{gathered}
\mathrm{Q}=-\mathrm{L} \operatorname{sen} \mathrm{U} \\
\mathrm{Q}=\mathrm{H} \cos \mathrm{U}-\mathrm{S} \operatorname{sen} \mathrm{U} \\
\operatorname{sen} \mathrm{I}=\mathrm{QC}+\operatorname{sen} \mathrm{U} \\
\operatorname{sen} \mathrm{I}^{\prime}=\frac{\mathrm{n} \operatorname{sen} \mathrm{I}}{\mathrm{n}^{\prime}} \quad \text { (Lei de Snell) } \\
\mathrm{U}^{\prime}=\mathrm{U}-\mathrm{I}+\mathrm{I}^{\prime}
\end{gathered}
$$

\footnotetext{
${ }^{\dagger \dagger}$ Os segmentos Q e Q' são grandezas positivas quando estão apontando para cima a partir do vértice e I e l' são grandezas positivas quando se deslocam em sentido horário na direção da normal à superfície.
} 


$$
\begin{gathered}
\mathrm{Q}=\frac{\mathrm{Q}\left(\cos U^{\prime}+\cos I^{\prime}\right)}{\cos U+\cos I} \\
y=\frac{Q[1+\cos (I-U)]}{(\cos U+\cos I)}=\frac{Q^{\prime}[1+\cos (I-U)]}{\left(\cos U^{\prime}+\cos I^{\prime}\right)}=\frac{\operatorname{sen}(I-U)}{C} \\
z=\frac{Q \operatorname{sen}(I-U)}{(\cos U+\cos I)}=\frac{1-\cos (I-U)}{C}
\end{gathered}
$$

Lembrando que $C=1 / R$.

As equações de transferência ficam, portanto, da seguinte forma:

$$
\begin{gathered}
Q_{j+1}=Q^{\prime}{ }_{j}+\operatorname{tsen} U^{\prime}{ }_{j} \\
U_{j+1}=U^{\prime}{ }_{j} \\
L_{k}^{\prime}=\frac{-Q_{k}^{\prime}}{\operatorname{sen} U_{k}^{\prime}} \\
H^{\prime}=\frac{Q_{k}^{\prime}+S^{\prime}{ }_{k} \operatorname{sen} U_{k}^{\prime}}{\cos U_{k}^{\prime}}
\end{gathered}
$$

Onde j e k referem-se, respectivamente, à uma superfície intermediária qualquer e à última superfície do sistema. Com essas equações, como discutiremos mais tarde, os programas de Desenho Óptico podem fazer iterações consecutivas até atingir o desempenho desejado num sistema.

\subsubsection{Aberturas e Pupilas}

Em todo sistema óptico há aberturas (normalmente denominadas stops) que limitam a passagem de energia através do sistema. Uma dessas aberturas, chamada de stop de abertura ou stop de entrada, determina o diâmetro do 
cone de energia que o sistema recebe vindo do ponto axial do objeto e seu tamanho define a irradiância ${ }^{\ddagger \ddagger}$ da imagem. Outra abertura, denominada field stop, ou abertura de campo determina a extensão angular do objeto que o sistema irá formar a imagem, ou seja, define o ângulo de visão do sistema.

O stop de entrada pode estar em qualquer posição do sistema. A imagem do stop de abertura formada pelas lentes no espaço objeto ${ }^{\S \S}$ é definida como pupila de entrada e, como toda imagem, tem um tamanho e uma posição. No espaço imagem, a imagem desse stop é definida como pupila de saída. O raio que passa através do sistema e intercepta o eixo óptico no plano do stop de entrada é chamado de raio principal. Os raios que passam através do sistema e interceptam o plano do stop em sua extremidade são chamados raios marginais.

O campo de visão do sistema é determinado pela posição do observador (sensor, filme fotográfico, etc.) e pelo diâmetro da janela de observação (Figura 11). A especificação do campo de visão em sistemas ópticos é feita através do ângulo $\beta$ ou do ângulo $\theta$ conhecido como ângulo de meia abertura ou ângulo de meio campo ${ }^{[3]}$ e tem a função de limitar o tamanho do objeto cuja imagem é formada pelo sistema. Dessa forma, quanto maior a janela de observação (ou quanto mais próximo estiver o observador) maior será o ângulo de visão do sistema. A abertura que faz o papel da janela de entrada é o field stop, ou diafragma de campo.

\footnotetext{
执 A irradiância de uma imagem é definida pela razão da potência luminosa pela área por steroradiano e é medida em Watts $/ \mathrm{m}^{2} . \mathrm{sr}$ ou Lúmen $/ \mathrm{m}^{2} . \mathrm{sr}$ dependendo se a unidade é radiométrica ou fotométrica respectivamente.

${ }^{\S \S}$ Espaço objeto e espaço imagem são representados pelo lado do sistema em que se encontra o objeto e a imagem respectivamente.
} 


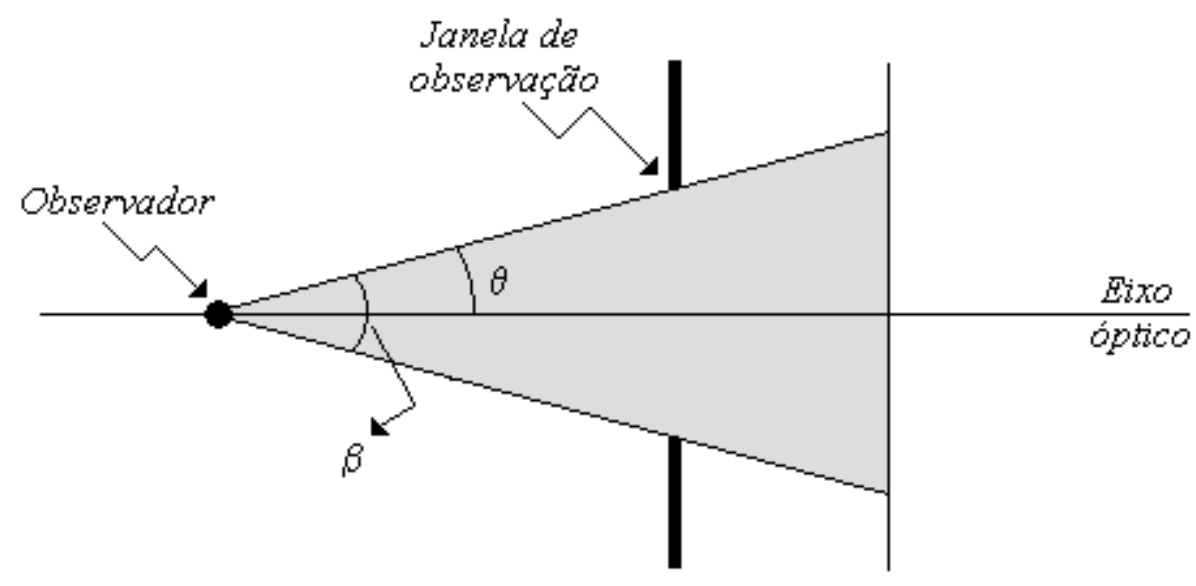

Figura 11: Representação esquemática do campo de visão de um sistema óptico.

A quantidade de luz na pupila de saída de um sistema óptico está diretamente relacionada com a abertura numérica do sistema (NA) que definida por:

$$
\mathrm{NA}=\mathrm{n}^{\prime} \operatorname{sen} \theta
$$

Onde n' é o índice de refração do meio onde se localiza a imagem e $\theta$ é o semi-ângulo do campo de visão.

Outro conceito freqüentemente utilizado em Desenho Óptico é o de abertura relativa do sistema, ou número f/\# (f-number) do sistema. O símbolo \# representa a razão da distância focal do sistema pelo diâmetro da pupila de entrada.

$$
f / \#=\frac{f^{\prime}}{D}
$$

Por exemplo, o valor f/4 significa uma distância focal igual a 8 e uma pupila de entrada igual a 2. O f/\# está diretamente relacionado com a quantidade de energia que chega à imagem e está associada à determinada velocidade do sistema óptico. Um f/\# pequeno determina um sistema com abertura grande e, portanto, o tempo de exposição necessário para formar a imagem de um 
objeto é curto, por isso usa-se o termo "lente rápida". sistemas com f/\# grande possuem uma abertura pequena o que necessita de um tempo de exposição longo para formar a imagem do objeto, por isso o termo "lente lenta" é atribuído ao sistema. Essa terminologia vem dos conceitos fotográficos, mas se aplicam a sistemas de aquisição com qualquer tipo de sensor.

\subsubsection{Olho Humano}

O olho humano é um complexo sistema óptico que funciona como receptor de luz e converte os sinais luminosos em pulsos elétricos transmitindo informações para o cérebro finalizar o processamento da imagem. Uma maneira muito simplificada de descrever a formação de uma imagem pelo olho é a seguinte: a luz incide na córnea onde ocorre refração; em seguida, passa pela íris cuja função é controlar o tamanho da pupila por onde a luz passa para parte interna do olho; após atravessar a pupila, a luz incide no cristalino que funciona como uma lente focalizando os raios incidentes sobre a retina e formando uma imagem formada invertida. Um desenho esquemático da formação de uma imagem no olho pode ser ilustrado pela Figura 12. Um olho que forma a imagem exatamente sobre a retina é considerado emétrope. Quando o olho possui alguma deformação ou dificuldade de focalização, a imagem é formada fora do plano da retina. Nesses casos, o olho é considerado míope ou hipermétrope. 


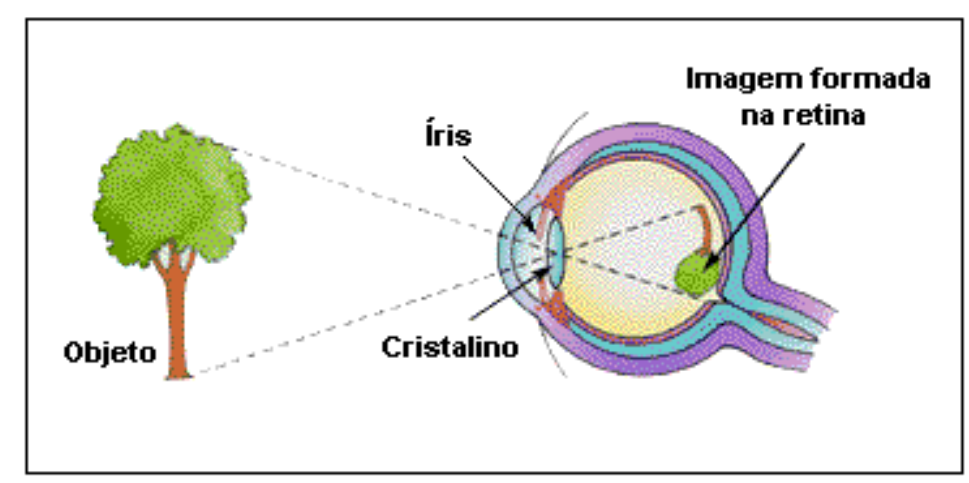

Figura 12: Esquema simplificado da formação de uma imagem pelo olho ${ }^{[5]}$.

Sob o ponto de vista óptico e biológico, o processo de receptação dos raios e formação da imagem é bem mais complexo. A anatomia do olho é muito mais detalhada como pode ser observado na Figura 13.

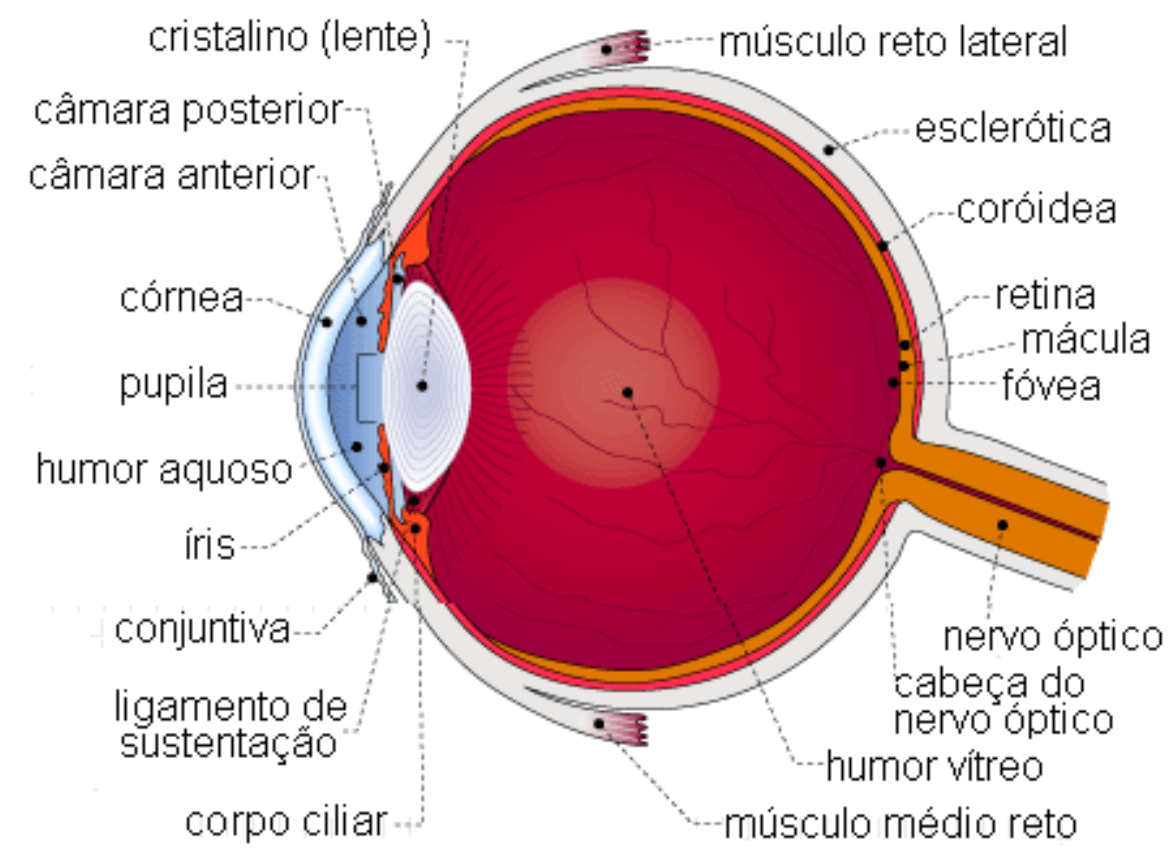

Figura 13: Estrutura anatômica do olho ${ }^{[6]}$. 
A córnea, o cristalino, o humor aquoso (HA) e o humor vítreo (HV) apresentam índices de refração e raios de curvaturas diferentes (Tabela 1) que proporcionam ao olho um poder dióptrico ${ }^{\star \star \star}$ de aproximadamente 60D.

Tabela 1: Valores aproximados dos raios de curvatura, espessuras e índices de refração do olho humano ${ }^{[2]}$, lembrando que estes valores variam para cada indivíduo e até mesmo para os dois olhos de um mesmo indivíduo.

\begin{tabular}{|c|c|c|c|}
\hline & Raio $(\mathbf{m m})$ & Espessura $(\mathbf{m m})$ & $\begin{array}{c}\text { Índice de } \\
\text { refração }\end{array}$ \\
\hline córnea & $+7.8 /+6.4$ & 0.6 & 1,376 \\
\hline Humor Aquoso & - & 3.0 & 1,336 \\
\hline Cristalino & $+10.1 /-6.1$ & 4.0 & $1,386-1,406$ \\
\hline Humor Vítreo & - & 16.9 & 1,337 \\
\hline
\end{tabular}

A córnea é responsável por dois terços do poder refrativo do olho ${ }^{[2]}$. $\mathrm{O}$ cristalino funciona como uma lente ajustável, comprimida ou relaxada pelos músculos ciliares (variando assim seu raio de curvatura), que serve para focalizar o objeto sobre a retina permitindo a formação de imagens de objetos que se encontram a distâncias diferentes.

A retina é uma película que reveste a maior parte posterior do globo ocular e é composta por células fotossensíveis que recebem o estímulo luminoso transformando-o em um estímulo elétrico que é transmitido ao cérebro através do nervo óptico. As imagens são formadas na retina sobre a fóvea, região central da mácula. É nessa região que se encontram os receptores denominados cones que são responsáveis pela percepção das cores e pelo detalhamento da imagem. Essa visão detalhada, ou de alta resolução,

\footnotetext{
${ }^{* \star \star}$ O poder dióptrico, ou potência, de uma lente ou de um sistema é dado por 1/f, onde f é a distância focal em metros. A unidade utilizada para esta grandeza é a dioptria, representada pela letra D.
} 
corresponde a apenas uma pequena parte da visão total ${ }^{[4]}$. Outro tipo de receptores presentes na retina são os bastonetes. Os bastonetes são responsáveis pela percepção da luz e distribuem-se por toda a retina relacionando-se com a visão periférica, visão com baixa resolução, porém, com alta sensibilidade.

Vale a pena ressaltar a importância da formação de duas imagens, uma por cada olho, cuja junção é feita pelo cérebro proporcionando a percepção tridimensional aos objetos. Essa é a chamada visão estereoscópica.

\subsection{Materiais Ópticos}

Muitos materiais, como plásticos, vidros e cristais, podem ser utilizados como substratos para a fabricação de componentes ópticos em diversas aplicações devido às suas diferentes propriedades. As características fundamentais de um material necessárias para um bom desempenho de um projeto óptico se resumem basicamente no material ser homogêneo e isotrópico, ter uma porcentagem mínima de espalhamento e uma alta transmissão na região espectral de interesse (em aplicações especiais, índices de refração variáveis ou propriedades de birrefringência podem ser necessários, porém, não é o caso da aplicação que vamos abordar).

Os vidros ópticos são o meio mais usual para a fabricação de lentes. Esses vidros são relativamente fáceis para fabricar e, produzidos em grande escala, atingem grande uniformidade no índice de refração com baixo custo além de, serem fabricados em blocos com tamanhos que atingem a maior parte das aplicações. 
A propriedade do material mais importante para elementos ópticos é o índice de refração que pode ser definido como:

$$
\mathrm{n}=\frac{\mathrm{v}_{\mathrm{vácuo}}}{\mathrm{v}_{\mathrm{mat}}}=\frac{\text { velocidade da luz no vácuo }}{\text { velocidade da luz no material }}
$$

O índice de refração varia com o comprimento de onda, ou seja, a velocidade da luz num vidro é diferente para cada comprimento de onda e isso faz do vidro um meio dispersivo. Para caracterizar de forma simples os vidros ópticos, três comprimentos de onda são selecionados e o índice de refração é medido para cada um deles. Por convenção, para vidros utilizados na região espectral do visível, os comprimentos de onda usados são d, F e C que correspondem às linhas espectrais para o Hélio em $587.6 \mathrm{~nm}$ e para 0 Hidrogênio em 486.1 nm e 656.3 nm respectivamente. ${ }^{[1]}$

Um vidro óptico é caracterizado pelos números correspondentes ao índice de refração, ao número de Abbe (V-number ou inverso da dispersão) e à dispersão parcial que são apresentados da seguinte forma:

$$
\begin{gathered}
\mathrm{n}_{\mathrm{d}}=\text { Índice de refração } \\
\mathrm{V}_{\mathrm{d}}=\frac{\mathrm{n}_{\mathrm{d}}-1}{\mathrm{n}_{\mathrm{F}}-\mathrm{n}_{\mathrm{C}}}=\text { Número de Abbe } \\
\mathrm{P}_{\mathrm{dC}}=\frac{\mathrm{n}_{\mathrm{d}}-\mathrm{n}_{\mathrm{C}}}{\mathrm{n}_{\mathrm{F}}-\mathrm{n}_{\mathrm{C}}}=\text { Dispersão parcial }
\end{gathered}
$$

Onde $\mathrm{d}, \mathrm{F}$ e C correspondem às linhas espectrais referidas nesta seção. Por convenção puramente histórica, os vidros são classificados em tipo crown e flint da seguinte forma: 
- Crown

$$
\begin{aligned}
& V_{d}>55 \text { para } n_{d}<1,6 \\
& V_{d}>55 \text { para } n_{d}>1,6
\end{aligned}
$$

- Flint

$$
\begin{aligned}
& \mathrm{V}_{\mathrm{d}}<55 \text { para } \mathrm{n}_{\mathrm{d}}<1,6 \\
& \mathrm{~V}_{\mathrm{d}}<55 \text { para } \mathrm{n}_{\mathrm{d}}>1,6
\end{aligned}
$$

Esta classificação pode ser ilustrada pela Figura 14.

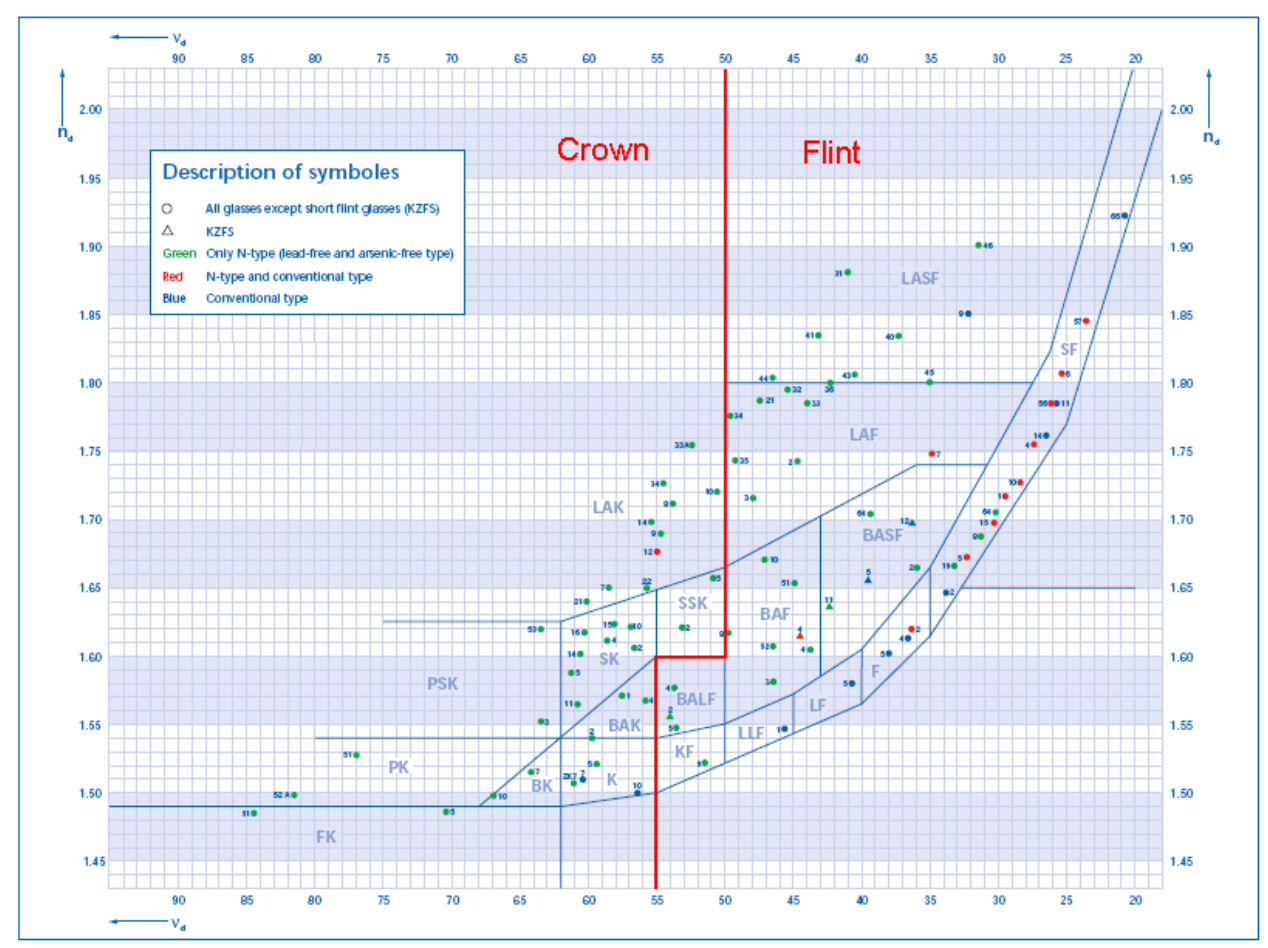

Figura 14: Diagrama de Abbe apresentado no catálogo de vidros do fabricante Schott com destaque para a classificação Crown ou Flint.

Nos catálogos de vidros fornecidos pelos fabricantes, são apresentados alguns índices de refração, para comprimentos de onda padrão, para cada tipo de vidro. Muitas vezes, é necessário para o desenvolvimento de um 
projeto óptico, o conhecimento do índice de refração em outros comprimentos de onda. Nesses casos, é conveniente representar o índice de refração pela fórmula da dispersão. Muitas fórmulas de dispersão são utilizadas, mas as mais comuns são a fórmula de Schott e a fórmula de Sellmeier ${ }^{[1]}$.

A fórmula da dispersão de Schott, apresentada abaixo, é uma fórmula empírica, com coeficientes lineares, e facilmente ajustada para o valor do índice de refração pelo método dos mínimos quadrados. Essa fórmula é capaz de calcular o índice de refração com precisão na sexta casa decimal num intervalo espectral de 0.386 a $0.750 \mu \mathrm{m}$.

$$
n^{2}-1=A_{0}+A_{1} \lambda^{2}+A_{2} \lambda^{-2}+A_{3} \lambda^{-4}+A_{4} \lambda^{-6}+A_{5} \lambda^{-8}
$$

A fórmula da dispersão de Sellmeier é baseada na média dos quadrados. Quando são utilizados 3 termos (6 constantes), como no expressão apresentada abaixo, essa fórmula garante uma aproximação com erro menor que 0.5 na sexta casa decimal para a região espectral entre 0.36 e $1.5 \mu \mathrm{m}^{[1]}$.

$$
n^{2}-1=\sum_{j=1}^{3} \frac{a_{j}+\lambda^{2}}{\lambda^{2}-b_{j}}
$$

\subsection{Aberrações}

As aberrações descrevem e quantificam as diferenças no traçado de raios entre um sistema óptico geometricamente perfeito e um sistema Real. Um sistema perfeito para a formação de imagem pode ser caracterizado por todos os raios que saem de um plano no objeto, interceptam um plano que passa pelo ponto focal secundário, percorrendo o mesmo caminho óptico do objeto até a imagem. Estes sistemas também podem ser definidos por um erro na 
frente de onda igual a zero, ou seja, a frente de onda do objeto é igual à da imagem.

As aberrações são representadas por uma soma de polinômios dependentes do ângulo que o raio incidente na superfície faz com a normal, da altura da imagem e da distância até a imagem. Todos os tipos de aberração podem ser descritos pelos coeficientes dessa equação. A seguir, estão apresentadas as principais características de alguns tipos de aberrações.

\section{- Aberrações Esféricas}

As aberrações esféricas caracterizam-se pela dependência da posição focal com a abertura do sistema. Os raios próximos ao eixo óptico formam a imagem muito próxima ao ponto paraxial. Conforme os raios se distanciam do eixo, a posição focal fica deslocada em relação ao ponto paraxial. A distância axial medida entre o ponto paraxial e o ponto real (horizontal) é chamada aberração esférica longitudinal. A distância medida na direção vertical é chamada aberração esférica lateral ou transversa.

O resultado desse tipo de aberração na imagem é a perda de contraste e a dificuldade de visualização dos detalhes com nitidez.

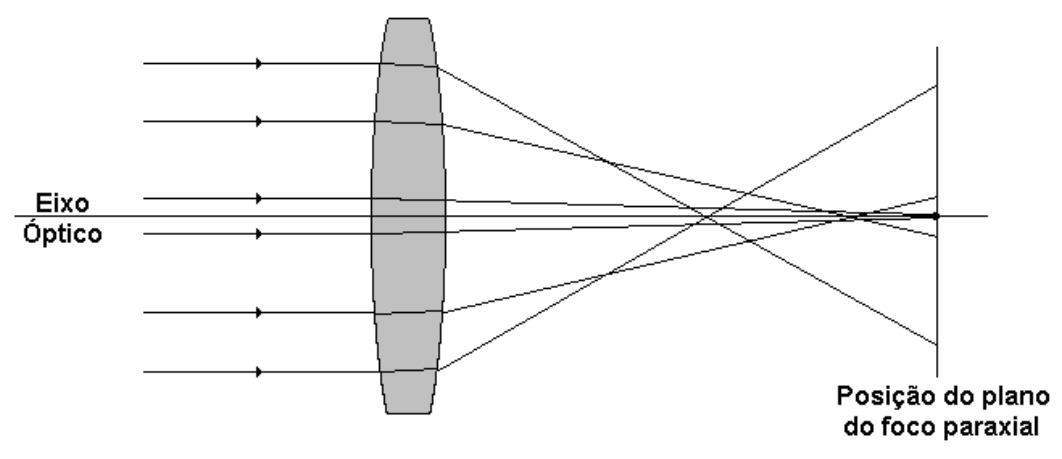

Figura 15: Ilustração do traçado de raios através de uma lente com aberração esférica. 


\section{- Astigmatismo}

O astigmatismo ocorre quando a imagem é focalizada no plano tangencial em uma posição diferente da focalizada no plano sagital. O astigmatismo é uma função da potência e da forma da lente e da distância da lente até o stop de entrada. No caso de lentes simples onde o próprio diâmetro limita o tamanho do feixe de raios que entra no sistema, o astigmatismo é dado por $-h^{2} / f$, onde f é a distância focal da lente e h é altura da imagem.

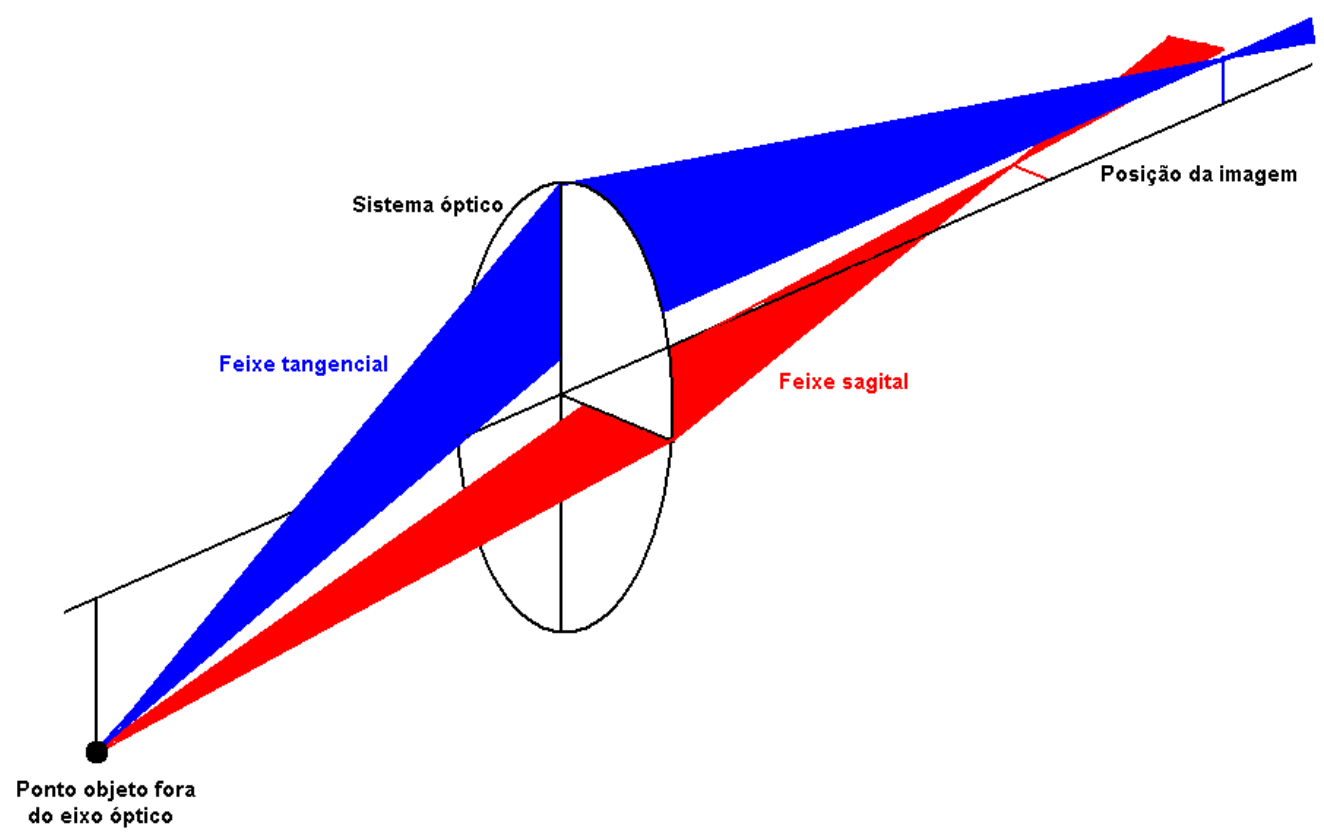

Figura 16: Ilustração do traçado de raios através de uma lente com astigmatismo.

\section{- Coma}

O coma é a variação da magnificação da imagem com a abertura. Lentes com esse tipo de aberração focalizam os raios que passam pelo centro da lente em uma altura diferente da que focalizam os raios que passam através da borda. 


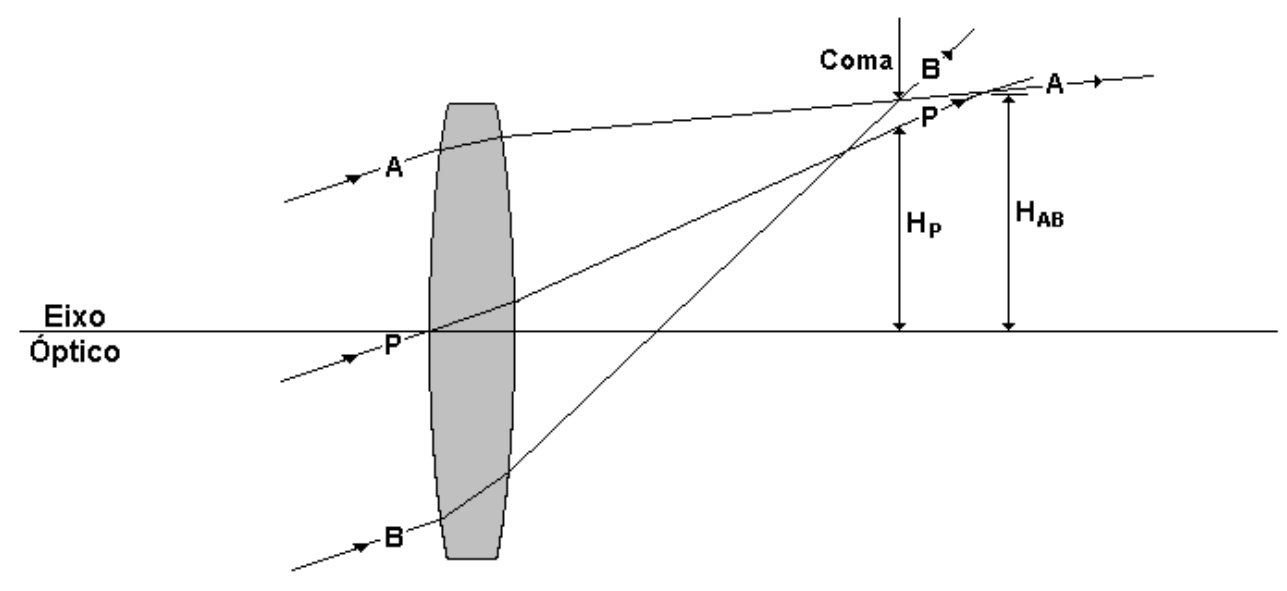

Figura 17: Ilustração do traçado de raios através de uma lente com coma.

\section{- Curvatura de campo}

Toda lente tem associada a ela uma curvatura de campo, chamada curvatura de Petzval, que é uma função dos raios de curvatura da lente e do índice de refração. A curvatura de Petzval representa um distanciamento longitudinal da posição de foco a partir do plano da imagem. Considerando uma lente em que a espessura pode ser desprezada, a curvatura de campo é dada por $-\mathrm{h}^{2} / 2 \mathrm{nf}$, onde $\mathrm{h}$ é a altura da imagem, $\mathrm{n}$ é o índice de refração e f é a distância focal da lente.

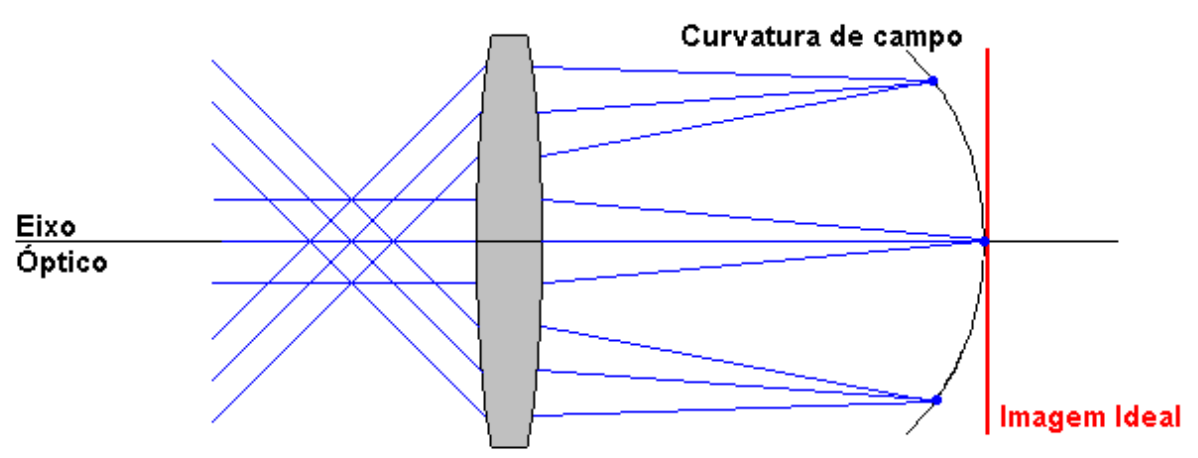

Figura 18: Ilustração de uma imagem com curvatura de campo formada por sistema óptico. 


\section{- Distorção}

A distorção aparece na imagem produzida por um objeto extenso quando os pontos das extremidades do objeto são formados em posições diferentes das calculadas paraxialmente para a imagem. A distorção pode ser definida como a diferença no posicionamento das extremidades da imagem em relação à posição paraxial.

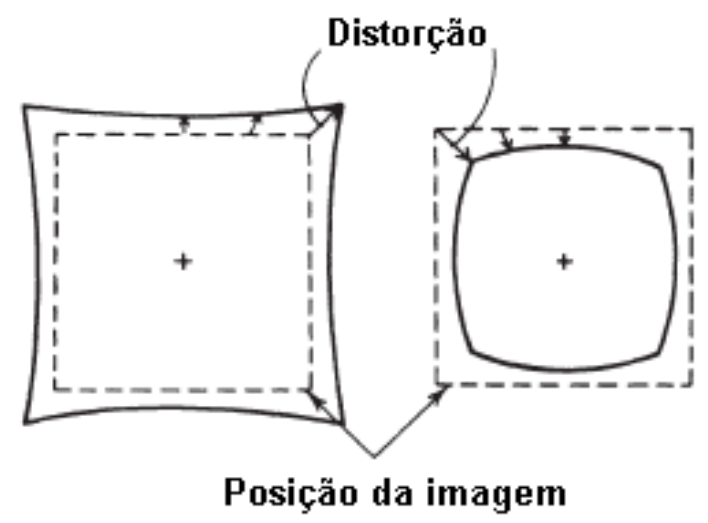

Figura 19: Ilustração de uma imagem formada por sistema que provoca distorção.

\section{- Aberração Cromática}

As aberrações cromáticas aparecem devido aos materiais ópticos terem o índice de refração dependente do comprimento de onda da luz. Nesse caso, a lente forma a imagem de um ponto sobre posições diferentes sobre o eixo óptico para cada comprimento de onda. A aberração cromática axial longitudinal é a medida da distância sobre o eixo do ponto focal de um comprimento de onda até o ponto focal de outro. Quando a lente forma a imagem de tamanhos diferentes para cada comprimento de onda, a diferença entre o tamanho da imagem em dois comprimentos de onda diferentes é chamada de cor lateral. 


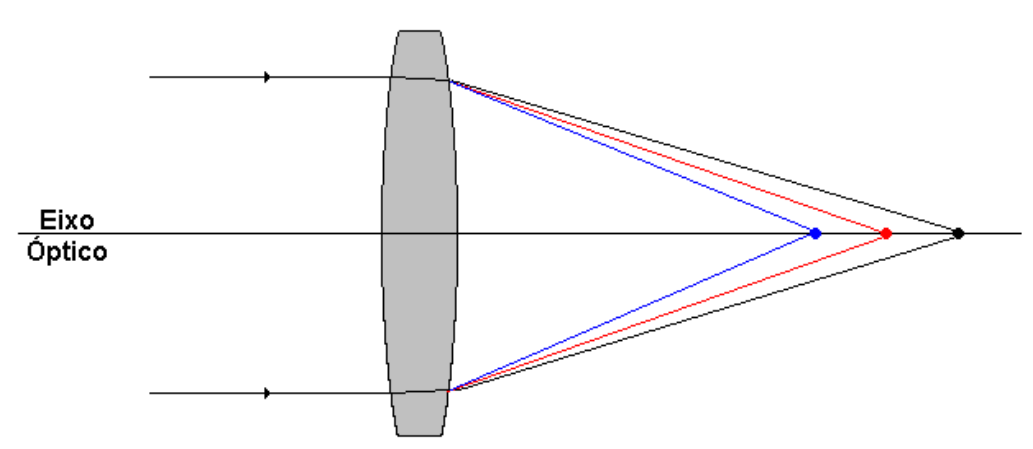

Figura 20:llustração do traçado de raios através de uma lente com aberração cromática axial longitudinal.

\subsection{Avaliação da Qualidade de Imagens}

Durante o projeto de sistemas ópticos para a formação de imagens, é preciso avaliar o desempenho que o sistema deve atingir, ou seja, mensurar a qualidade da imagem necessária para a aplicação desejada.

A medida da qualidade da imagem pode ser baseada em algum critério subjetivo do observador. Porém, a quantificação da qualidade da imagem é feita utilizando técnicas numéricas. Nesse caso, a imagem é representada numericamente e é comparada com o objeto para que se obtenha a degradação produzida pelo sistema óptico.

A Função de Transferência Óptica, ou OTF (Optical Transfer Function), é a função utilizada para a realização de uma medida quantitativa da qualidade da imagem. A OTF descreve a estrutura de uma imagem em termos do contraste e da fase espacial num intervalo de freqüências. A análise de Fourrier permite descrever qualquer objeto como a soma de componentes senoidais e por isso, a OTF pode ser usada para representar de forma detalhada uma imagem, relacionando-a com o objeto e com as aberrações introduzidas pelo sistema óptico ${ }^{[2]}$. 
A intensidade de um objeto pode ser representada pela função

$$
\mathrm{I}(\mathrm{x})=1+\Gamma \cos (2 \pi v+\phi(v))
$$

Onde $\phi(v)$ é uma fase espacial e $\Gamma$ é o contraste de um período senoidal p (ou de uma freqüência espacial $v=1 / p$ ) dado por:

$$
\Gamma=\frac{I_{\max }-I_{\min }}{I_{\max }+I_{\min }}
$$

A representação da OTF é feita por uma função complexa, dependente da freqüência espacial $\left(v_{x}, v_{y}\right)$, relacionada com o contraste e com a fase da seguinte forma:

$$
\operatorname{OTF}\left(v_{x}, v_{y}\right)=\left|F\left(v_{x}, v_{y}\right)\right| e^{i \phi\left(v_{x}, v_{y}\right)}
$$

O primeiro termo, $\left|F\left(v_{x}, v_{y}\right)\right|$, é Função de Transferência de Modulação, conhecida como MTF (Modulation Transfer Function) e o segundo termo é chamado de Função de Transferência de Fase (FTF).

A MTF pode ser definida como a razão do contraste da imagem pelo contraste do objeto, que é calculada matematicamente através da Transformada de Fourrier da Função de Espalhamento Pontual, PSF (Point Spread Function) ${ }^{\dagger \dagger}$.

Para uma região onde $\phi=0$, a OTF pode ser representada apenas pela parte real, ou seja, pela MTF. A MTF, definida como a razão entre o contraste de uma imagem e do objeto associado a ela em uma determinada freqüência espacial, é apresentada como:

${ }^{\dagger \dagger \dagger}$ A Função de Espalhamento de Ponto representa a distribuição da intensidade de luz de um ponto do objeto. 


$$
\operatorname{MTF}\left(v_{x}, v_{y}\right)=\frac{\Gamma_{\text {imagem }}}{\Gamma_{\text {objeto }}}
$$

A MTF pode também ser apresentada em termos da PSF, $f(x, y)$ :

$$
\operatorname{MTF}\left(v_{x}, v_{y}\right)=\int_{-\infty}^{\infty} \int_{-\infty}^{\infty} f(x, y) e^{-i 2 \pi\left(v_{x} x+v_{y} y\right)} d x d y
$$

Dessa forma, o contraste para cada freqüência espacial é dado pelo valor da MTF em cada freqüência.

Para realizar a medida da MTF de um sistema óptico, uma seqüência de padrões, formados por pares de linhas iluminadas e escuras (Figura 21), é projetada através do sistema óptico. O menor valor da largura dessas linhas que pode ser distinguido pelo sistema óptico é chamado de resolução do sistema e pode ser expresso em pares de linhas por $\mathrm{mm}(\mathrm{lp} / \mathrm{mm})$. O inverso da quantidade de pares de linhas por milímetro é o chamado poder de resolução, ou seja, se a imagem tem uma resolução de $50 \mathrm{lp} / \mathrm{mm}$, um objeto com $0,01 \mathrm{~mm}$ pode ser resolvido pelo sistema óptico com uma "fidelidade" relacionada com o valor da modulação.

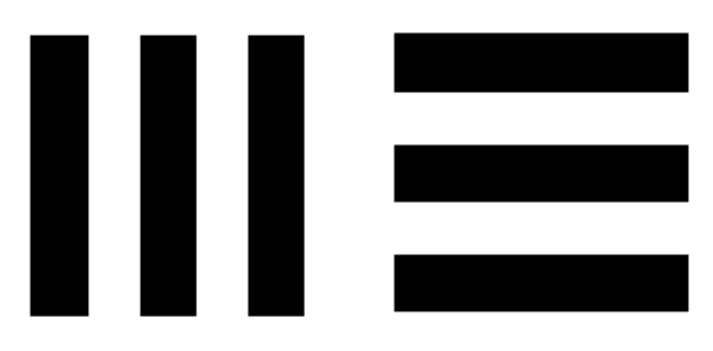

Figura 21: Padrão de linhas iluminadas e escuras que é projetado pelo sistema óptico pode fornecer informações sobre a resolução e o contraste do sistema.

Num sistema ideal, a intensidade da parte iluminada da projeção desses padrões, deve ser equivalente a 1 e da parte escura deve ser zero. Isso 
indicaria o máximo de contraste na imagem. Porém, quando esses padrões são projetados por sistemas reais, cada linha do objeto aparece na imagem como uma linha borrada e a seção transversal de cada uma dessas linhas é a chamada Função de Espalhamento Linear, também conhecida como LSF (Line Spread Function). Isso pode ser ilustrado na Figura 22.

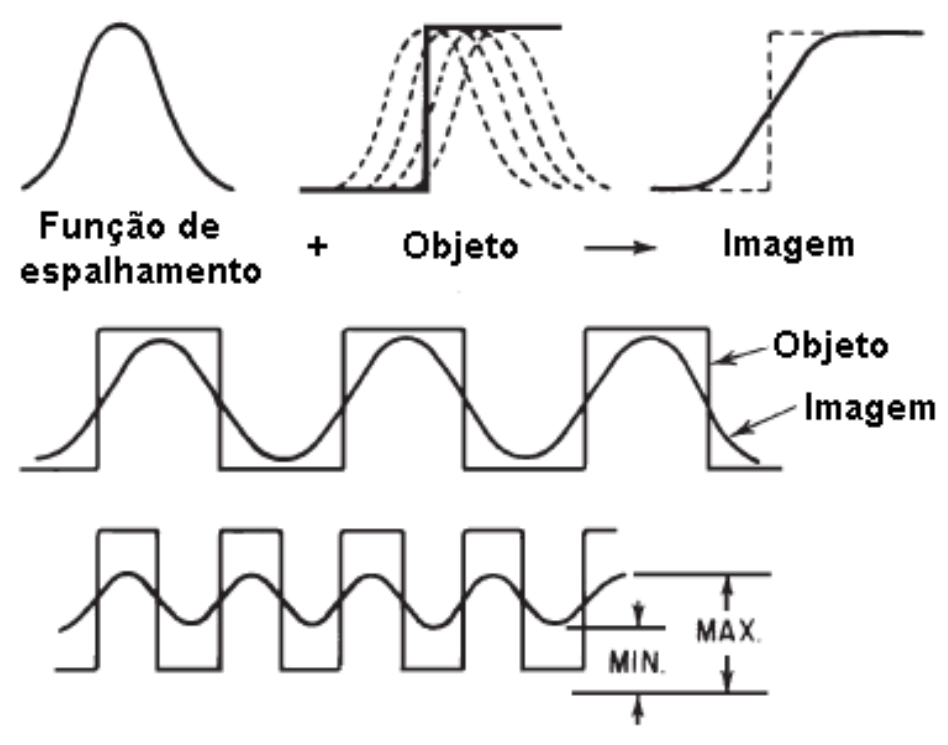

Figura 22: Ilustração da radiância do objeto e da irradiância da imagem após a passagem pelo sistema óptico.

\subsection{Retinografia}

A Retinografia é um exame clínico que consiste na observação da retina. Muitas doenças, não necessariamente ligadas ao olho, como diabetes, toxoplasmose e outras, afetam a retina e podem provocar perda parcial ou total da visão. O exame é aplicado para acompanhar a evolução (progressiva ou regressiva) dessas e de outras doenças, como neurites ou degeneração macular relacionada à idade, e deve ser feito periodicamente dependendo da patologia. 


\subsubsection{Descrição do Exame}

Dois tipos de exames podem ser realizados para diagnóstico de anomalias ou patologias do fundo do olho, a Retinografia e a angiografia. Os dois exames podem ser realizados num mesmo paciente sucessivamente permitindo complementaridade no diagnóstico.

\subsubsection{Retinografia}

Nesse exame o paciente deve estar com a pupila dilatada (midríase). Dessa maneira, o olho é iluminado por uma fonte luz interna ao retinógrafo com comprimento de onda na região visível do espectro e a imagem da retina pode então ser fotografa, filmada ou observada pelo médico dependendo do tipo de equipamento. Algumas estruturas da retina podem ser ressaltadas quando iluminadas com luz de comprimento de onda na região verde do espectro e esse tipo de Retinografia pode ser realizada com o equipamento utilizando uma fonte de luz emitindo apenas nessa região. Esse exame é conhecido como Retinografia anerítra (ou Red Free) enquanto o primeiro é chamado de Retinografia colorida. A Figura 23 e a Figura 24 mostram imagens de Retinografias colorida e anerítra respectivamente. 


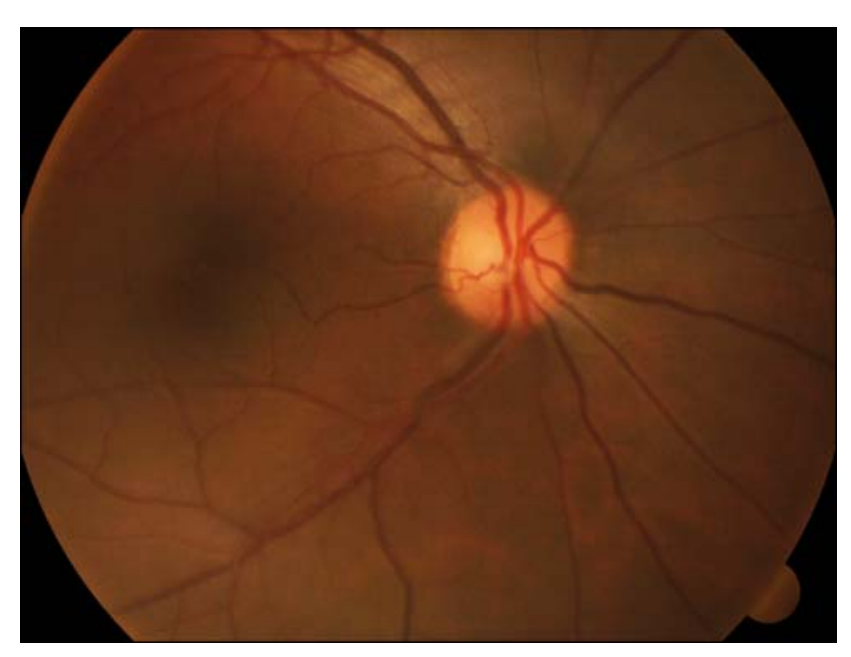

Figura 23: Retinografia colorida realizada com o equipamento "ADS 1.3 color" da Opto Eletrônica S/A.

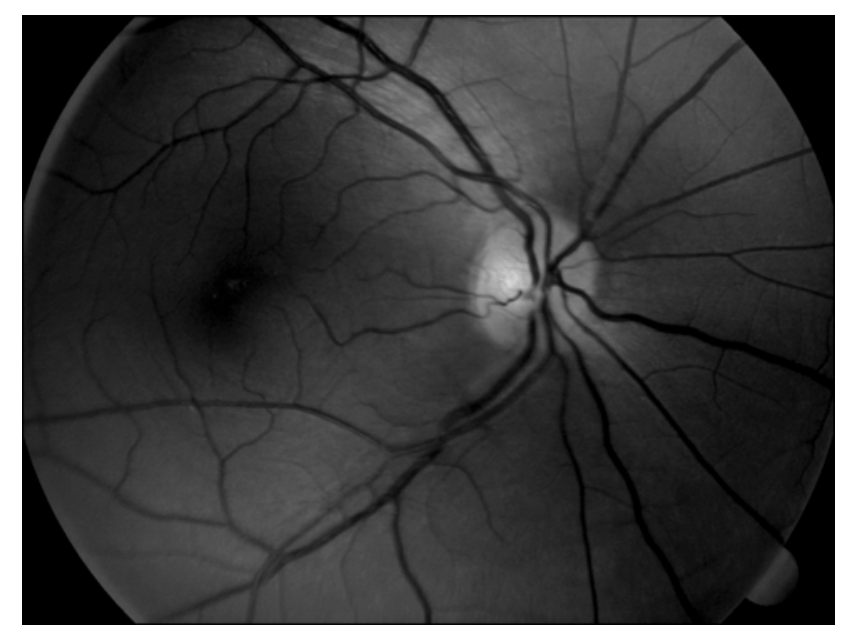

Figura 24: Retinografia anerítra realizada com o equipamento "ADS 1.3 color" da Opto eletrônica.

\subsubsection{Angiografia}

A angiografia consiste na observação da retina após a inserção de um contraste no paciente, por meio de uma veia periférica. Dois tipos de angiografia são realizados, a angiografia fluoreceínica e a angiografia indocianínica que utilizam como contraste a fluoresceína e a indocianina verde respectivamente. O olho do paciente é iluminado por uma luz de comprimento de onda específico (dependendo do exame) que excita a 
substância injetada por absorção, elevando seus elétrons para um nível mais energético. Por decaimento dos elétrons para um nível menos energético, a substância emite luz de comprimento de onda diferente do da luz de excitação, esta é a chamada fluorescência da substância. Simultaneamente, a imagem é capturada por meio de um filtro espectral passa banda que permite apenas a passagem de luz de comprimento de onda emitido na fluorescência.

A angiografia fluoresceínica usa como contraste uma substância chamada fluoresceína sódica $\left(\mathrm{C}_{2} \mathrm{OH}_{10} \mathrm{NA}_{2} \mathrm{O}_{5}\right)$. O pico de absorção dessa substância está entre 450 e 500 nm e o de emissão entre 510 e 550 nm. São utilizados dois filtros espectrais chamados de par "excitador/barreira" que permitem a passagem da luz nos comprimentos de onda especificados.

Na angiografia indocianínica (ICG) a substância utilizada é a Indocianina verde $\left(\mathrm{C}_{43} \mathrm{H}_{47} \mathrm{~N}_{2} \mathrm{NaO}_{6} \mathrm{~S}_{2}\right)$, cujo pico de absorção é entre 790 e $810 \mathrm{~nm}$ e o pico de emissão fica em torno de $835 \mathrm{~nm}$. Devido ao pico de absorção e o de emissão estarem na região do comprimento de onda infra-vermelho do espectro, há maior penetração de luz através das células do eptélio pigmentado retiniano $^{\ddagger \neq \ddagger}$ e de outras opacidades do meio ${ }^{[7]}$, permitindo assim a observação de estruturas das camadas mais internas da retina.

\subsubsection{Descrição do Equipamento}

A observação da retina é um exame que vem sendo realizado há décadas. Em geral, os equipamentos utilizados para a realização deste exame são

\footnotetext{
执 Eptélio pigmentado retiniano é uma camada única de células contíguas que se encontra abaixo dos fotorreceptores na retina.
} 
compostos de uma fonte luz para iluminar o olho, um sistema óptico para projetar a imagem e um meio para a observação dessa imagem que pode ser uma câmera fotográfica, um sensor ou o próprio olho do médico. O primeiro e mais simples equipamento utilizado até hoje para este fim é o oftalmoscópio que consiste basicamente de uma lente com a qual o médico observa o fundo do olho iluminado por fonte externa. Em seguida vieram os retinógrafos que permitem não só a observação do fundo do olho, mas fazer o registro da imagem através de fotos (retinógrafo convencional) ou filmes (retinógrafo digital).

\subsubsection{Oftalmoscópio}

O oftalmoscópio nada mais é do que uma lente ocular com grande abertura angular que funciona em conjunto com uma pequena fonte de luz que tem a característica de focalizar a luz na pupila e iluminar um amplo campo de visão na retina. Dentre as vantagens desse equipamento estão o preço reduzido, a simplicidade do uso pelo fato da pupila do paciente não precisar estar dilatada para a realização do exame. Os equipamentos mais modernos já possuem filtros espectrais para a realização da Retinografia anerítra.

\subsubsection{Retinógrafo Convencional}

O retinógrafo convencional é produzido há décadas em escala comercial. Este equipamento é composto por um sistema óptico de iluminação, um sistema óptico de captação, uma câmera fotográfica e um conjunto de filtros espectrais, tudo isso associado a um sistema eletrônico e um sistema mecânico robusto e preciso. 
O sistema óptico de iluminação projeta a luz, vinda de uma lâmpada, na pupila e deve proporcionar uma iluminação homogênea no fundo do olho. A maioria dos equipamentos usa uma iluminação em forma de anel que foi patenteada há mais de 30 anos. Para que estas características sejam atendidas, esses equipamentos usam o sistema de iluminação descrito na Figura 25.

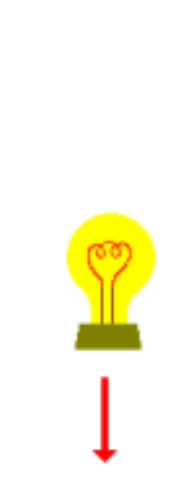

Fonte de luz

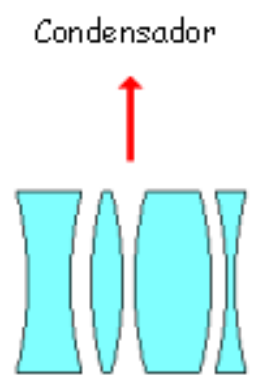

Objeto

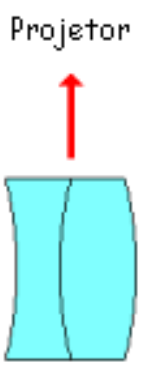

Imagem

Figura 25: Esquema do sistema de iluminação utilizado em grande parte dos retinógrafos.

Esse sistema é composto por uma fonte de luz, um conjunto de lentes chamado condensador que serve para uniformizar a iluminação e evitar que o filamento da lâmpada seja projetado junto com a imagem, um objeto em forma de anel e um conjunto de lentes para formar a imagem desse anel. A iluminação deve chegar à pupila do paciente em forma de anel para que não haja reflexão inoportuna na córnea atrapalhando a captação da imagem proveniente do fundo do olho, e deve ser homogênea no fundo do olho, ocupando uniformemente toda a área da retina a ser examinada. Pode-se observar na Figura 26 que o anel entra no olho com aproximadamente 0 diâmetro da pupila e a captação é feita pela área delimitada pela parte interna do anel de iluminação. 


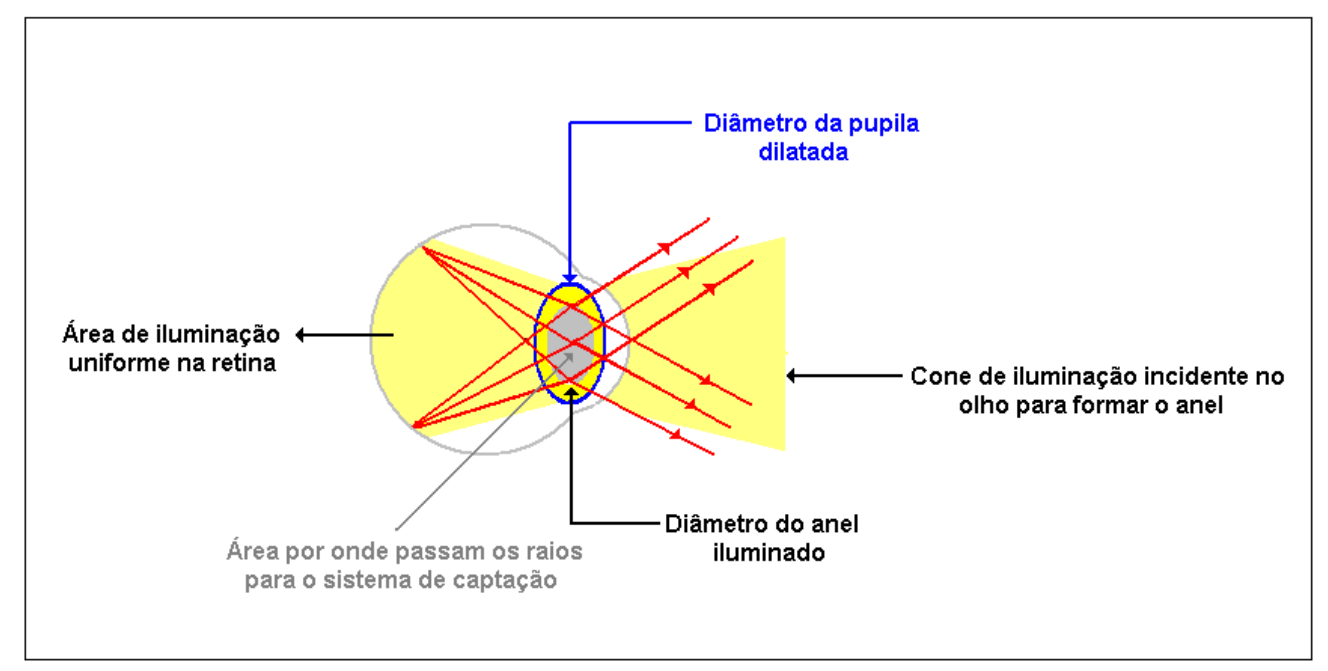

Figura 26: Ilustração do traçado de raios dos sistemas de iluminação e captação através da pupila do olho.

O sistema de captação permite a observação direta da retina iluminada e a aquisição da imagem através de uma câmera fotográfica. O sistema óptico de captação é composto por um conjunto de lentes que tem a função de formar a imagem da retina sobre o plano de observação e sobre o plano de captação (nesse caso um filme fotográfico). O desenho esquemático de um sistema de captação convencional está descrito na Figura 27.

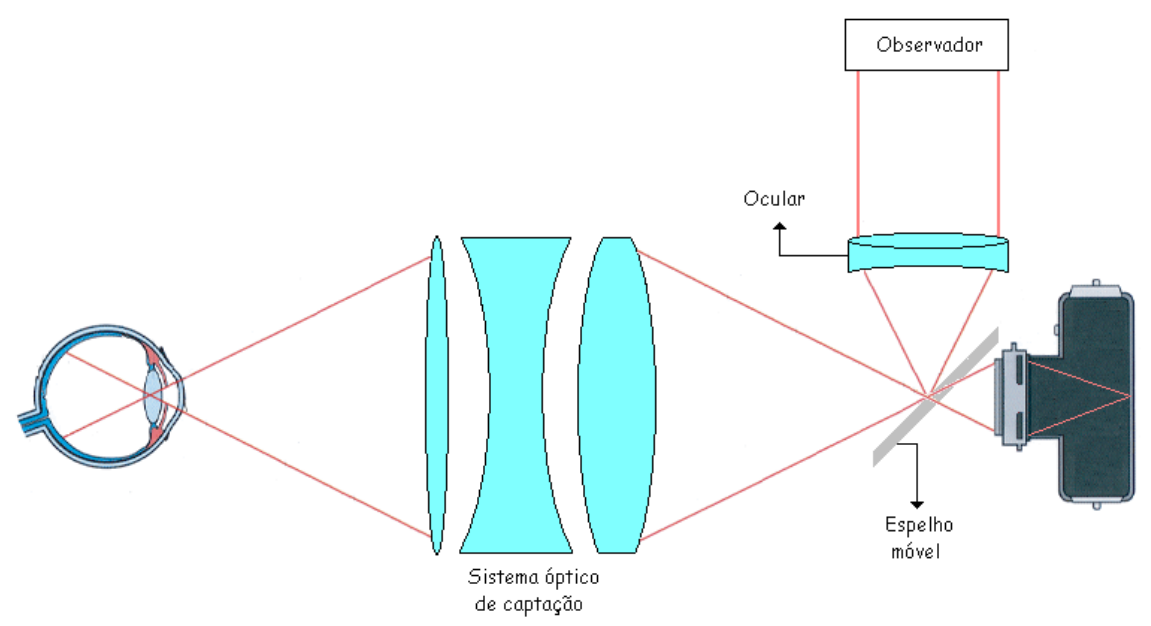

Figura 27: Desenho esquemático do sistema de captação de um retinógrafo convencional. 
A imagem da retina, projetada pelo sistema óptico pode ser observada através da ocular ou capturada por uma câmera fotográfica. Isso é possível com o auxílio de um espelho plano móvel que é retirado da frente da câmera na hora da aquisição da foto (esse papel pode ser desempenhado também por um prisma). Ao acionar a câmera fotográfica, um flash é disparado percorrendo o caminho óptico da iluminação e iluminando intensamente o fundo do olho do paciente. A vantagem dessa arquitetura é que a iluminação constante no olho do paciente é muito fraca pois possibilita apenas a observação através da ocular. Por outro lado, no momento da captação da imagem, a luz do flash disparado é tão intensa que, mesmo com uma abertura muito pequena, a película fotográfica é sensibilizada e a fotografia fica com um nível de iluminação adequado. Nessa arquitetura é possível minimizar o máximo a abertura do sistema diminuindo consideravelmente as aberrações associadas a ela.

Dentre os retinógrafos convencionais que estão no mercado, os que possuem maior destaque são das marcas Canon $\AA$, Topcon ${ }^{\circledR}$ e Zeiss $\AA$. A base das arquiteturas destes equipamentos será brevemente descrita a seguir através da Figura 28. 


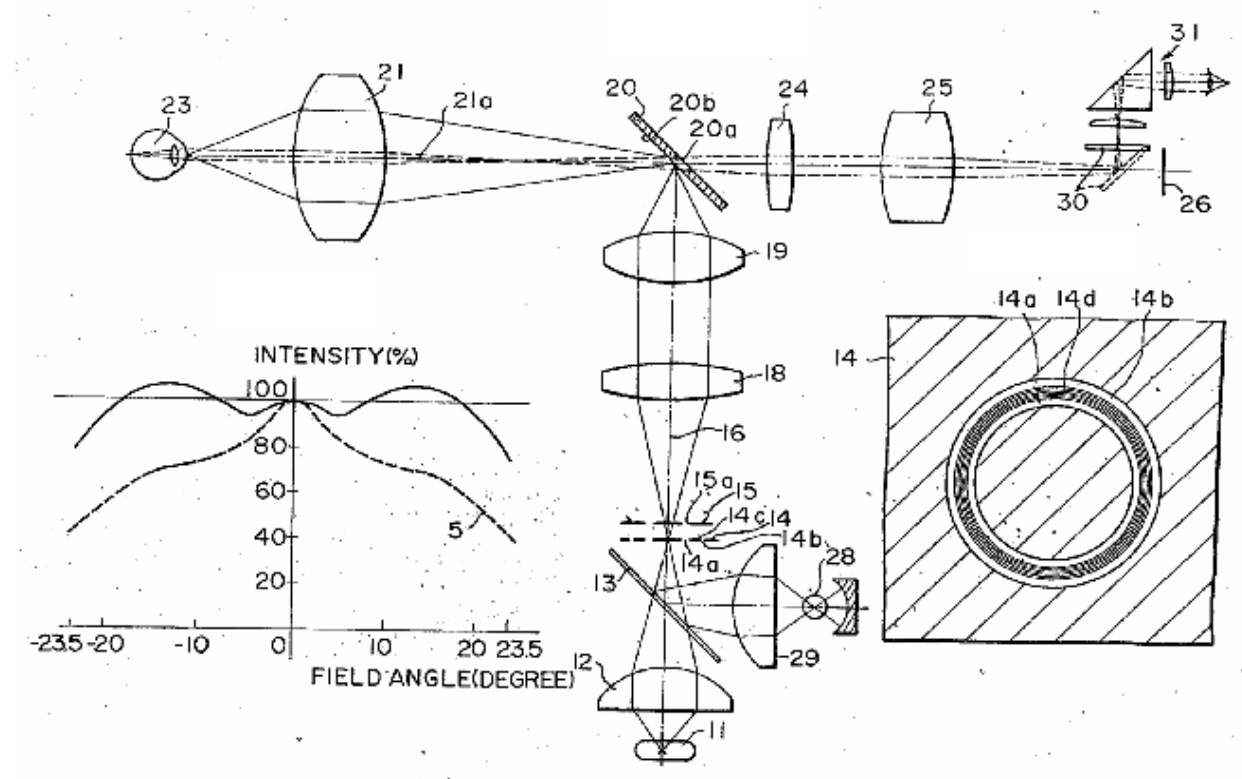

Figura 28: Arquitetura geral dos retinógrafos convencionais patenteados há mais de 30 anos.

\subsubsection{Retinógrafo Digital}

O retinógrafo digital é uma evolução do retinógrafo convencional que, além de permitir a observação direta da imagem na tela do computador, fazer filmagens e registrar fotos, elimina o inconveniente processo de revelação de filmes, e ainda permite a escolha das melhores imagens e o processamento direto das mesmas em tempo real. O diagnóstico pode ser feito, na maioria dos casos, junto com o exame. No retinógrafo digital, é utilizado um CCD ao invés de uma película fotográfica, o que traz muitas vantagens ao sistema, porém, torna sua arquitetura muito mais complicada. Na Retinografia digital, a imagem é observada em tempo real exigindo a necessidade de uma iluminação constante com nível de intensidade suficiente para sensibilizar o CCD. Nesse caso, a abertura do sistema deve ser calculada para captar com maior eficiência a energia vinda do olho, o que necessariamente a torna maior comparada com a que está presente em um retinógrafo convencional. Além disso, a faixa dinâmica do CCD é muito menor que a de um filme fotográfico, 
exigindo a necessidade de uma iluminação muito mais homogênea e uniforme. 


\section{Metodologia}

Como o objeto de observação é o fundo do olho, temos que estudar a priori o sistema óptico do olho com as aberturas e o traçado de raios através dele. Outro fator importante que deve ser definido nessa etapa é o ângulo de observação e a resolução desejada para o sistema óptico. Em seguida, deve ser escolhido o tipo de sistema a ser desenvolvido e devem ser estudadas suas dimensões para possibilitar seu funcionamento correto e a montagem dentro de um layout comercial.

O próximo passo é introduzir os parâmetros iniciais do sistema no programa, em seguida otimizá-lo impondo restrições com 0 intuito de atingir 0 desempenho desejado e viabilizar o sistema obtido para sua fabricação.

Por último, o sistema deve ser fabricado, montado e alinhado de acordo com as tolerâncias de fabricação especificadas durante o projeto.

\subsection{Estudo de Primeira Ordem do Sistema}

O exame será realizado com o olho do paciente relaxado. Nessas condições, os feixes de luz oriundos do fundo do olho saem paralelos através da abertura da pupila. Devido ao fato desses raios entrarem paralelos no sistema, o sistema óptico escolhido para a captação é baseado num telescópio invertido com uma objetiva na seqüência. Este telescópio invertido é formado por dois conjuntos de lentes, um capta a imagem do fundo o olho (captadora) e o outro a projeta no infinito (projetor afocal) como está ilustrado na Figura 29. A objetiva serve apenas para focalizar a imagem no CCD. 

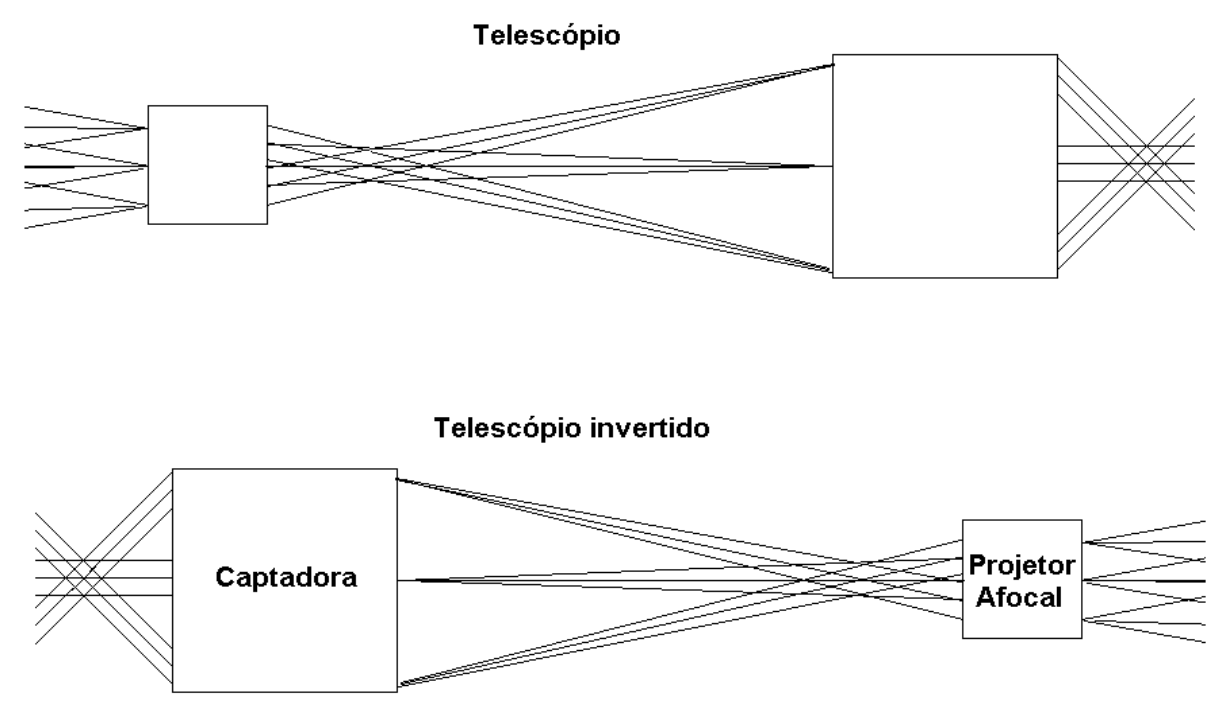

Figura 29: Esquema de um telescópio e um telescópio invertido.

A abertura do sistema é definida pela área útil ${ }^{\S \S \S}$ da abertura da pupila de entrada do olho relaxado, $4 \mathrm{~mm}$, e o EFL da objetiva deve ser escolhido

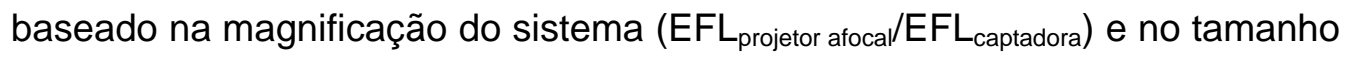
do CCD. O poder de resolução do sistema óptico foi estabelecido em torno de 0,02 mm, que corresponde a metade do tamanho de uma veia estreita da retina.

O anel de iluminação terá $6 \mathrm{~mm}$ de diâmetro e é definido de forma a ser um pouco menor que o tamanho máximo atingido pela pupila dilatada (em torno de $7 \mathrm{~mm}$ ). O sistema de iluminação escolhido é coaxial. Nesse tipo de sistema, o conjunto chamado captadora também faz parte do sistema como ilustrado na Figura 30. O sistema coaxial possui um espelho com um furo central para que os raios vindos da primeira parte do sistema de captação cheguem até a câmera. Este espelho serve também para permitir que o anel iluminado alcance a segunda parte do sistema de iluminação. Dessa maneira é importante lembrar que o sistema de iluminação deve formar a imagem de um anel iluminado com a magnificação correta primeiro sobre este espelho,

§§§ A área da pupila considerada como útil é a área da parte interna do anel de iluminação. 
evitando assim que parte da iluminação direta atinja a câmera provocando um ruído indesejado.

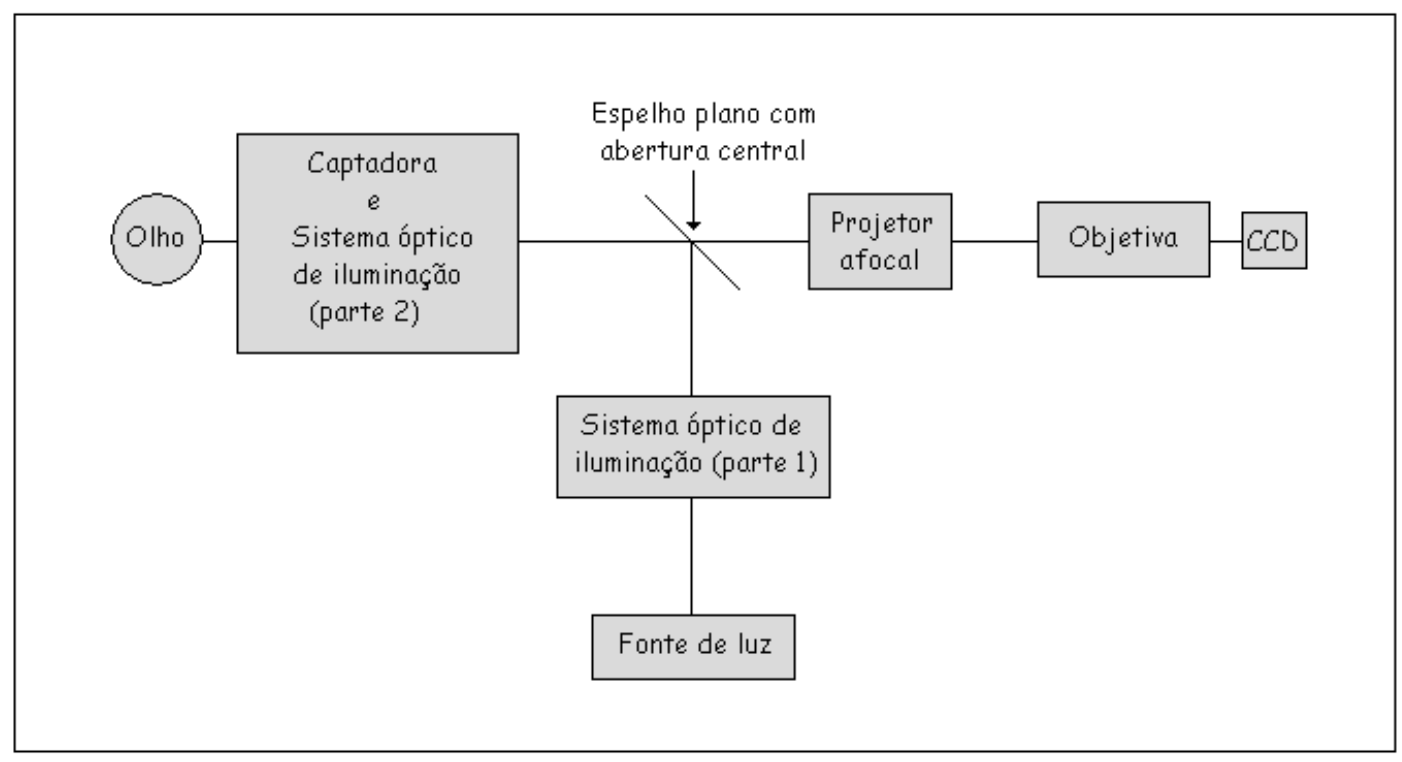

Figura 30: Desenho esquemático da proposta para o retinógrafo

A câmera utilizada possui um CCD de 1.5 Megapixels com pixels quadrados de $4.65 \mu \mathrm{m}$ de comprimento e sua curva de sensibilidade está ilustrada na Figura 31.

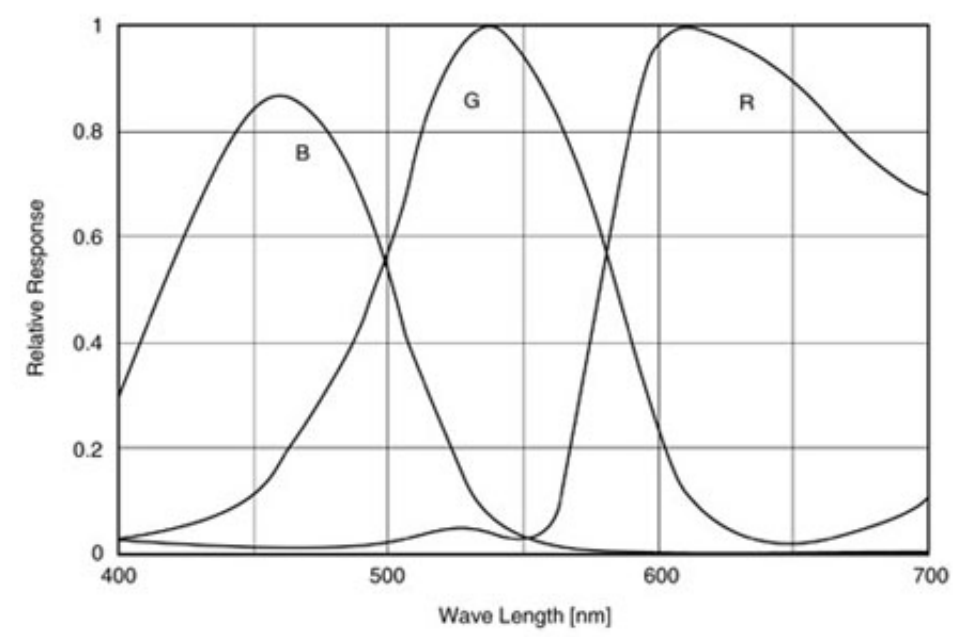

Figura 31: Curva de sensibilidade da câmera utilizada. 
O CCD possui um padrão geométrico de distribuição de sensibilidade cromática que visa aproximar a resposta espectral à do olho humano. Esse tipo de padrão é conhecido como padrão Bayer e está ilustrado na Figura 32. Esse tipo de geometria causa ruído espacial e perda de resolução exigindo um tipo de correção por interpolação conhecida como "demosaicking".

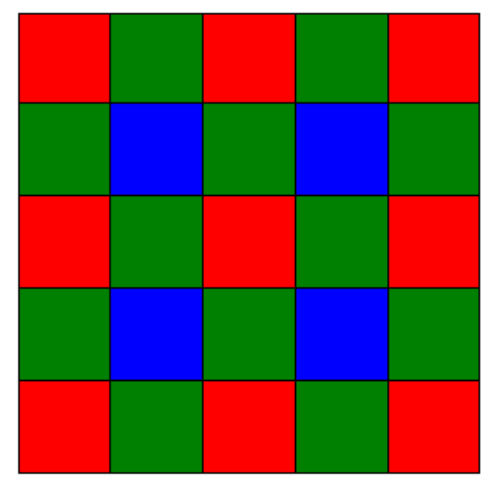

Figura 32: Padrão de distribuição geométrica de sensibilidade cromática (padrão Bayer)

O CCD limita o MTF em 53,7 Ip/mm. Esse valor é freqüência de Nyquist ${ }^{\star \star \star \star}$ calculada para o CCD levando em conta o padrão Bayer, ou seja, o tamanho do pixel considerado é $9.3 \mu \mathrm{m}$ e não $4,65 \mu \mathrm{m}$ que é o valor do pixel real.

\subsection{Montagem e Otimização do Sistema no Programa}

O sistema previamente definido deve ser inserido no programa de Desenho Óptico para que sua otimização seja realizada. Nesta etapa, não só requisitos ópticos pré-estabelecidos para o funcionamento do sistema devem ser levados em conta, mas também a fabricação e a montagem do sistema. É importante lembrar que o objetivo desse sistema óptico não é ser montado em uma bancada, mas sim em um equipamento comercial. Um sistema pode

\footnotetext{
${ }^{\star \star \star \star ~ A ~ f r e q u ̈ e ̂ n c i a ~ d e ~ N y q u i s t ~ e ́ ~ d e t e r m i n a d a ~ p e l o ~ i n v e r s o ~ d o ~ d o b r o ~ d o ~ t a m a n h o ~ d o ~ p i x e l . ~}$
} 
atingir perfeitamente o desempenho desejado, mas se não couber nas dimensões adequadas de um layout comercial ou suas lentes possuírem dimensões que não podem ser fabricadas, este sistema torna-se inviável.

A otimização do sistema é feita de modo a atender tanto aos requisitos ópticos estabelecidos em 3.1 quanto às condições de fabricação e montagem desejadas. O método de avaliação da qualidade da imagem escolhido é a OTF que será apresentada em gráficos de MTF em função da freqüência espacial.

\subsubsection{Sistema Óptico de Captação}

O sistema de captação tem a função de formar a imagem de uma área do fundo do olho correspondente a um ângulo de visão de 45 graus em uma câmera CCD. Esse ângulo de visão é utilizado na maioria dos equipamentos comerciais e é viável pois com os equipamentos realizam diversos tipos de diagnósticos, uns onde é necessária a observação detalhada de áreas pequenas (glaucoma) e outros onde é necessária a observação de uma área maior (descolamento de retina), dessa forma, esse ângulo é considerado intermediário para todas as aplicações. Em alguns equipamentos tradicionais, esse ângulo é igual a $60^{\circ}$, podendo ser variável. Os retinógrafos digitais utilizam o padrão de ângulo de $45^{\circ}$ por atingir um ângulo visual que atende a maioria das aplicações.

Como o sistema óptico é coaxial, um conjunto do sistema óptico de captação faz parte do sistema óptico de iluminação, o que implica na necessidade de otimizar o sistema no modo multiconfiguração, possibilitando que as duas condições sejam atendidas simultaneamente. Dessa forma, uma configuração é montada considerando como objeto o fundo do olho e outra considerando 
um anel de iluminado na pupila. As restrições são impostas ao sistema de modo que este anel iluminado seja formado na posição do espelho furado, fazendo com que a captadora desempenhe sua função nos dois sistemas.

A otimização dos conjuntos captadora e projetor afocal deve ser feita simultaneamente para que as aberrações sejam minimizadas.

A objetiva é otimizada inicialmente separada do sistema e finalizada com o conjunto acoplado à captadora e ao projetor afocal. Para iniciar esta otimização é necessário conhecer a magnificação do sistema de captação (razão do EFL do projetor afocal pelo EFL da captadora) e tamanho do CCD para fixar o EFL da objetiva de modo a utilizar toda a extensão do sensor.

\subsubsection{Sistema Óptico de lluminação}

Como foi mencionado em 2.5.2.2, o resultado do sistema óptico de iluminação deve ser um anel projetado na pupila de entrada do olho que, ao atingir a retina, torna-se um círculo de iluminação uniforme. Para iniciar o projeto do sistema óptico de iluminação é necessário escolher a fonte de luz que será utilizada. Optamos pelo uso de uma lâmpada dicróica acoplada a uma fibra óptica com uma das pontas em forma de anel. Essa escolha foi feita, dentre outras razões, por fornecer uma iluminação uniforme permitindo o posicionamento da lâmpada fora da estrutura principal do equipamento. Com isso, eliminou-se um sistema óptico adicional para uniformizar a iluminação proveniente da lâmpada e evitou-se a dissipação de calor da lâmpada dentro do equipamento.

O sistema de iluminação deverá inicialmente formar a imagem de um anel sobre o espelho furado de modo que esta imagem, ao ser reprojetada pelo 
sistema sobre a pupila tenha o tamanho adequado. Por outro lado, a área interna do anel projetado sobre o espelho dever ter um diâmetro que permita ao espelho ter um furo com tamanho adequado para deixar que os raios do sistema de captação passem através dele.

A fibra óptica escolhida é composta por uma série de fibras pequenas (diâmetro igual a 0,1 mm) montadas em uma estrutura formando um disco na ponta que vai acoplada à lâmpada e um anel iluminado na ponta que entra no sistema óptico. As fibras pequenas que compõem o conjunto não devem aparecer na imagem do anel iluminado pois isso dificultaria a homogeneidade da iluminação. Para que isso seja evitado, o sistema de iluminação deve resolver uma imagem apenas com tamanho maior que 0,1 mm. Portanto, o MTF do sistema de iluminação dever ser próximo de zero a partir de uma freqüência espacial de $10 \mathrm{lp} / \mathrm{mm}$.

\subsubsection{Estudo da Eliminação do Reflexo}

Como os sistemas de iluminação e de captação são coaxiais, a luz, vinda da Parte 1 do sistema de iluminação, ao incidir na Parte 2 (captadora) irá provocar o aparecimento de um anel iluminado no centro das lentes desse conjunto. Quando a câmera estiver captando a imagem vinda do fundo olho, esse anel iluminado, que chamamos simplesmente de reflexo, irá aparecer na imagem comprometendo o diagnóstico. A primeira condição para que isso não ocorra é restringir a curvatura das superfícies das lentes da captadora de forma que a luz refletida por elas incida numa superfície fora do campo de visão da objetiva. Outra condição é projetar, com o sistema de iluminação, pontos escuros ou "sombras" sobre as lentes da captadora. Dessa maneira, o sistema de iluminação deve ser projetado para que, inserindo um objeto em 
algum ponto de sua extensão, sua imagem elimine o reflexo formado nas superfícies das lentes da captadora sem aparecer uma sombra na imagem do olho.

\subsubsection{Estudo da Montagem do Sistema}

Os sistemas de captação e iluminação devem ser projetados de maneira que permite sua montagem e alinhamento dentro de uma estrutura mecânica conveniente.

O espelho com furo central deve ser posicionado na região onde ocorre 0 estreitamento dos raios no sistema de captação e, ao mesmo tempo, deve ocupar a posição de segundo objeto no sistema de iluminação.

Como foi mencionado em 2.5, serão utilizados filtros espectrais para a realização dos exames. O espaçamento entre os elementos ópticos deve prever a existência desses filtros assim como a colocação de motores para posicioná-los corretamente em cada tipo de exame.

Como será discutido a seguir, possíveis erros são inevitáveis durante a fabricação dos elementos ópticos e mecânicos do sistema. A colocação de mecanismos de ajuste ao longo do sistema é fundamental para a correção desses erros e para garantir o alinhamento do sistema.

\subsubsection{Análise da Dioptria Alcançada}

O sistema óptico foi projetado considerando como parte do sistema o olho relaxado, ou seja, como se os raios saíssem paralelos do olho. Quando o paciente não é emétrope, os raios provenientes do olho não saem 
exatamente paralelos e então o plano onde são focalizados pelo sistema óptico de captação é ligeiramente deslocado. Dessa maneira, a objetiva do sistema deve ser móvel para que seja realizado um ajuste focal durante o exame.

O movimento da objetiva para realização desse ajuste é limitado devido às dimensões do equipamento. Portanto, é necessário realizar um estudo para determinar quantas dioptrias do olho amétrope o equipamento será capaz de continuar focalizando adequadamente. Para este estudo, foi adicionada ao sistema uma lente perfeita posicionada na pupila de saída do olho com dioptria variável.

\subsubsection{Estudo da Fabricação do Sistema}

Durante o projeto de um sistema, as rotinas de otimização utilizadas pelos programas de Desenho Óptico procuram minimizar as aberrações do sistema o que implica muitas vezes em um elemento óptico impossível de ser fabricado. Mesmo que uma lente esteja dentro dos limites de fabricação, é preciso estimar o seu custo de fabricação, incluindo o tipo de vidro a ser utilizado e as tolerâncias necessárias para que ela cumpra seu desempenho lembrando que quanto mais precisão é exigida do elemento, mais tempo ele leva para ser feito e maior é a possibilidade de perda da peça.

\subsubsection{Limites de Fabricação}

Há diversos tipos de equipamentos para a fabricação de componentes ópticos e mecânicos que vão desde a fabricação de componentes "grosseiros" para aplicações que não exigem precisão até o uso de lasers e interferômetros para aferir sistemas ultraprecisos. Os equipamentos disponíveis para a 
fabricação dos componentes do sistema óptico projetado fornecem a precisão especificada na Tabela 2. O valor expresso para o erro em peças de precisão é o erro normalmente exigido em lentes utilizadas em equipamentos de precisão comuns no mercado.

Tabela 2: Especificação da precisão dos equipamentos de fabricação e aferição utilizados no projeto.

\begin{tabular}{|c|c|c|c|}
\hline Parâmetro & $\begin{array}{c}\text { Limite de } \\
\text { fabricação }\end{array}$ & $\begin{array}{c}\text { Erro em peças } \\
\text { comerciais }\end{array}$ & $\begin{array}{c}\text { Erro em peças } \\
\text { de precisão }\end{array}$ \\
\hline $\begin{array}{c}\text { Raio de curvatura } \\
\text { das lentes }\end{array}$ & $0,025 \%$ & $0,01 \mathrm{~mm}$ & $0,2 \%$ \\
\hline $\begin{array}{c}\text { Espessura das } \\
\text { lentes }\end{array}$ & $0,01 \mathrm{~mm}$ & $0,15 \mathrm{~mm}$ & $0,05 \mathrm{~mm}$ \\
\hline $\begin{array}{c}\text { Centragem das } \\
\text { lentes }\end{array}$ & $0,01^{\circ}$ & $0,8^{\circ}$ & $0,025^{\circ}$ \\
\hline $\begin{array}{c}\text { Irregularidade na } \\
\text { superfície das } \\
\text { lentes }\end{array}$ & 0,1 franjas & 2 franjas & 0,5 franjas \\
\hline
\end{tabular}

\subsubsection{Análise de Tolerâncias}

Nenhuma peça, óptica ou mecânica, é fabricada na medida exata em que é especificada. Por esta razão é necessário estabelecer os critérios de aceitação de uma peça que descrevem o quanto as medidas reais dessa peça devem estar próximas das medidas nominais. Esses critérios são denominados tolerâncias de fabricação e vão desde o diâmetro de um furo até o índice de refração de um vidro óptico.

Após o estudo dos equipamentos disponíveis para a fabricação, determinamos a máxima precisão que pode ser atingida para cada medida. 0 intervalo de valores de cada parâmetro é introduzido no programa juntamente com o decréscimo máximo permitido no MTF do sistema. Algumas grandezas 
são utilizadas como compensadores, ou seja, medidas que podem variar ou serem alteradas estruturalmente ao longo do processo de montagem para corrigir eventuais erros na fabricação. O programa fornece um gráfico da probabilidade de desempenho do sistema em uma determinada freqüência espacial. Com isso é possível analisar se, após o sistema ser fabricado, ele atingirá o desempenho estabelecido. 


\section{Resultados}

Com o trabalho conjunto de engenheiros eletrônicos e mecânicos, o resultado do trabalho como um todo foi a montagem de um equipamento completo para a realização de imagens do fundo olho. Toda a fabricação das lentes peças mecânicas, filtros espectrais, filmes anti-reflexo e a montagem do equipamento incluindo o desenvolvimento dos circuitos eletrônicos e do programa de controle, aquisição e processamento de imagem, foi feita na OPTO ELETRÔNICA S.A. O equipamento final está apresentado na Figura 33.

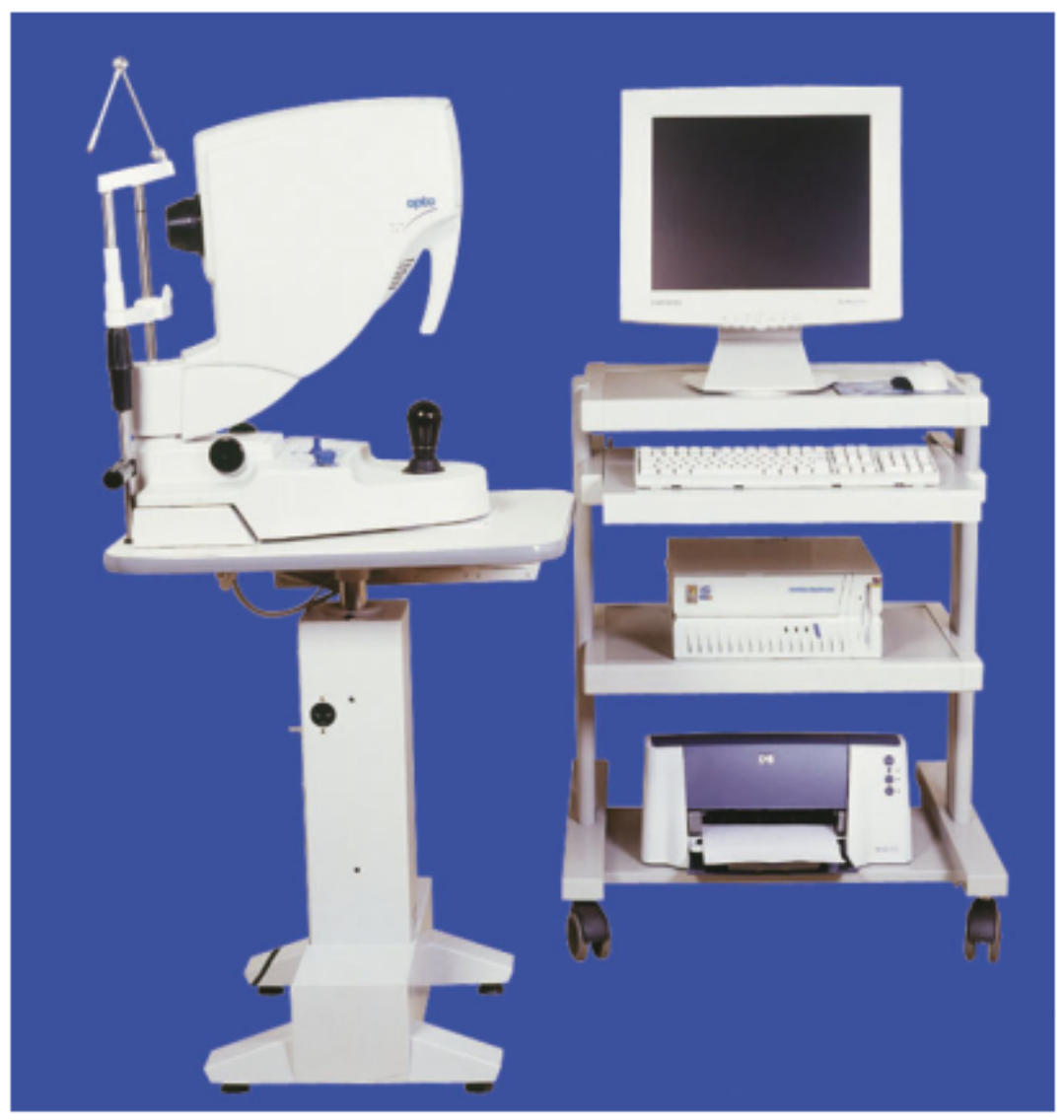

Figura 33: Foto do equipamento montado. 
Os desenhos finais para os sistemas ópticos estão apresentados seguindo a ordem em que foram desenvolvidos. Alguns problemas relacionados à fabricação e à montagem do sistema foram encontrados e solucionados não comprometendo o funcionamento do equipamento.

\subsection{Captadora}

O Desenho Óptico final do conjunto captadora possui 2 meniscos, 1 doubleto e 1 tripleto. O desenho desse conjunto está apresentado na Figura 34 e um resumo de suas características está descrito na Tabela 3. Os raios entram paralelos no sistema após passarem por uma pupila de entrada de $6 \mathrm{~mm}$ de diâmetro que corresponde à abertura do olho.

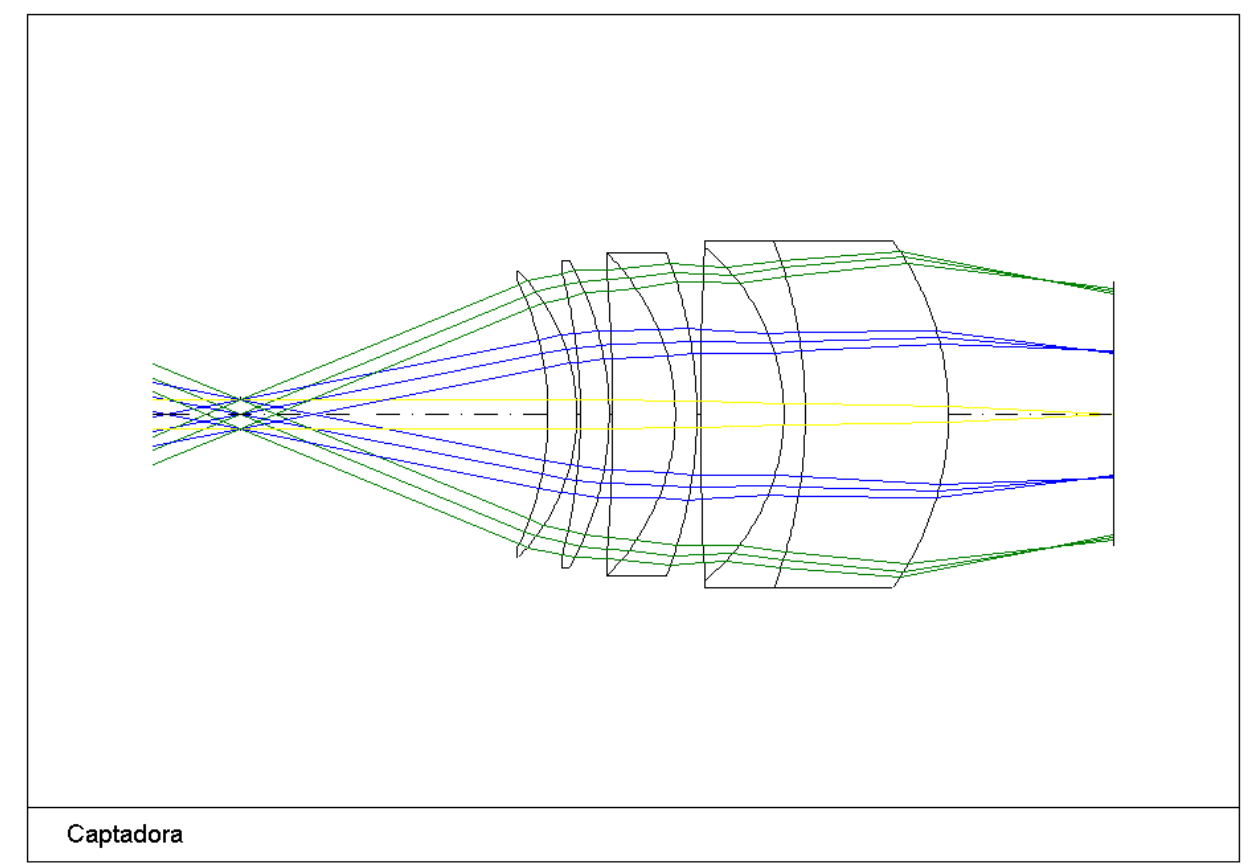

Figura 34: Desenho Óptico da captadora formando a imagem proveniente do fundo do olho. 
Tabela 3: Principais parâmetros ópticos do conjunto captadora.

\begin{tabular}{|c|c|}
\hline Parâmetro & Valor \\
\hline EFL & $45 \mathrm{~mm}$ \\
\hline Distância Imagem & $20 \mathrm{~mm}$ \\
\hline Comprimento total & $56 \mathrm{~mm}$ \\
\hline Número de elementos & 7 \\
\hline
\end{tabular}

A Figura 35 ilustra o mesmo conjunto porém desempenhando o papel de Parte 2 do sistema de iluminação. Os raios entram no sistema, vindos de um objeto na posição da pupila (o anel) e formam uma imagem a uma distância de aproximadamente $100 \mathrm{~mm}$. Pode-se observar que o stop de abertura do sistema nessa configuração está localizado na primeira lente e não mais na pupila como na configuração anterior.

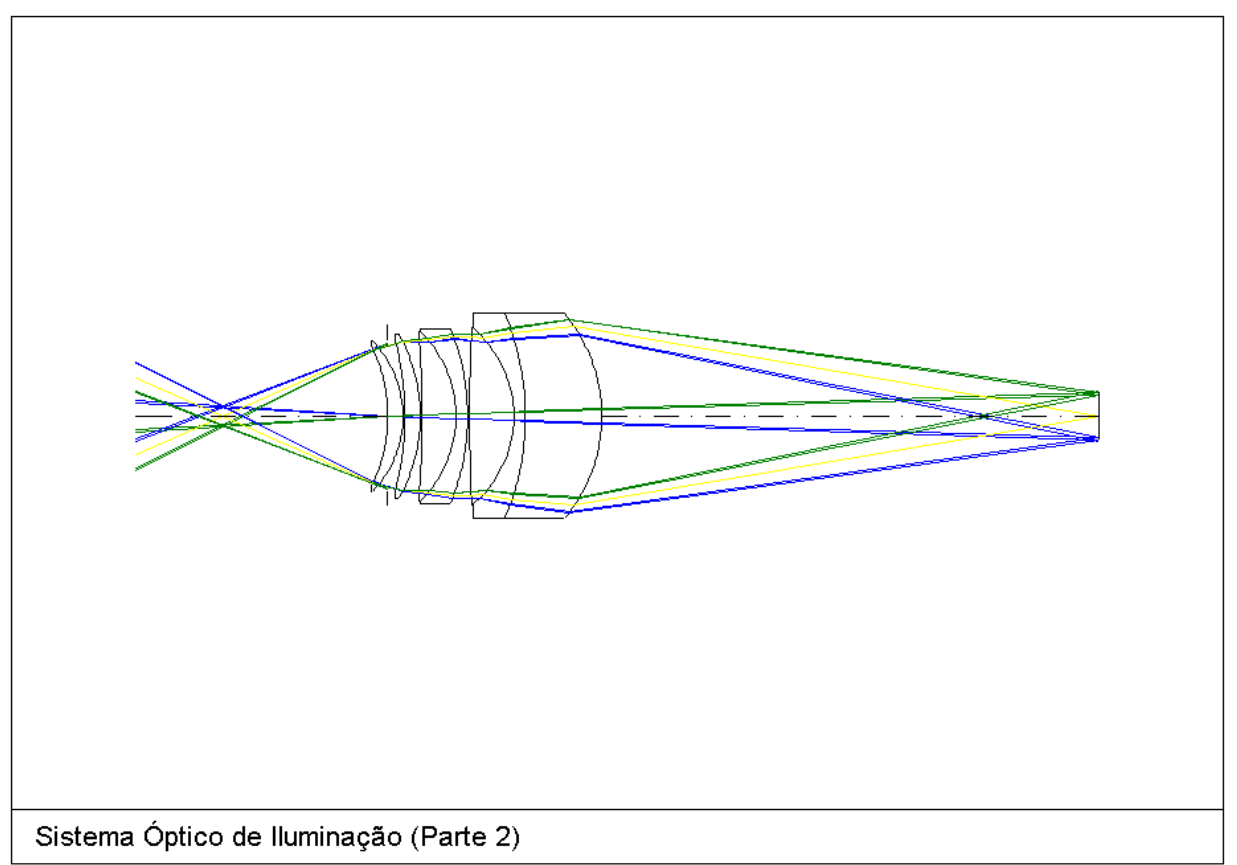

Figura 35: Ilustração da captadora desempenhando o papel da Parte 2 do sistema de iluminação. 


\subsection{Captadora com Projetor Afocal}

O desenho dos conjuntos captadora e projetor afocal está apresentado na Figura 36. Os raios saem paralelos do projetor afocal e são focados por uma objetiva para formar a imagem sobre o CCD. As principais características ópticas do sistema estão apresentadas na Tabela 4.

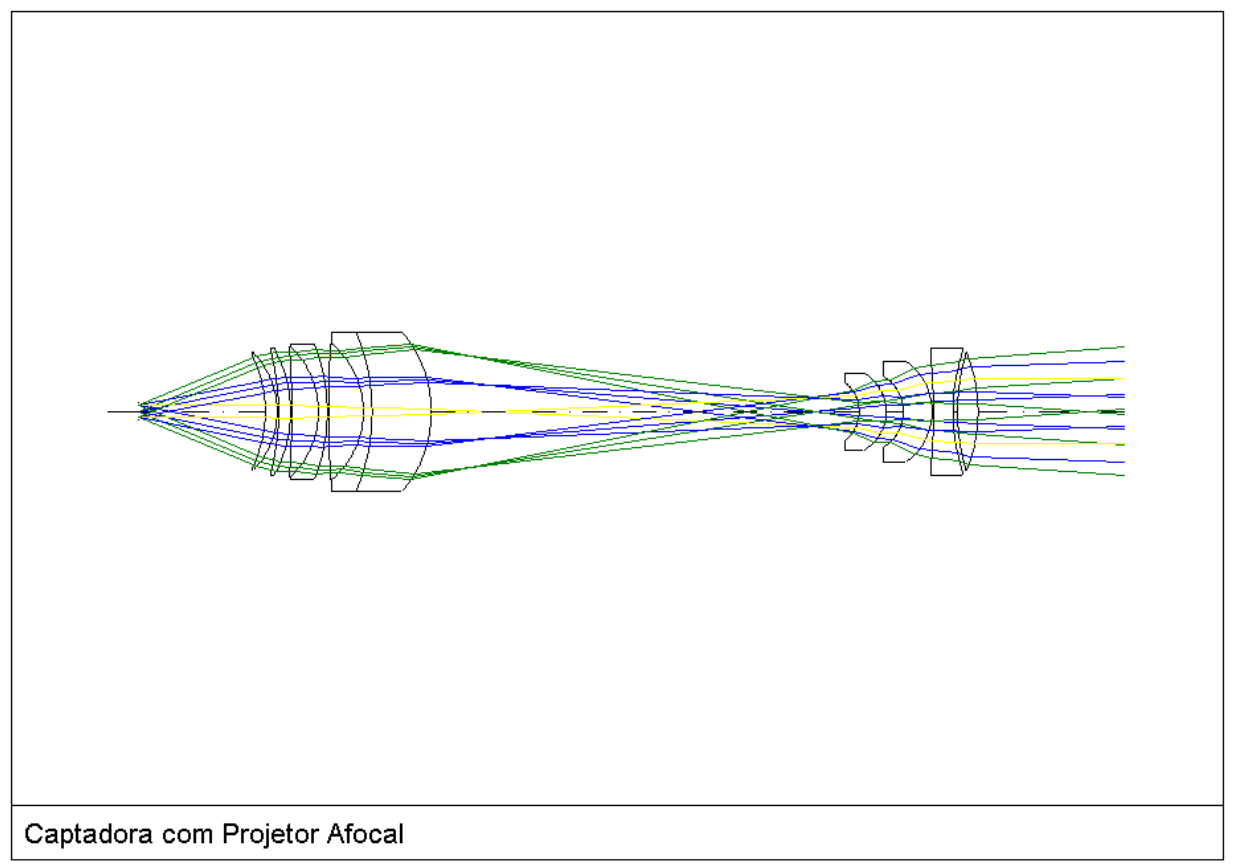

Figura 36: Desenho Óptico do projetor afocal acoplado à captadora.

Tabela 4: Parâmetros ópticos do projetor afocal.

\begin{tabular}{|c|c|}
\hline Parâmetro & Valor \\
\hline EFL* $^{*}$ & $245 \mathrm{~mm}$ \\
\hline Distância Imagem & infinito \\
\hline Comprimento total* $^{*}$ & 40 \\
\hline Número de elementos & 4 \\
\hline
\end{tabular}

*Valores apenas para o projetor afocal. 
A Figura 37 apresenta o Desenho Óptico do conjunto com a simulação de uma objetiva ideal.

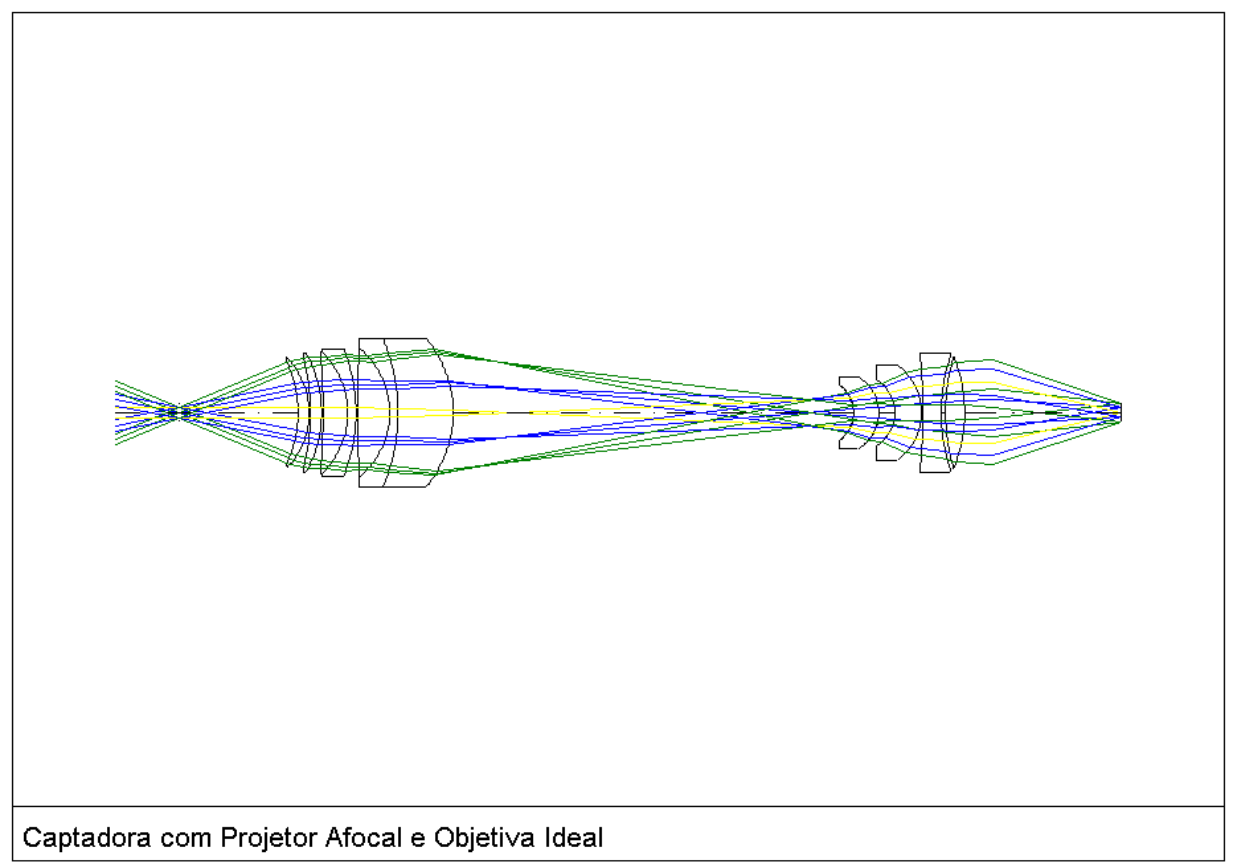

Figura 37: sistema de captação utilizando uma objetiva Ideal.

\subsection{Objetiva}

A objetiva foi inicialmente otimizada fora do sistema e depois acoplada ao conjunto. As principais característica ópticas do conjunto estão apresentadas na Tabela 5. O Desenho do sistema óptico está ilustrado na Figura 38.

Tabela 5: Parâmetros ópticos do conjunto objetiva.

\begin{tabular}{|c|c|}
\hline Parâmetro & Valor \\
\hline EFL & $56 \mathrm{~mm}$ \\
\hline Distância Imagem & $10 \mathrm{~mm}$ \\
\hline Comprimento total & $60 \mathrm{~mm}$ \\
\hline Número de elementos & 6 \\
\hline
\end{tabular}




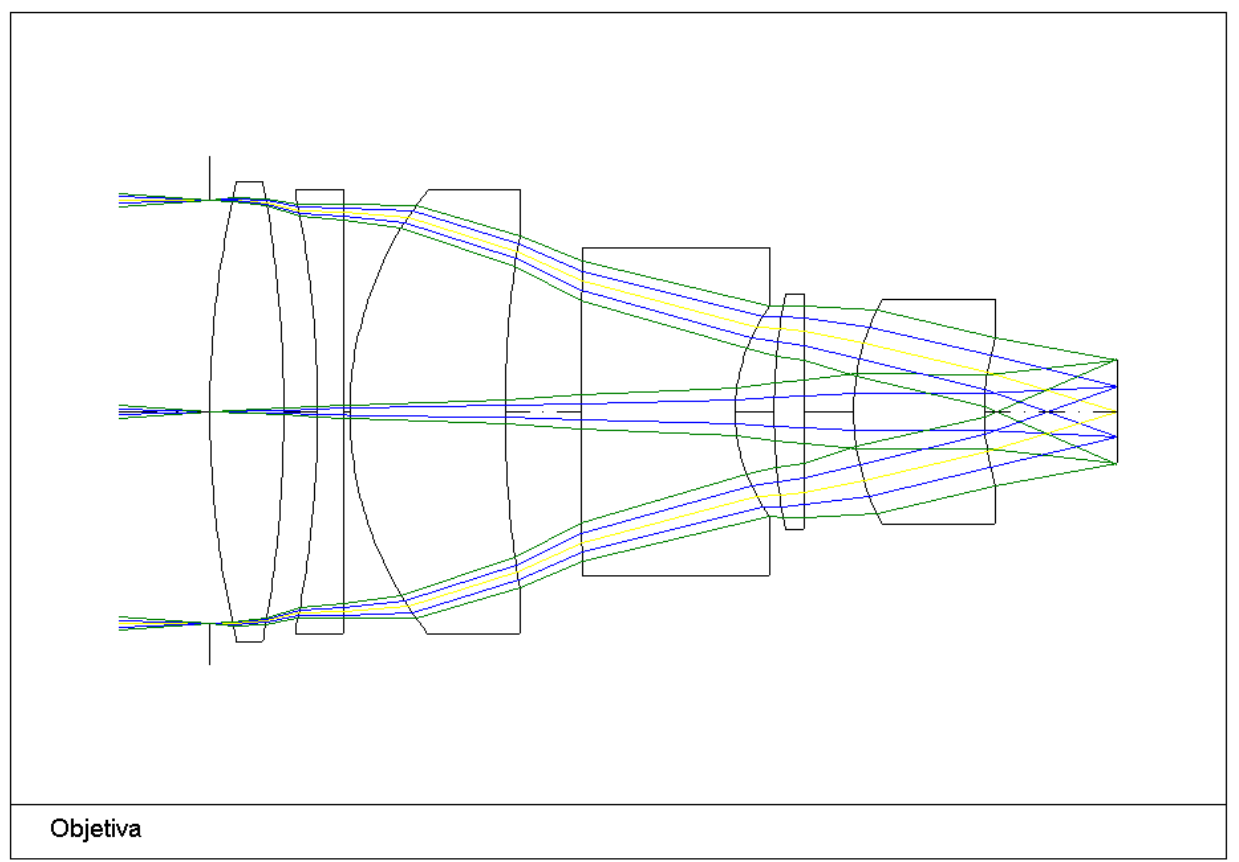

Figura 38: Desenho Óptico da objetiva do sistema

Após o acoplamento da objetiva no sistema de captação, obtemos o sistema de captação completo ilustrado na Figura 39.

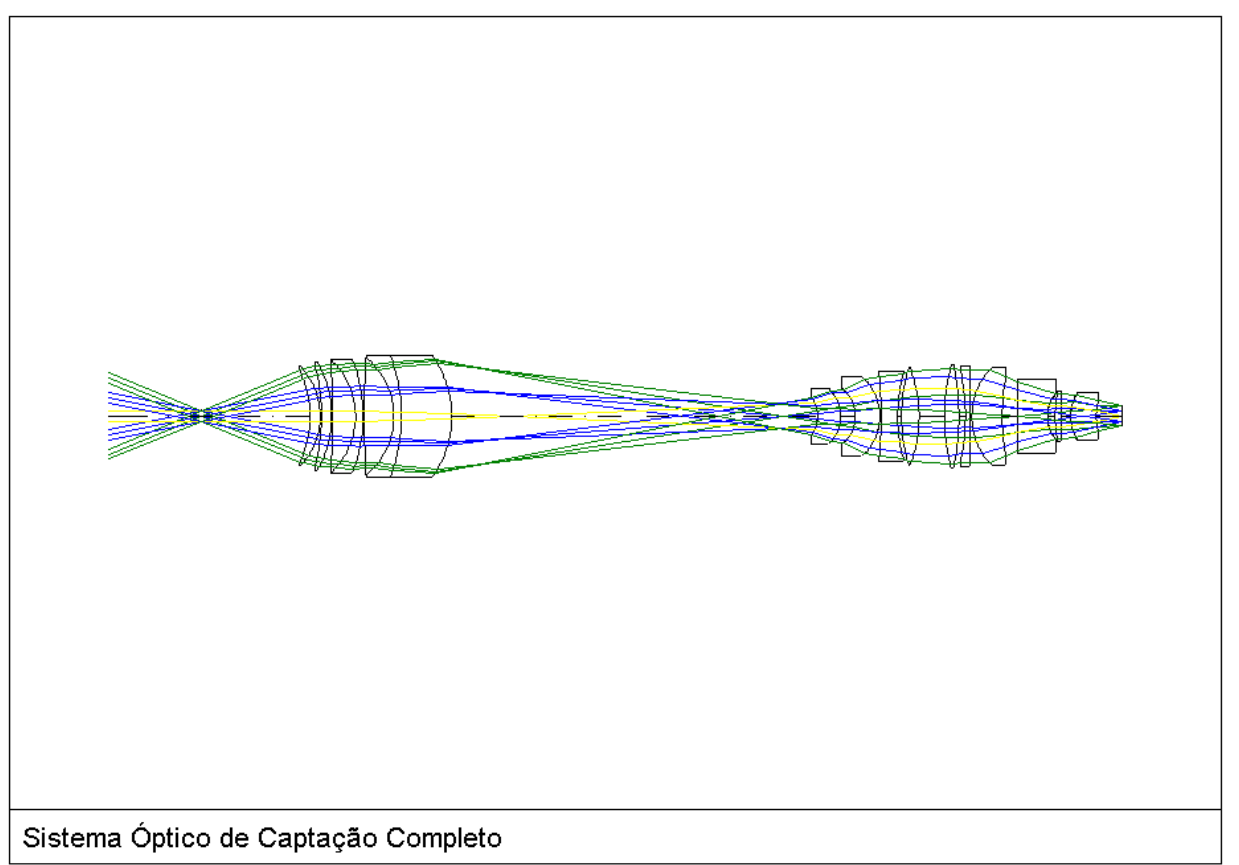

Figura 39: sistema de captação completo incluindo a objetiva desenvolvida no projeto. 


\subsection{Sistema de Iluminação}

A primeira parte do sistema de iluminação, projeta um anel iluminado sobre o espelho furado e pontos escuros sobre as lentes da captadora. A Tabela 6 apresenta as principais características ópticas desse sistema. O Desenho Óptico do sistema está apresentado na Figura 40. A Figura 41 ilustra o sistema de iluminação completo, incluindo o conjunto captadora.

Tabela 6: Parâmetros ópticos da primeira parte do sistema de iluminação.

\begin{tabular}{|c|c|}
\hline Parâmetro & Valor \\
\hline EFL & $71 \mathrm{~mm}$ \\
\hline Distância Imagem & $2 \mathrm{~mm}$ \\
\hline Comprimento total & $145 \mathrm{~mm}$ \\
\hline Número de elementos & 8 \\
\hline
\end{tabular}

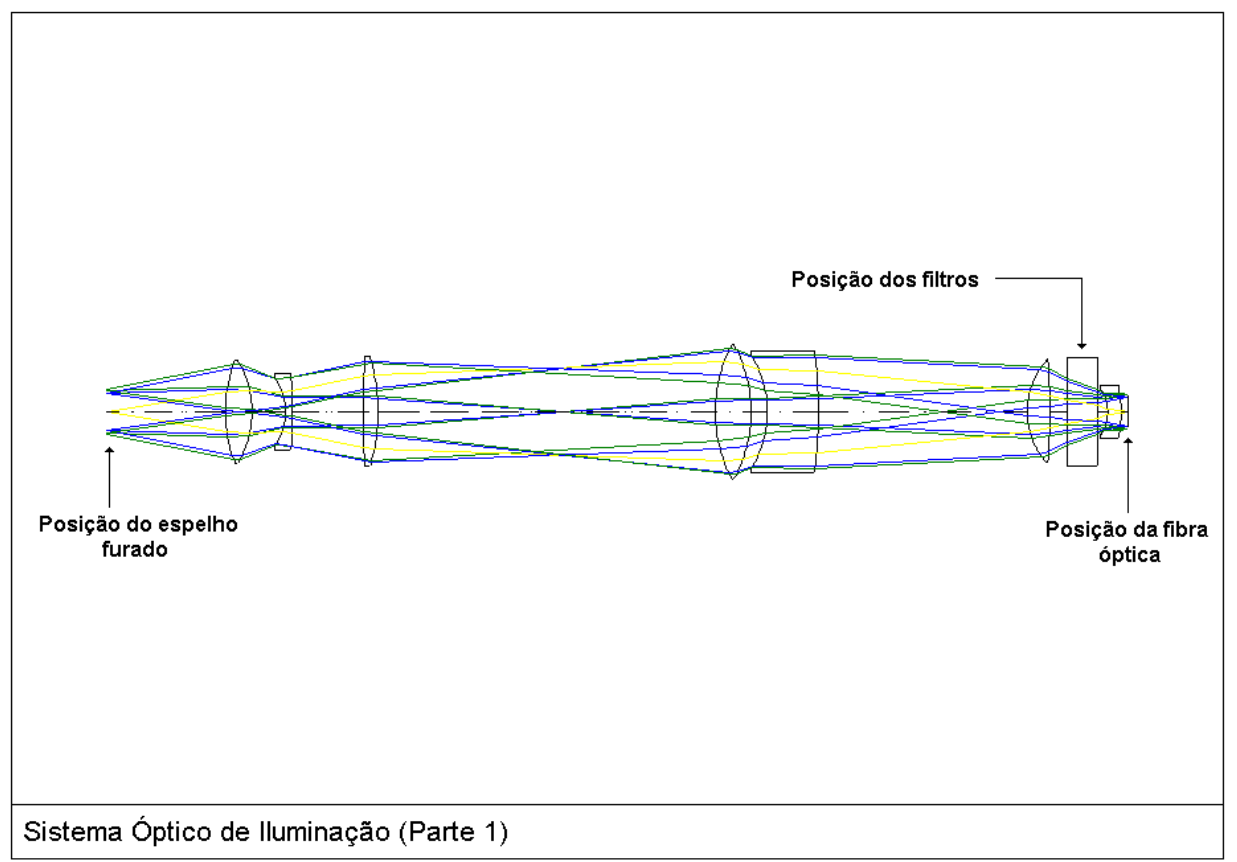

Figura 40: Desenho Óptico da Primeira parte do sistema de iluminação 


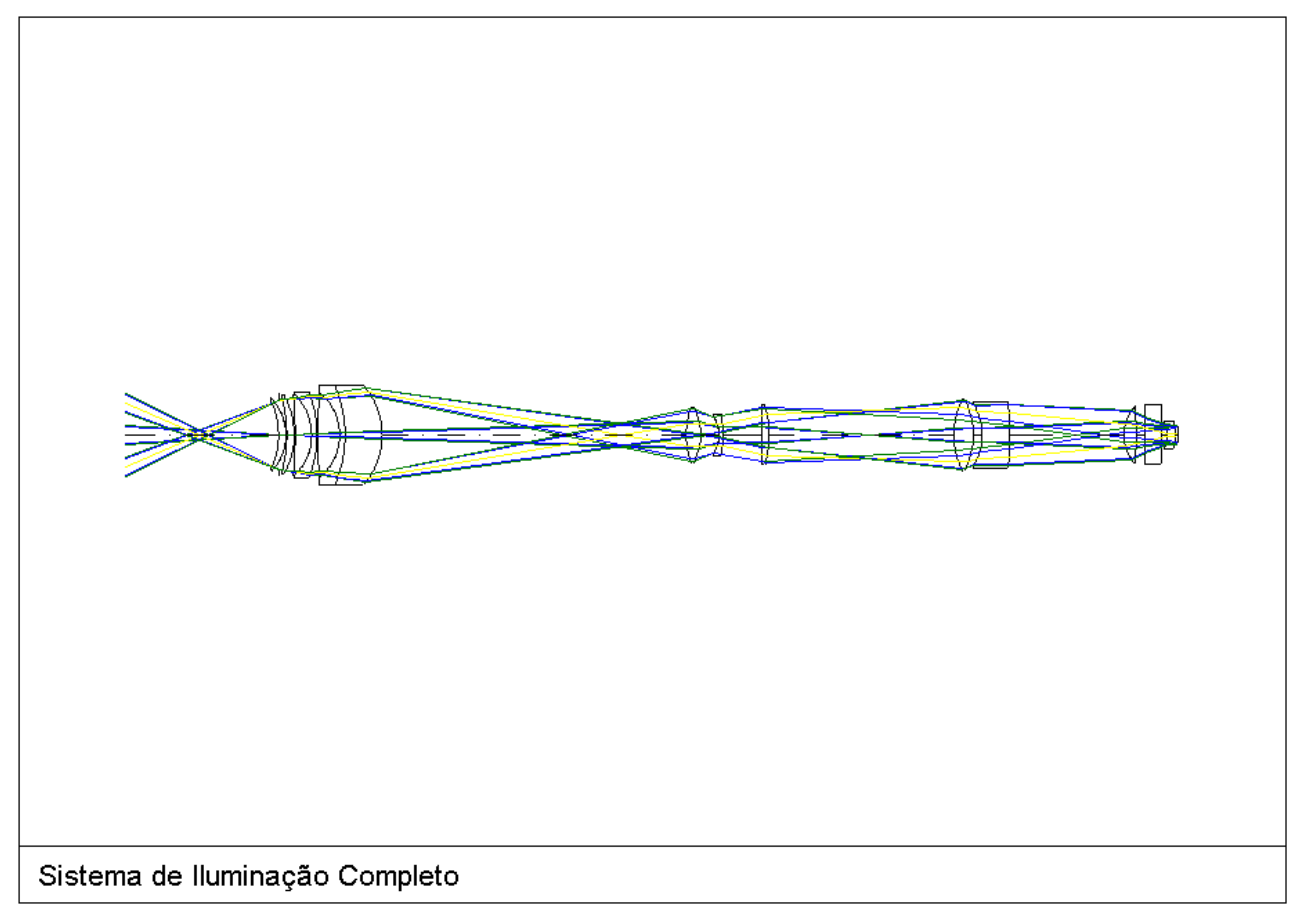

Figura 41: Desenho Óptico do sistema de iluminação completo.

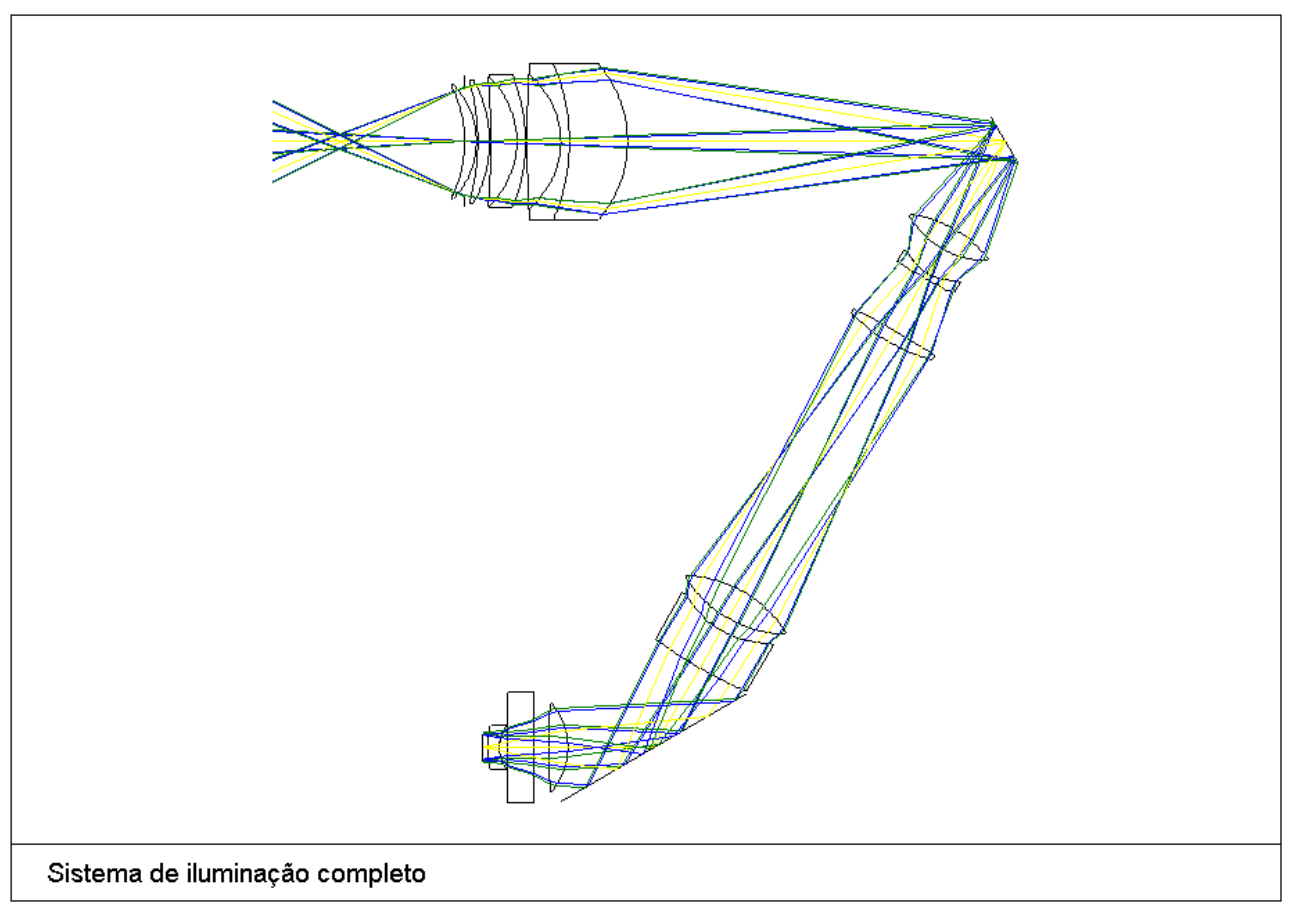

Figura 42: Figura do sistema óptico de iluminação completo na posição para a montagem. 
O objeto inserido no sistema para projetar uma sombra sobre as lentes da captadora é um ponto muito pequeno, com tamanho baseado na magnificação do sistema e na superfície da captadora em que ele deve ser projetado. Ao realizar esta projeção, os raios vindos do ponto escuro (objeto) serão formados na região central da captadora, diminuindo a intensidade da iluminação apenas nessa região. É necessário, porém garantir que este ponto não formará uma sombra na imagem. Se considerarmos o caminho inverso no qual o ponto está no fundo do olho, ele será projetado numa determinada posição dentro do sistema de iluminação. Dessa forma, determinamos a posição onde o ponto não deve estar no sistema de iluminação para que ele não apareça na imagem.

A Figura 43 ilustra a posição em que a imagem do fundo do olho é projetada dentro do sistema de iluminação.

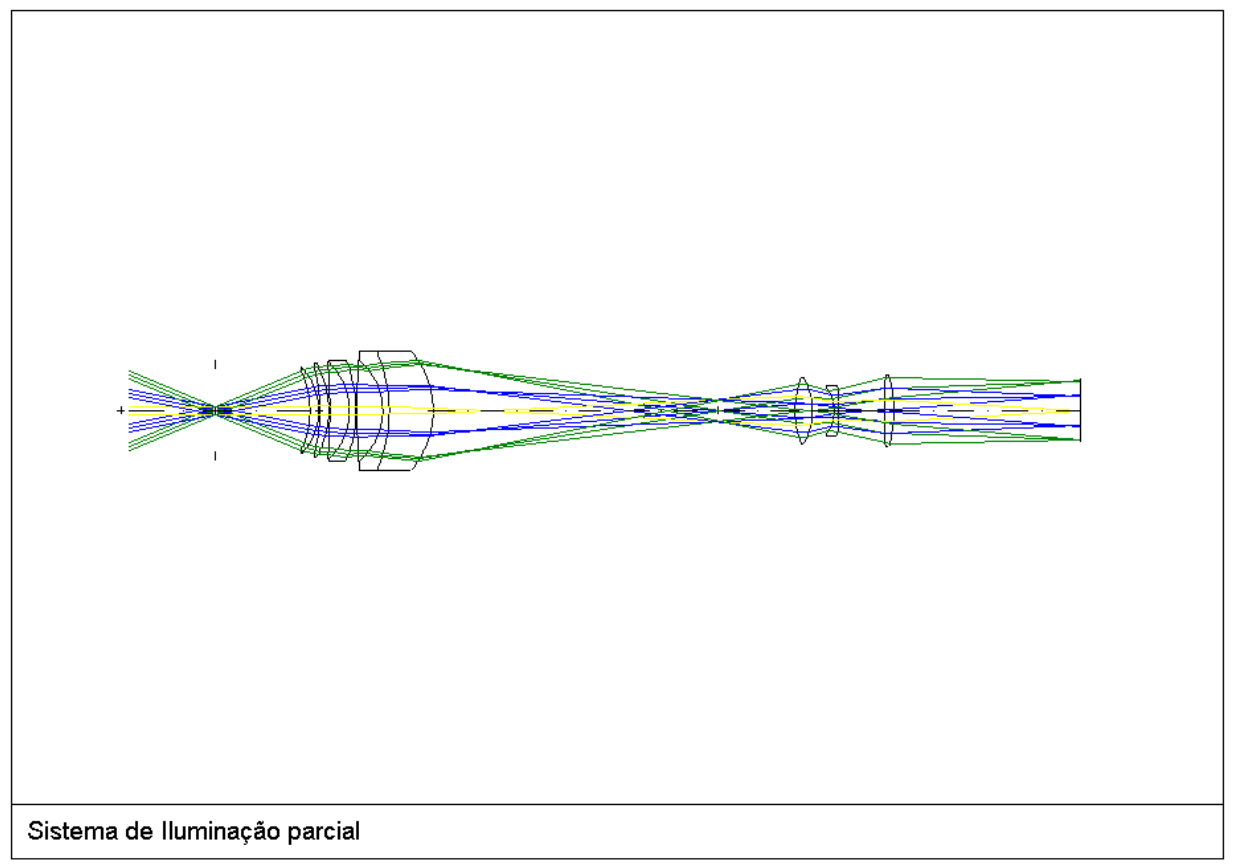

Figura 43: Indicação da posição da formação da imagem do fundo do olho dentro do sistema de iluminação. 
Para cada posição de foco da objetiva, o anel de reflexo que aparece na imagem é referente a uma superfície diferente da captadora. Como alguns raios de curvatura da captadora já foram previamente ajustados na otimização para que a imagem do reflexo incida numa região fora da objetiva, é necessário realizar este procedimento apenas para as demais superfícies. No caso desse projeto, foram utilizados 3 pontos escuros. A posição desses pontos é determinada pela posição do anel de reflexo dentro do sistema de iluminação.

Após a montagem dos sistemas de captação e de iluminação observou-se que a limpeza das lentes, assim como defeitos cosméticos provocam um outro tipo de reflexo na imagem. Este reflexo aparece na imagem final como uma seqüência aleatória de pontos iluminados comprometendo o diagnóstico. Como ainda não foi possível refinar o processo de fabricação para eliminar este reflexo, optou-se pelo uso de um par de polarizadores cruzados. Um polarizador é colocado no sistema de iluminação para polarizar a luz incidente na captadora e outro é colocado em frente à objetiva. Ao incidir no fundo do olho, a luz sofre uma reflexão difusa e, portanto a imagem não é afetada. Por outro lado, ao incidir na captadora, a luz vinda do reflexo na captadora é especular e pode ser eliminada com o segundo polarizador, cruzado em relação ao primeiro.

Como os dois tipos de reflexo são decorrência da objetiva do sistema captar a iluminação incidente na captadora, isso não irá ocorrer nas Angiografias, pois nestes exames, o comprimento de onda da iluminação é diferente do comprimento de onda da captação. Um polarizador durante uma Angiografia apenas diminui a intensidade da imagem, fazendo com que uma intensidade maior seja aplicada na iluminação para possibilitar a captação. Com isso, foi 
necessário adotar motores para fazerem a movimentação desse par de polarizadores deixando-os fora do caminho óptico durante as Angiografias.

\subsection{Fotos da Retina Tiradas com o Equipamento}
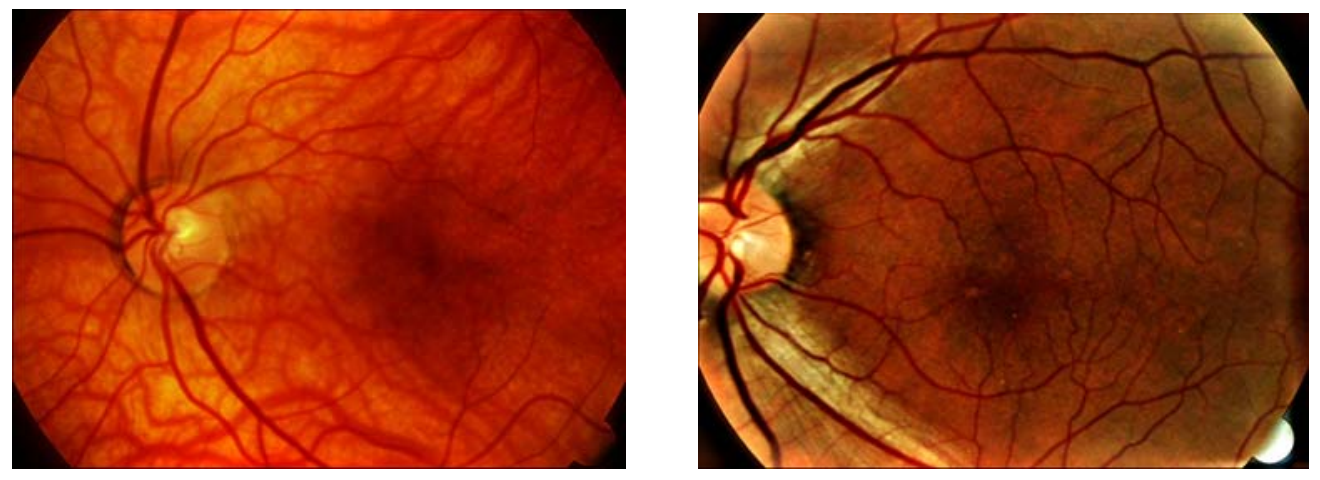

Figura 44: Fotos de Retinografia Colorida em olho normal.
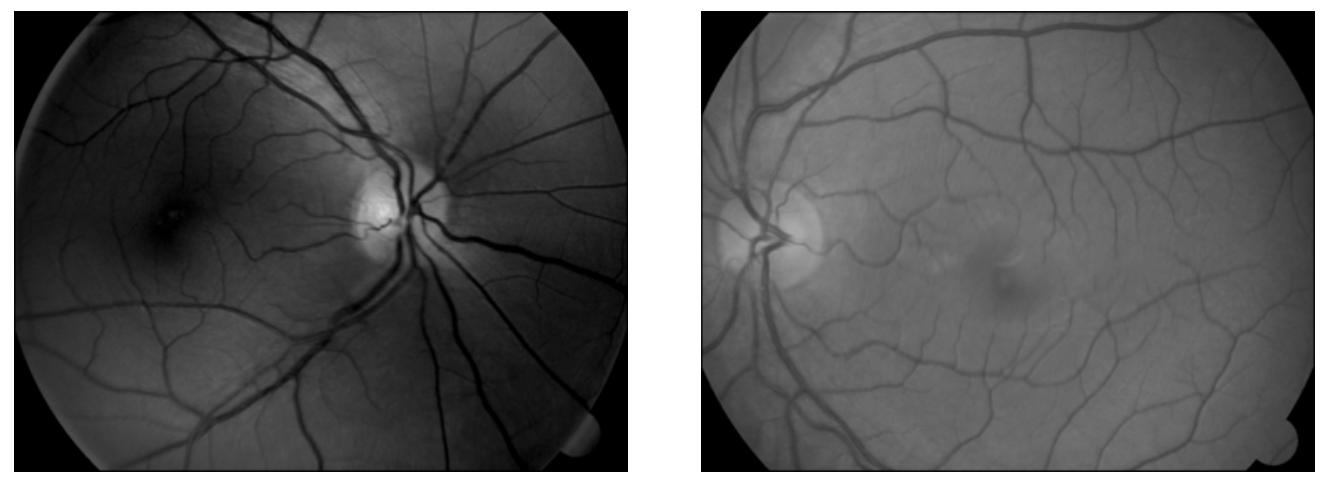

Figura 45: Fotos de Retinografia Anerítra em olho normal.
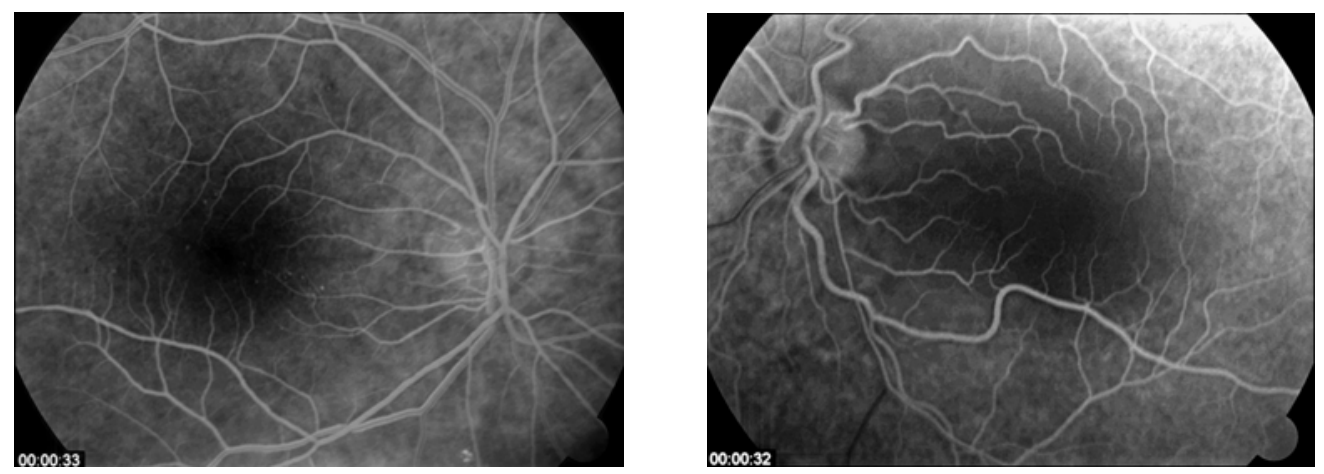

Figura 46: Fotos de Angiografia Fluoresceínica em olho normal. 

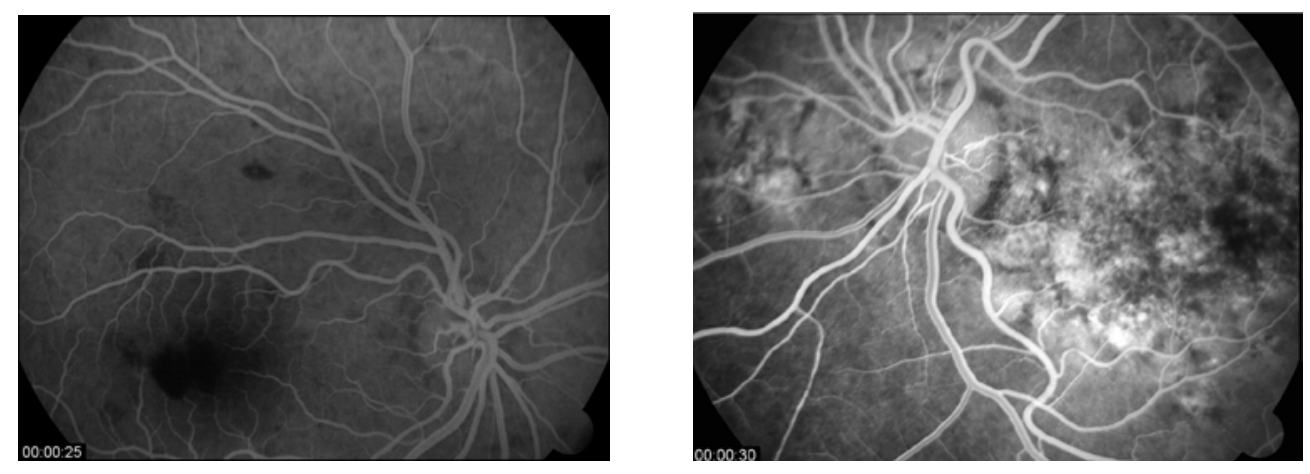

Figura 47: Fotos de Angiografia Fluoresceínica em olho com patologia.
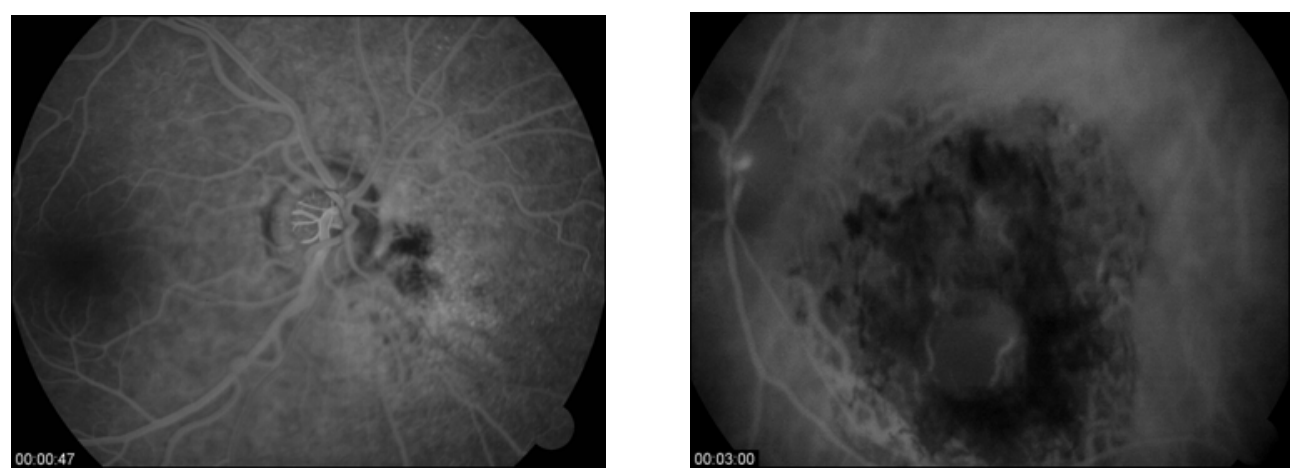

Figura 48: Fotos de Angiografia Indocianínica em olho com patologia. 


\section{Análise dos Resultados}

As análises de qualidade de imagem do sistema óptico obtido foram realizadas basicamente sobre o sistema de captação não havendo uma preocupação muito grande com a qualidade das imagens do sistema de iluminação.

Os primeiros parâmetros a serem analisados foram os gráficos de MTF que serviram também para o critério de aceitação do sistema óptico durante o projeto. Em seguida foram feitas as análises de tolerância do sistema óptico e um estudo adicional para determinar até quantas dioptrias o paciente pode ter sem que a qualidade do exame fique prejudicada.

\subsection{Análise de MTF do Sistema}

Os gráficos de MTF do sistema de captação foram analisados para três conjuntos separados: o primeiro é a objetiva projetada; o segundo é o conjunto de captação com uma objetiva ideal e o último é o sistema de captação com a objetiva real desenvolvida no projeto. Estes gráficos estão apresentados nas Figuras a seguir (Figura 49, Figura 50 e Figura 51). O MTF atingido garante que as imagens de veias da retina com espessura a partir de 0,01mm sejam focalizadas com nitidez sobre o CCD.

O Gráfico de MTF do sistema de iluminação está apresentado na Figura 52. Pode-se observar que o objetivo de obter-se uma resolução abaixo de 5lp/mm foi atingindo. 


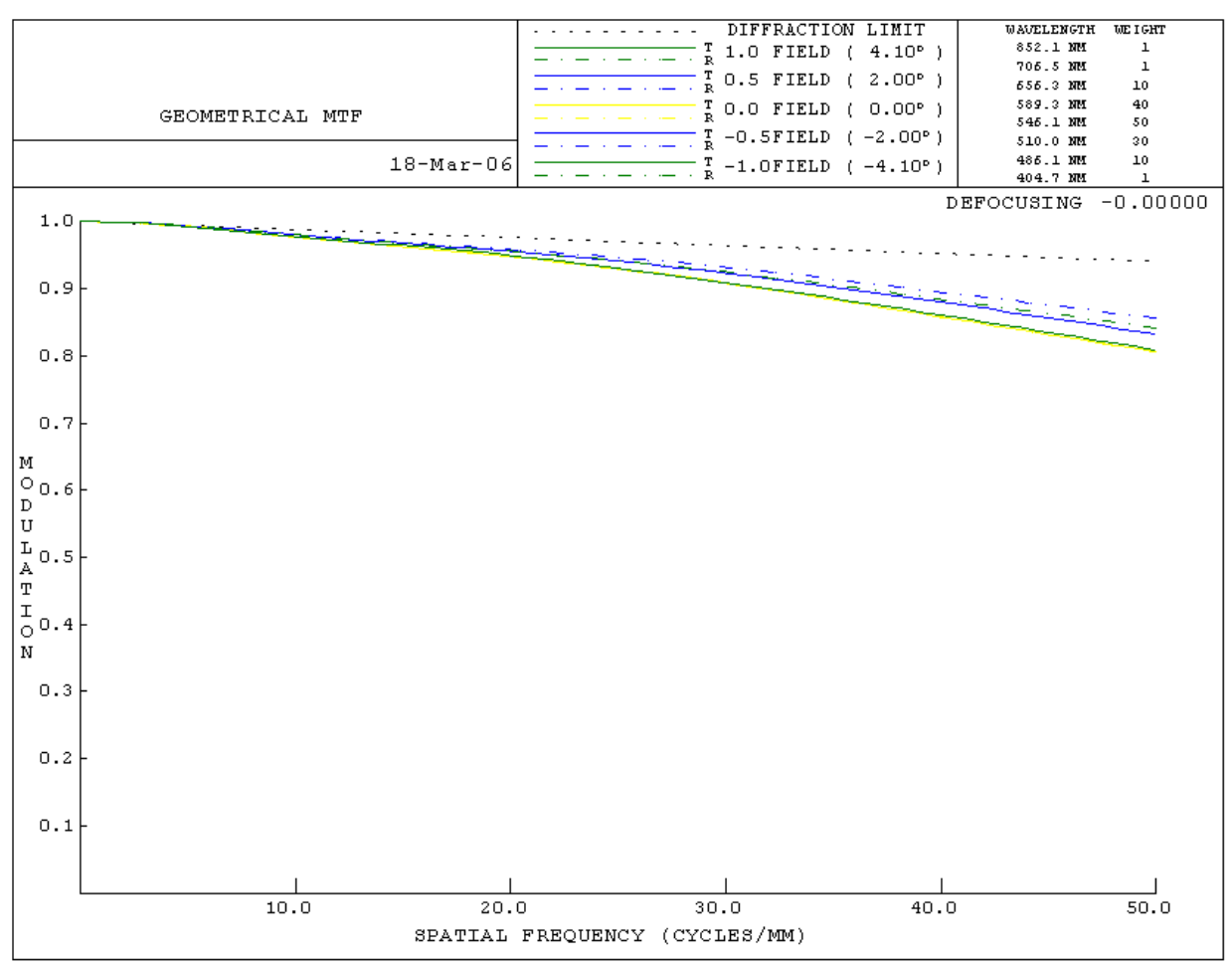

Figura 49: Gráfico de MTF da objetiva do sistema.

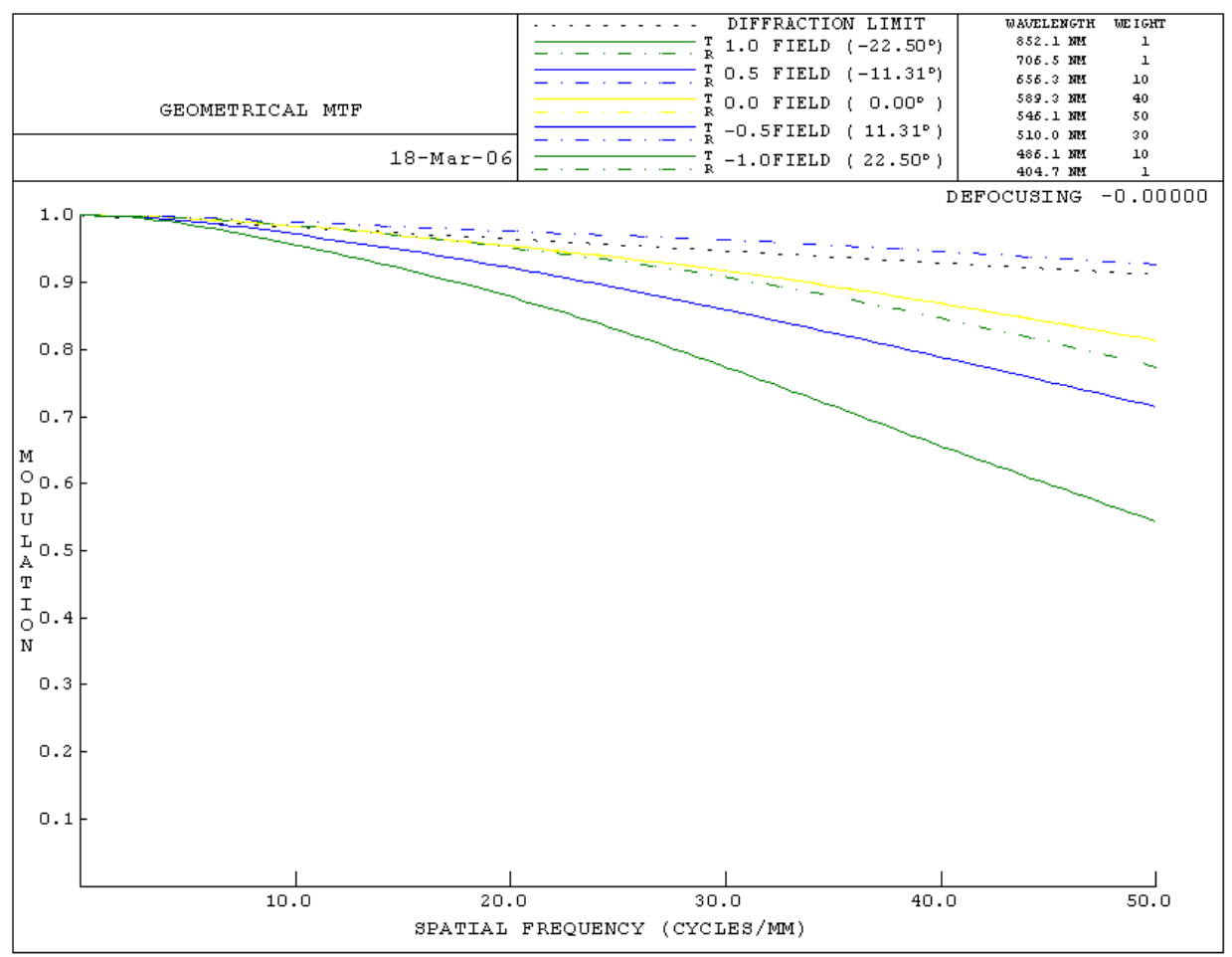

Figura 50: MTF do sistema de captação considerando uma objetiva ideal. 


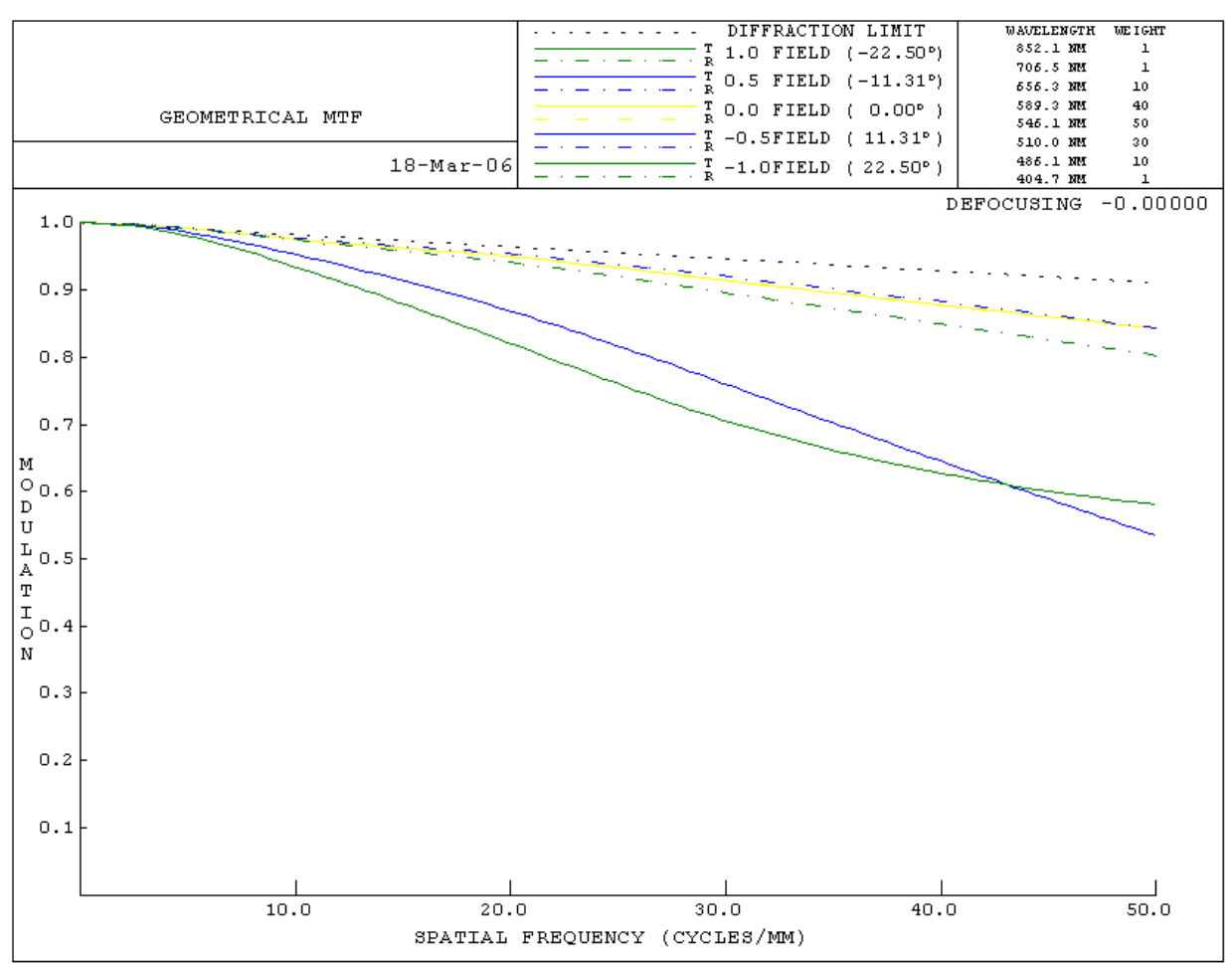

Figura 51: Gráfico de MTF do sistema de captação completo.

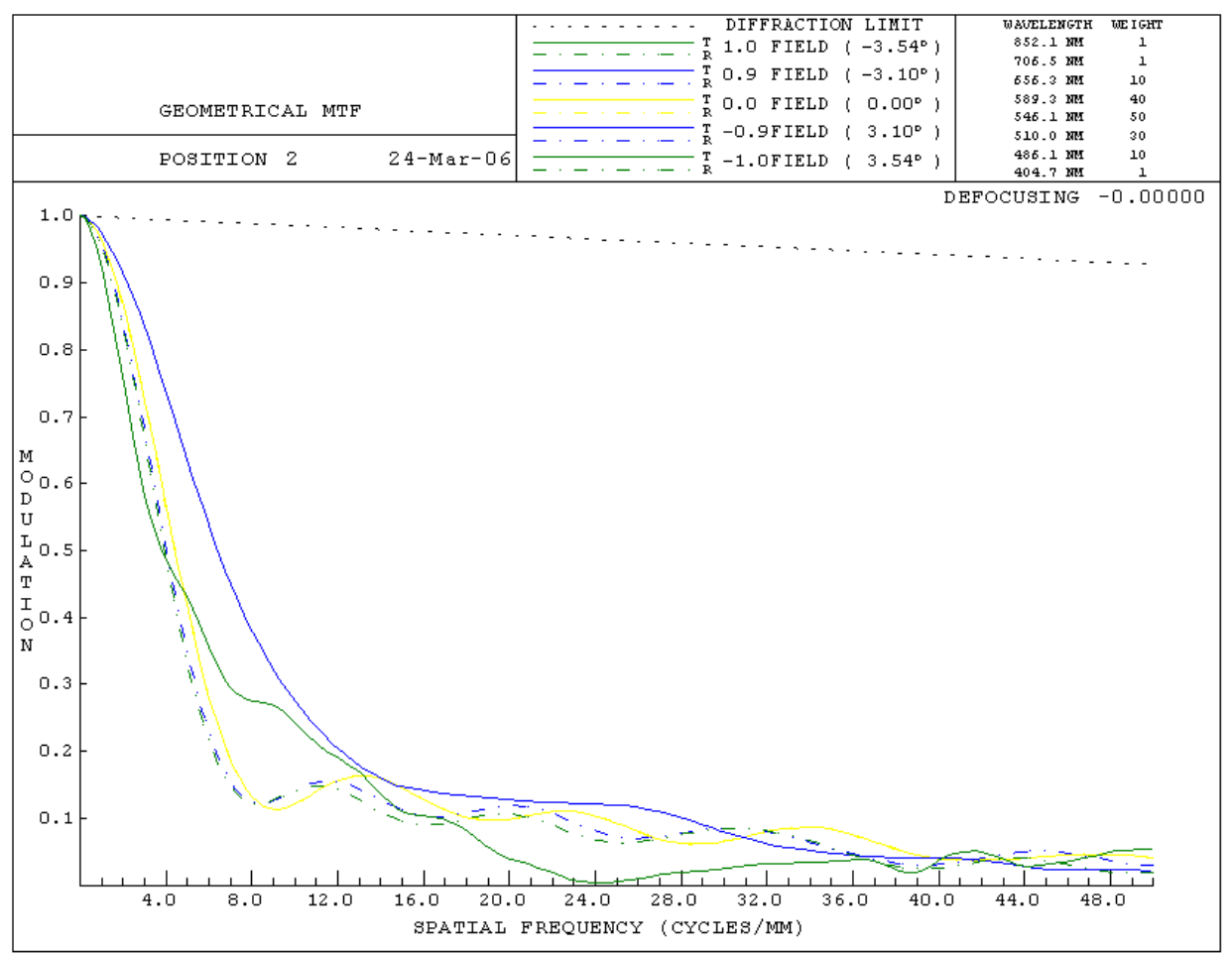

Figura 52: Gráfico de MTF do sistema de iluminação completo. 


\subsection{Análise da Dioptria Alcançada}

Uma lente variável com -20D a 20D foi adicionada na pupila de saída do olho e observou-se o deslocamento necessário imposta à objetiva para que a imagem do olho continuasse a ser formada pelo sistema de captação. Os resultados atingidos com esta simulação estão apresentados na Tabela 7 . Com isso observou-se que o equipamento será capaz de realizar o exame com eficiência em pacientes que possuem até \pm 20 dioptrias com um movimento de foco total de $5 \mathrm{~mm}$. Porém, como essa distância é também utilizada como compensador na análise de tolerâncias, aumentou-se o curso foco para $10 \mathrm{~mm}$ e considera-se, com uma margem de segurança, que o equipamento realiza exames em pacientes com até $\pm 15 D$.

Tabela 7: Tabela indicando o resultado da alteração no foco do sistema para uma lente simulando as dioptrias do olho.

\begin{tabular}{|c|c|}
\hline Dioptria da lente & Posição do foco (mm) \\
\hline-20 D & 12 \\
\hline-15 D & 11.5 \\
\hline$-12.5 \mathrm{D}$ & 11.27 \\
\hline$-10 \mathrm{D}$ & 11.02 \\
\hline$-7.5 \mathrm{D}$ & 10.77 \\
\hline$-5 \mathrm{D}$ & 10.51 \\
\hline$+5 \mathrm{D}$ & 9.49 \\
\hline$+7.5 \mathrm{D}$ & 9.23 \\
\hline$+10 \mathrm{D}$ & 8.97 \\
\hline$+12.5 \mathrm{D}$ & 8.71 \\
\hline$+15 \mathrm{D}$ & 8.45 \\
\hline$+20 \mathrm{D}$ & 7.91 \\
\hline
\end{tabular}




\subsection{Análise de Tolerância do Sistema}

A análise de tolerâncias foi realizada utilizando o intervalo nos parâmetros para peças comerciais e de precisão apresentados na Tabela 2. Foram utilizados como compensadores a separação entre a captadora e o projetor afocal e o movimento de foco da objetiva. Os valores das tolerâncias determinados pelo programa variam de acordo com o raio e espessura e ficam entre $0.02 \mathrm{~mm}$ e $0.5 \mathrm{~mm}$.

Os gráficos traçados pelo programa representando a probabilidade do sistema manter um valor de MTF para determinada freqüência estão apresentados nas Figuras a seguir. Foram simuladas 5 freqüências diferentes: 10lp/mm (Figura 53), 20lp/mm (Figura 54), 30lp/mm (Figura 55), 40 Ip/mm (Figura 56) e 50lp/mm (Figura 57).

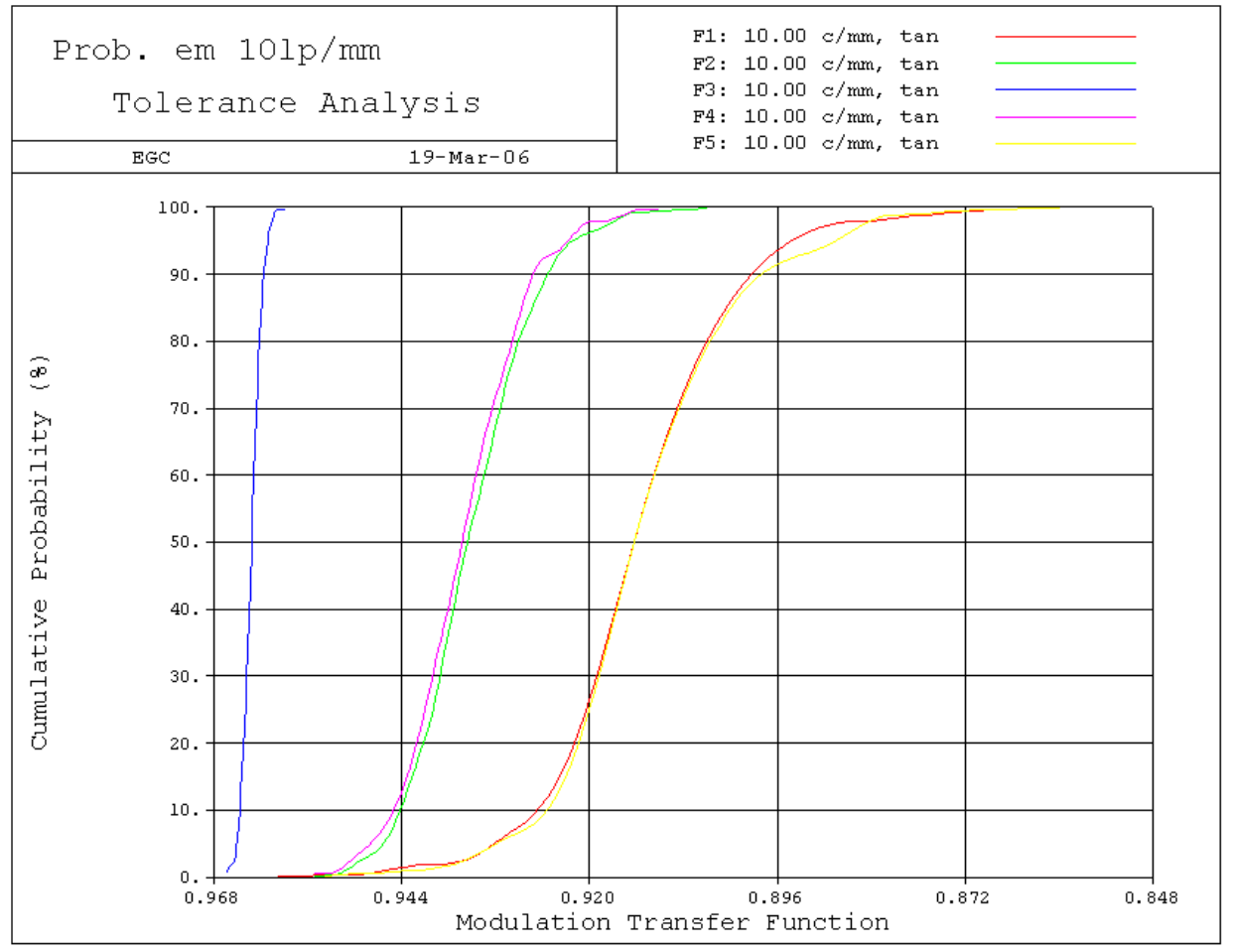

Figura 53: Gráfico da probabilidade da Modulação ser alcançada em 10 lp/mm. 


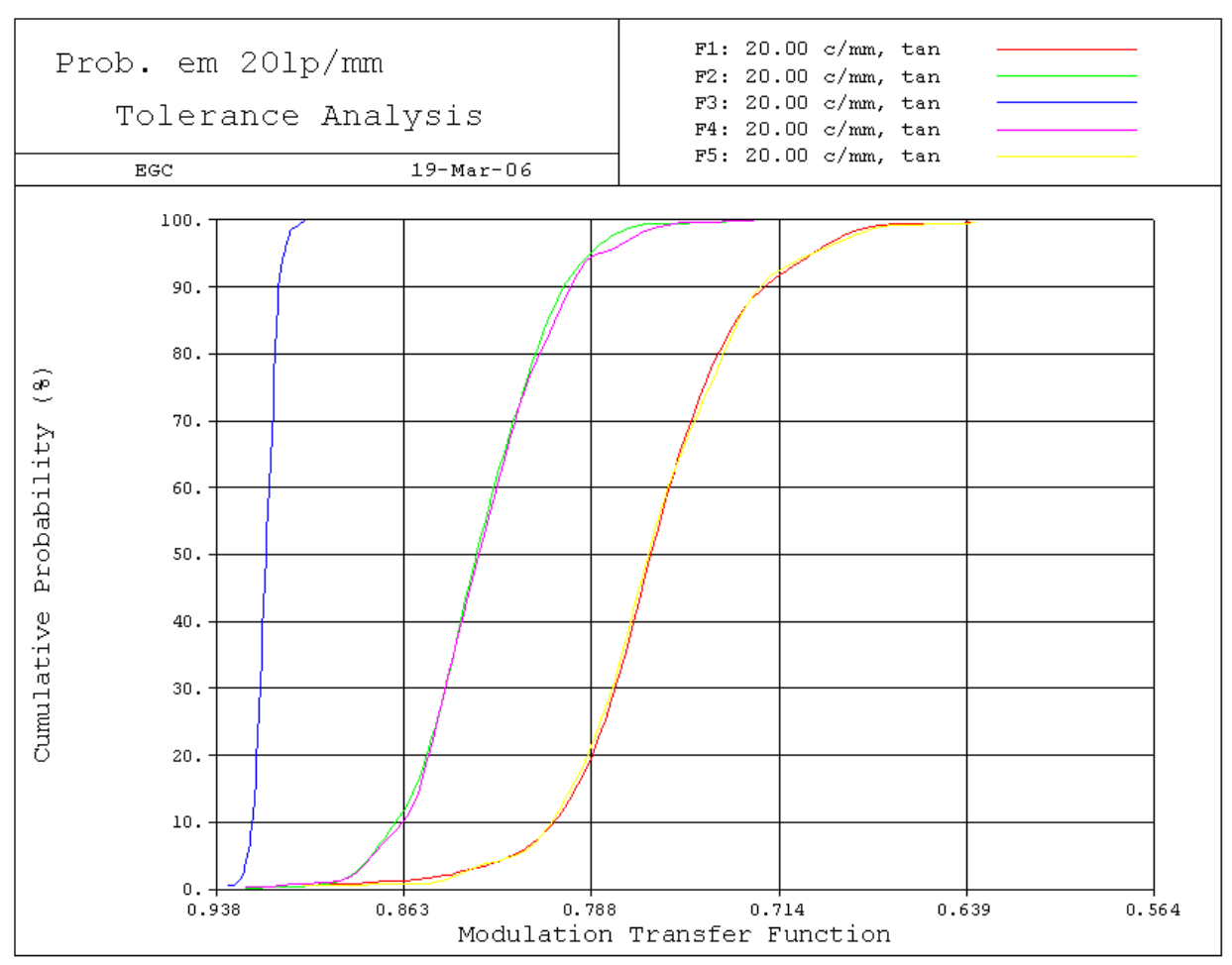

Figura 54: Gráfico da probabilidade da Modulação ser alcançada em 20 lp/mm.

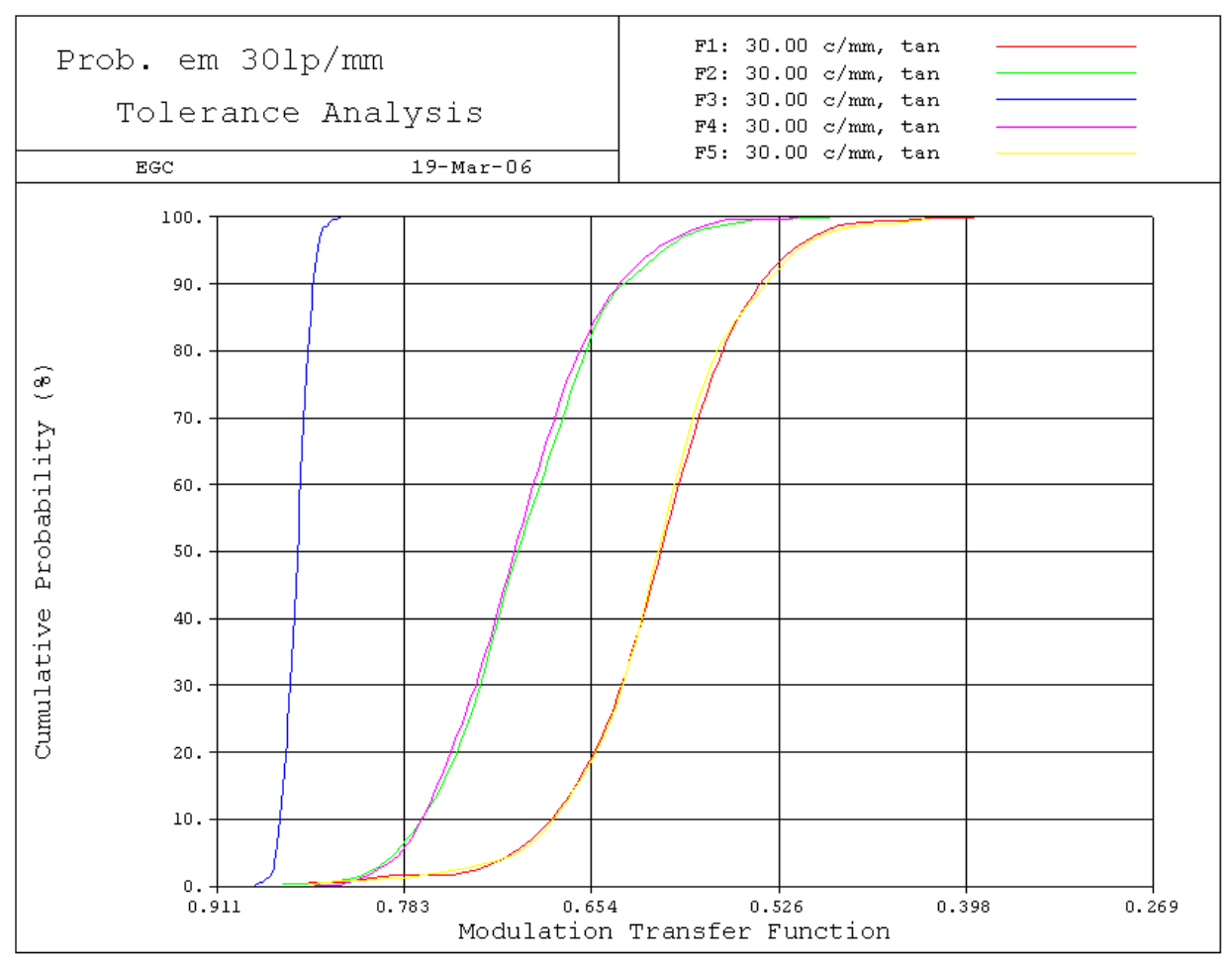

Figura 55: Gráfico da probabilidade da Modulação ser alcançada em 30 lp/mm. 


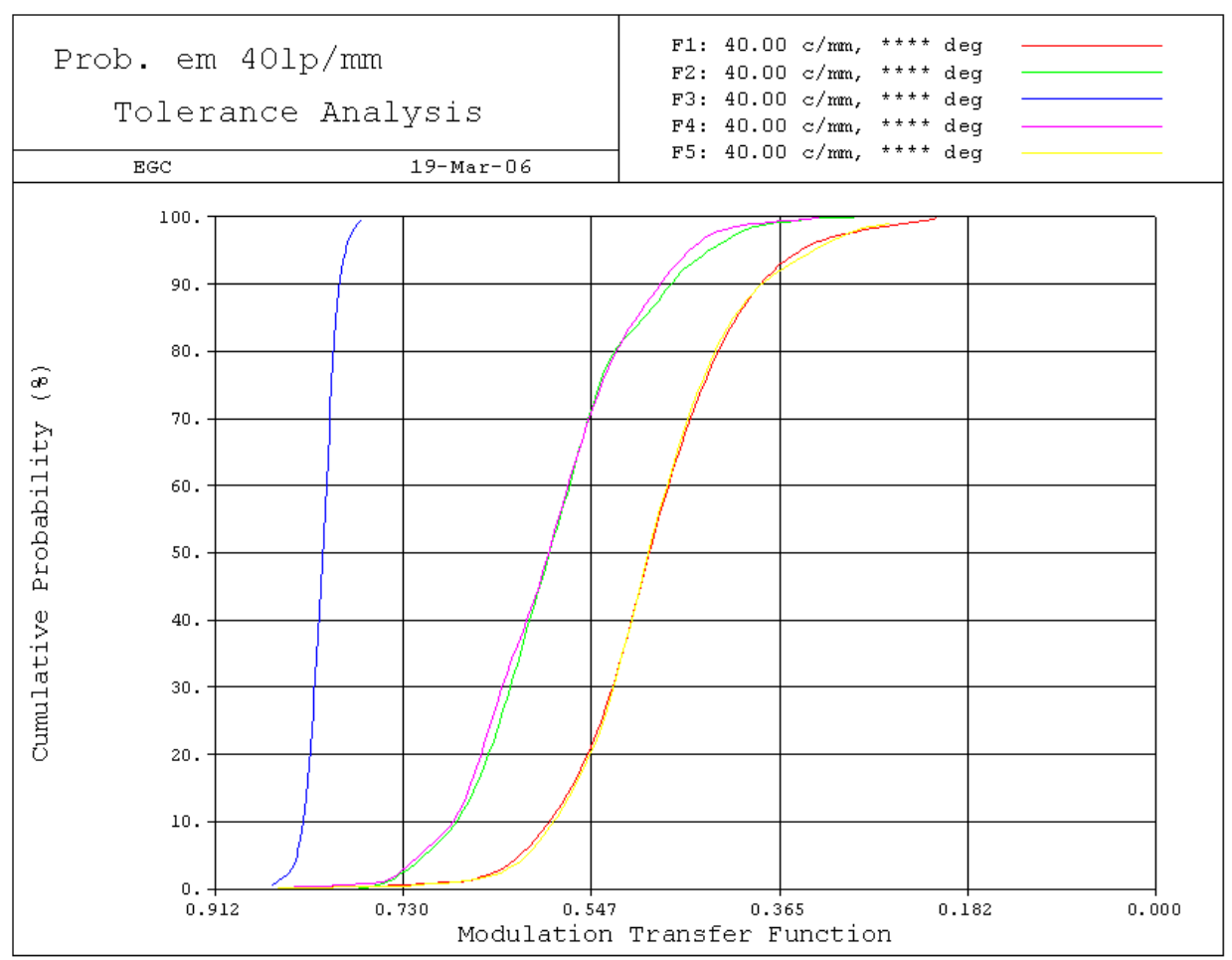

Figura 56: Gráfico da probabilidade da Modulação ser alcançada em 40 lp/mm.

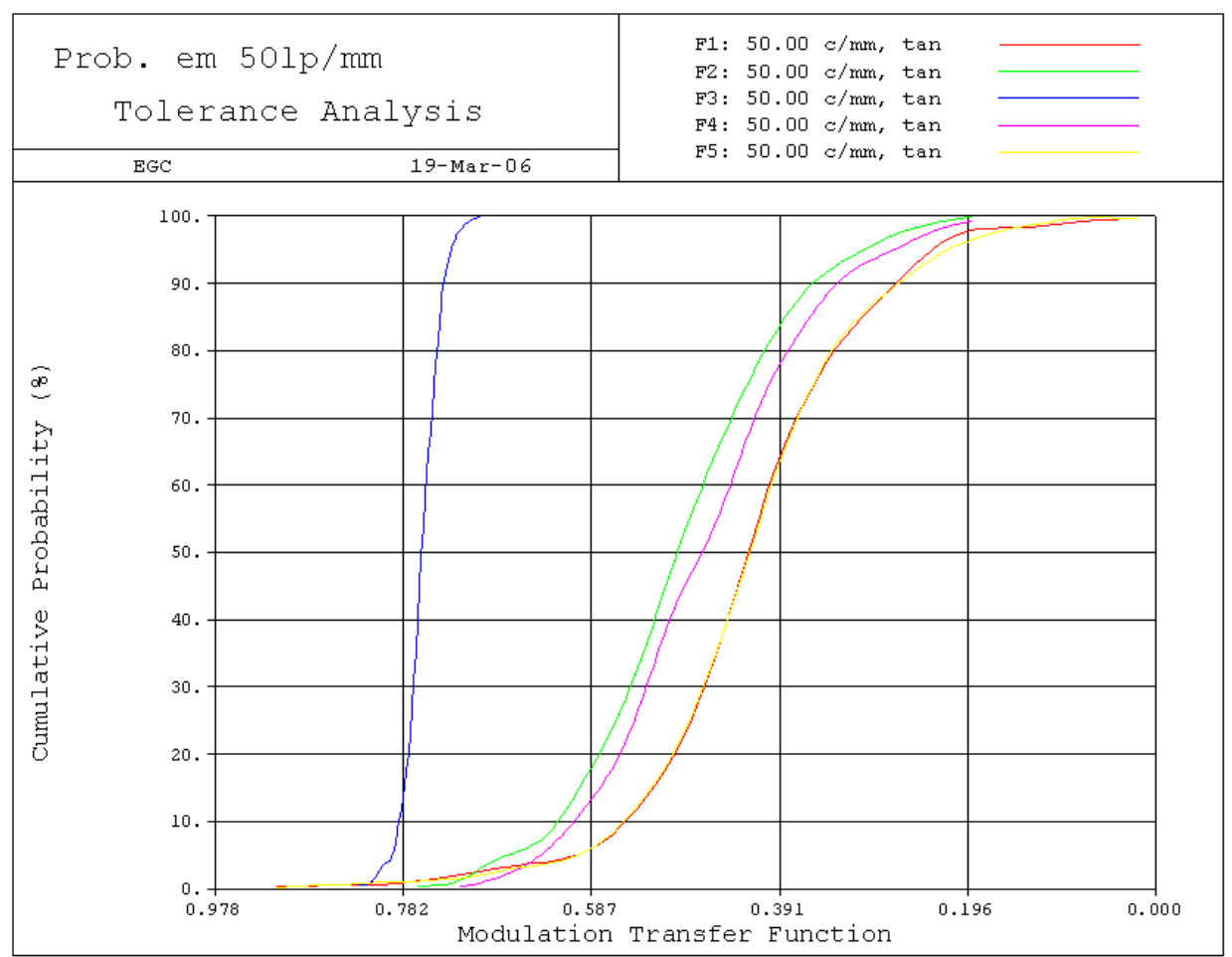

Figura 57: Gráfico da probabilidade da Modulação ser alcançada em 50 lp/mm. 
Considerando o ponto em que a porcentagem corresponde a $80 \%$ para cada raio e para cada freqüência, foi traçado o gráfico apresentado na Figura 58 que mostra como fica o MTF do sistema considerando os erros de fabricação e montagem.

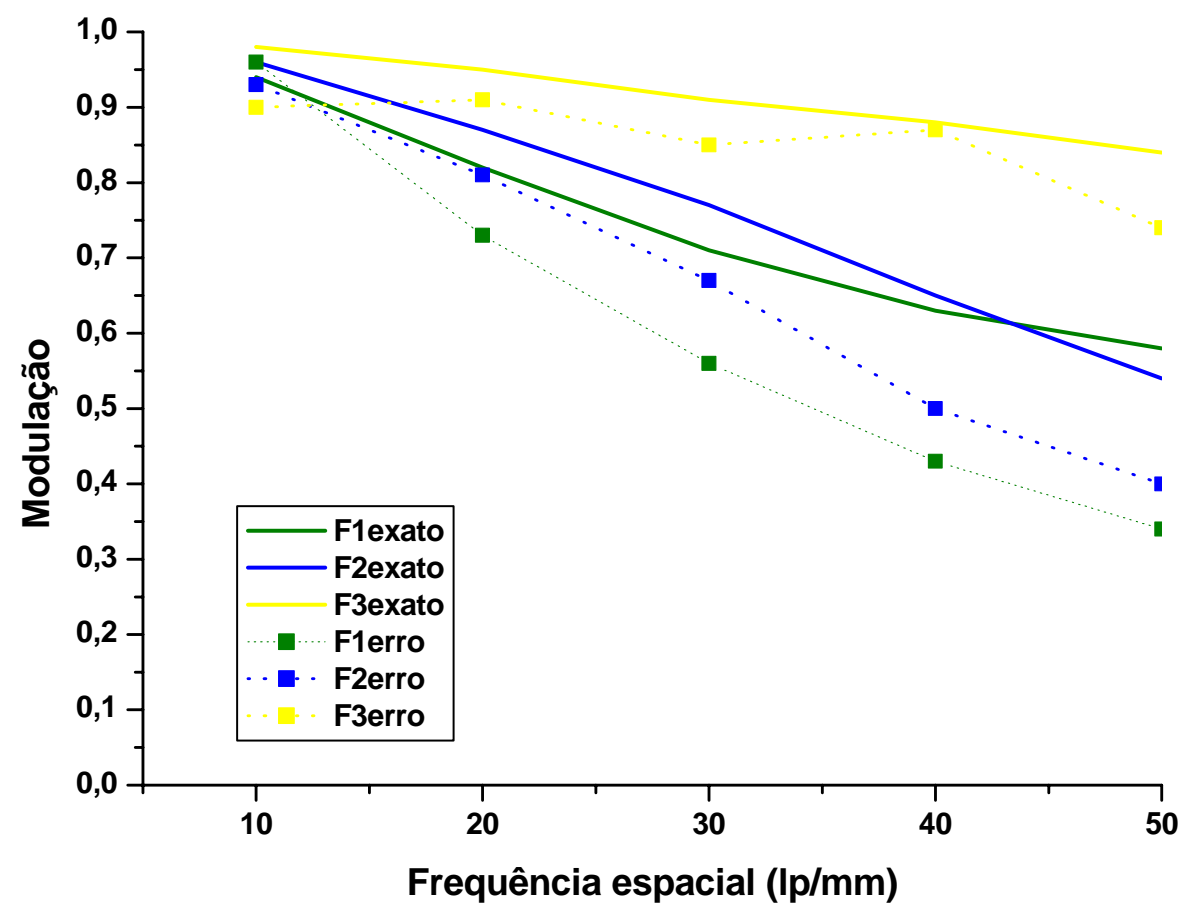

Figura 58: Gráfico do MTF 80\% provável após a fabricação do sistema.

Pode-se observar pelo gráfico que mesmo com os erros impostos à fabricação e à montagem, o sistema manterá um poder de resolução que atende às necessidades do equipamento. 


\section{Conclusões}

Neste trabalho foi possível o desenvolvimento completo de um sistema óptico para captação de imagens do fundo olho.

O sistema de captação, formado por uma captadora e um projetor afocal, seguidos de uma objetiva permite que a otimização dos conjuntos seja feita previamente separada, facilitando o trabalho de otimização.

O sistema desenvolvido possibilita a focalização da imagem em pacientes possuem até $\pm 15 \mathrm{D}$. Nesse caso, a magnificação do sistema completo fica ligeiramente alterada. Para que isso não ocorra, o projeto pode ser aperfeiçoado fazendo com que o projetor afocal tenha um movimento relativo ao movimento da objetiva.

Como resultado do estudo das tolerâncias de fabricação montagem do sistema, foi observado que torna-se muito mais fácil e aplicável a realização deste estudo durante o desenvolvimento do projeto, evitando imprevistos desagradáveis que comprometem a qualidade da imagem e, em alguns casos, impedem o diagnóstico. Um estudo das tolerâncias das peças mecânicas deve necessariamente ser feito em conjunto com o dos componentes ópticos.

O estudo da eliminação do reflexo produzido pela iluminação coaxial foi testado e mostrou-se eficiente embora não tenha sido utilizado na prática devido à fatores de fabricação e montagem das lentes. O uso de um par de polarizadores cruzados para solucionar este problema foi incorporado ao equipamento e está desempenhando sua função de forma eficiente. 
O trabalho que dará seqüência imediata a este é o projeto de um sistema óptico, baseado no mesmo princípio do sistema apresentado, composto por lentes com superfícies anesféricas. Um sistema equivalente a este, porém com elementos anesféricos, permite que o desempenho seja atingido com um número menor de elementos. Nesse caso, além de melhorar a resolução do sistema, é possível eliminar com mais facilidade o reflexo central.

Outro trabalho que ainda dará continuidade a este é o projeto de um retinógrafo digital capaz de realizar imagens esteroscópicas. Nesse caso, a imagem será divida adequadamente antes de atingir o sensor e será novamente reconstituída por processamento antes de ser exibida. Para a observação dessas imagens será necessário o uso de óculos de visão 3D apropriados para a aplicação. 


\section{Referências Bibliográficas}

[1] Shannon, R.R. The Art and Science of Optical Design, University of Arizona, 1997.

[2] Smith, W.J. Modern Optical Engineering, 3.ed.McGraw-Hill, sd.

[3] Yasuoka, Fátima M.Mitsue. Técnicas de Desenho Óptico e Avaliação da Qualidade de Imagem em sistemas ópticos por Medição de Função de Transferência Óptica. São Carlos, 1997. Tese - Instituto de Física de São Carlos, Universidade de São Paulo.

[4] O'Shea, D.C. Elements of modern Optical Design, Georgia Institute of tecnology, 1985.

[5] http://www.editorasaraiva.com.br/eddid/ciencias/explorando/7 olho.html

[6] http://www.escolavesper.com.br/olho humano.htm

[7] Dantes D.; Siqueira R. C.Angiografia da Retina, Revinter, 2004.

[8] http://www.scielo.br/scielo.php?pid=S0004$\underline{27492004000600001 \& \text { script=sci } \text { arttext\&tlng=pt }}$ 